UNIVERSIDADE DE BRASÍLIA

FACULDADE DE TECNOLOGIA

PROGRAMA DE PÓS-GRADUAÇÃO EM CIÊNCIAS FLORESTAIS

\section{DIAGNÓSTICO FLORÍSTICO ESTRUTURAL DE CAATINGA EM GRADIENTES ALTITUDINAIS NO ESTADO DA PARAÍBA}

PIERRE FARIAS DE SOUZA

ORIENTADOR: Prof. Dr. MAURO ELOI NAPPO

TESE DE DOUTORADO EM CIÊNCIAS FLORESTAIS

BRASÍLIA/DF 2016 
UNIVERSIDADE DE BRASÍLIA

FACULDADE DE TECNOLOGIA

PROGRAMA DE PÓS-GRADUAÇÃO EM CIÊNCIAS FLORESTAIS

\title{
DIAGNÓSTICO FLORÍSTICO ESTRUTURAL DE CAATINGA EM \\ GRADIENTES ALTITUDINAIS NO ESTADO DA PARAÍBA
}

PIERRE FARIAS DE SOUZA

\section{TESE DE DOUTORADO SUBMETIDA AO PROGRAMA DE PÓS-GRADUAÇÃO EM CIÊNCIAS FLORESTAIS DA UNIVERSIDADE DE BRASÍLIA COMO REQUISITO PARCIAL À OBTENÇÃO DO TÍTULO DE DOUTOR EM CIÊNCIAS FLORESTAIS (HABILITAÇÃO EM MANEJO FLORESTAL).}

Aprovado por:

Prof. Dr. Mauro Eloi Nappo

Departamento de Engenharia Florestal - UnB (Orientador)

Prof. Dr. Ricardo de Oliveira Gaspar

Departamento de Engenharia Florestal - UnB (Examinador interno)

Prof. Dr. Eder Pereira Miguel

Departamento de Engenharia Florestal - UnB (Examinador interno)

\author{
Pesquisadora Dra. Fabiana de Góis Aquino \\ Centro de Pesquisa Agropecuária dos Cerrados - Embrapa Cerrados (Examinador externo) \\ Prof ${ }^{a}$. Dra. Sílvia da Luz Lima Mota \\ Universidade Federal do Mato Grosso - (Examinador externo) \\ Prof. Dr. Alcides Gatto \\ Departamento de Engenharia Florestal - UnB (Examinador suplente)
}

BRASÍLIA/DF 2016 
Ficha catalográfica elaborada automaticamente, com os dados fornecidos pelo(a) autor(a)

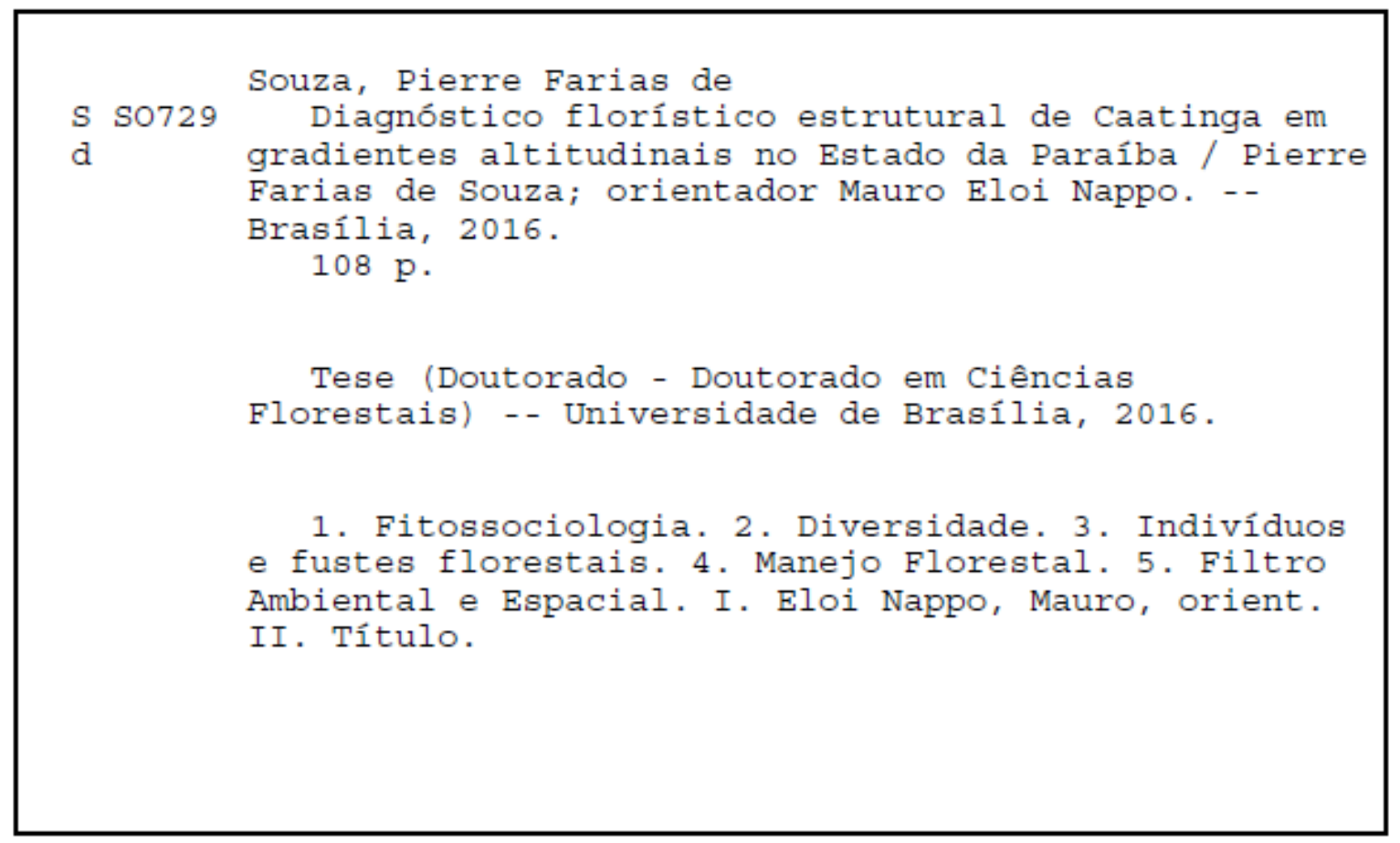

\section{REFERÊNCIA BIBLIOGRÁFICA}

SOUZA, P. F. (2016). Diagnóstico florístico estrutural de Caatinga em gradientes altitudinais no estado da Paraíba. Tese de Doutorado em Ciências Florestais. Publicação PPG/EFL. TD-071/2016. Programa de Pós-graduação em Ciências Florestais, Universidade de Brasília-DF, 108p.

\section{CESSÃO DE DIREITOS}

AUTOR: Pierre Farias de Souza

TÍTULO: Diagnóstico florístico estrutural de Caatinga em gradientes altitudinais no estado da Paraíba.

GRAU: Doutor; ANO: 2016; ÁREA DE CONCENTRAÇÃO: Manejo Florestal.

Concedo à Universidade de Brasília-UnB, permissão para reproduzir cópias desta tese de doutorado e para emprestá-las somente para propósitos acadêmicos e científicos. Reservo outros direitos de publicação, de forma que nenhuma parte desta tese de doutorado pode ser reproduzida sem minha autorização por escrito.

Pierre Farias de Souza

Endereço eletrônico: pierreflorestal@yahoo.com.br 


\section{DEDICATÓRIA}

Aos meus pais,

Helena \& Antônio (in memoriam) 


\section{AGRADECIMENTOS}

Toda a minha gratidão, a Deus, a quem pertenço, por me conceder a vida e perseverança para seguir meu caminho, tributo a ele tudo o que tenho e o que sou.

Ao Professor Mauro Eloi Nappo, pela orientação, apoio, ensinamentos, conselhos e dedicação na orientação deste trabalho.

A CAPES, pela concessão da bolsa de estudos.

Ao Bioma Caatinga, por ter a oportunidade de conhecer um pouco mais da sua vida e da sua história.

Aos professores Dr. José Roberto Rodrigues Pinto e Dr. Ricardo Oliveira Gaspar, pelas contribuições e correções no meu projeto de tese e exame de qualificação.

Aos membros da banca examinadora na defesa da tese, pela disponibilidade em participar deste trabalho e por suas contribuições.

Aos meus pais: Antônio Farias (in memoriam) e Helena Honorato, pelas orações, amor, educação, e cuidado, e aos meus irmãos Farias: Alexandre, Ibéria, Mônica e Remy, pelo apoio, amizade e companheirismo por toda a vida.

Aos professores e funcionários do Programa de Pós Graduação em Ciências Florestais e ao Departamento de Engenharia Florestal da Universidade de Brasília, pelo meu aperfeiçoamento técnico científico.

Aos professores do departamento de Engenharia Florestal que me orientaram em disciplinas: Alba Rezende, Alcides Gatto, Álvaro Nogueira, Anderson Marcos, Ildeu Martins, José Roberto, Mauro Nappo e Reginaldo Sérgio e aos professores da UnB: Cássia Munhoz do departamento de botânica e Welitom Rodrigues do departamento de geofísica, e aos professores Fábio Venturolli da UFG e Pedro Eisenlohr da UNEMAT.

Aos secretários que fazem e fizeram parte do PPGCF/UnB: Yuri, Tiago, Francisco (Chiquinho) e Pedro, pelos serviços prestados.

Aos proprietários das áreas de estudo por me possibilitar o acesso e coleta de dados: Dr. Eduardo Jorge da área em São José do Bonfim-PB, seu Anísio da área em ItaporangaPB e aos que fazem o assentamento Santa Mônica da área em Lagoa-PB.

Ao pessoal que participou na coleta de dados, pela dedicação em todos os momentos: Álvaro, Daniel, Danielly, Davi, Francisco (seu Dodô), Francisco Pimentel, Hernandes, Íkalo, Iuri, Júnior, Leonardo, Marcelo, Manoel, Remy, Titi, Vladimir e William, obrigado a todos. 
As senhoras que me receberam em suas casas depois de um dia de coleta árduo: Ana da Silva - dona Ana, Glislândia - Guiguiu, Maria Tomaz - Laninha, Maria Lucena irmã Maria e Glisnailda - Nanazinha.

À família Freire, Elenildo, Verglauber, Levi, Lívia, Diego e Irene pelo acolhimento em Brasília, pelo amor, carinho e cuidado, vocês são especiais na minha vida.

Ao pessoal dos herbários "herbário CSTR" da UFCG e do "HU UnB" que contribuíram com a identificação das espécies vegetais. À professora e Curadora do "Herbário CSTR", Dra. Maria de Fátima de Araújo Lucena, pelas orientações, identificações e amizade e aos discentes: Danielly, Francione, Neide, Rafael e Wéley, e aos funcionários: Carlos e Nira, pelo convívio e orientações prestadas.

Aos especialistas botânicos que identificaram as espécies presentes neste estudo.

À Milton Serpa Meira Júnior, pela ajuda na análise dos dados.

Aos meus amigos em Brasília: Vânia Miranda e Eduardo Henrique pela nossa amizade, companheirismo e carinho, aos demais amigos Eduardo Nascimento, Eliane, Felipe, Guilherme, Geilson, Gileno, Glauce, Hugo, Irene Ribeiro, João Paulo, Juliana Rigueto, Juliana Castro, Larissa, Levi, Lívia, Ludmila, Luduvico, Mariana, Matheus Rodrigues, Paulo Igor, Pauliane, Pamela, Patrícia Pires, Priscila, Renan, Stephany, Samantha, Thamires, Thiago Nascimento e Victor pela amizade e carinho de todos.

Ao Edilson, pela hospitalidade e convivência.

A toda a família de seu Raimundo e Feliciana, filhos, filhas, netos e netas, por terem cuidado da minha vida e pela atenção prestada.

Aos meus amigos/PB: Danilo, Emanuel, Felipe Almeida, Francisco Pimentel, Ítala, Ismael, Jane Elli, Josenilsson, Lázaro, Maiara Lucena, Edinalva Profirio, Rafael e Valdo, pela nossa amizade, carinho e respeito, obrigado a todos por fazerem parte da minha vida.

Aos pastores: Cleudimar de Lima, Clério, Édsson, Elenildo Freire, Márcio Simões e José Carlos Peréa pela confiança, amizade e ensinamentos.

À Simone Salviano, pelo companheirismo, compreensão e conselhos nos momentos de necessidade.

Aos professores que fazem parte dos Departamentos de Engenharia Florestal e de Ciências Biológicas no CSTR da Universidade Federal de Campina Grande, por permitirem utilizar as dependências da universidade nas necessidades que surgiram.

A todos que participaram para que este trabalho fosse desenvolvido dando a sua contribuição nesta realização.

Obrigado a todos. 


\title{
DIAGNÓSTICO FLORÍSTICO ESTRUTURAL DE CAATINGA EM GRADIENTES ALTITUDINAIS NO ESTADO DA PARAÍBA
}

\author{
Autor: Pierre Farias de Souza \\ Orientador: Mauro Eloi Nappo \\ Programa de Pós-graduação em Ciências Florestais
}

RESUMO GERAL - Considerando grandes lacunas de conhecimento sobre a composição florística e a estrutura fitossociológica da vegetação de Caatinga, este estudo teve como objetivo contribuir para o conhecimento da flora arbustivo-arbórea, mediante análise da estrutura interna e autocorrelações da vegetação arbustivo-arbórea, com variáveis espaciais e ambientais em três fragmentos localizados nos municípios de São José do Bonfim, Itaporanga e Lagoa, no estado da Paraíba - Brasil. Para este estudo, foi realizado inventário florestal dos estratos adulto e regenerante, sendo estabelecidas 25 parcelas de $400 \mathrm{~m}^{2}$, em cada área, sistematicamente distribuídas em malha de $150 \times 150 \mathrm{~m}$. Nas parcelas, foram amostrados todos os indivíduos arbóreos e arbustivos, a partir de $6 \mathrm{~cm}$ de CAP para o estrato adulto, e em subparcelas de $25 \mathrm{~m}^{2}$, enquanto para o estrato regenerante foi coletado a partir de $0,5 \mathrm{~m}$ de $\mathrm{CAB}$ até CAP igual a $6 \mathrm{~cm}$. Foram tomadas para o estrato adulto a altura total, a altura de bifurcação, a vitalidade e a qualidade em cada fuste; e identificadas categorias de usos potenciais das espécies. Para a quantificação de biomassa, foram cubados 56 fustes, sendo 44 para o ajuste dos modelos e 12 para validação das equações selecionadas. Em cada parcela, foram obtidas coordenadas geográficas e coletadas amostras de solo na profundidade $0-60 \mathrm{~cm}$. Os dados ambientais e espaciais foram submetidos à análise de redundância (RDA), que relacionou variáveis de vegetação com variáveis ambientais e espaciais, utilizando o software " $R$ " versão 3.2.5. Foram medidos e identificados 3.118, 2.847 e 3.057 indivíduos, com riqueza de 20, 70 e 68 espécies, respectivamente, em São José do Bonfim, Itaporanga e Lagoa. Para as três áreas, no estrato adulto, as famílias Euphorbiaceae e Fabaceae são as mais ricas em número de espécies e as dominantes em número de indivíduos. Este estudo apresenta o primeiro registro de ocorrência na flora arbustivo-arbórea do estrato adulto de Caatinga para o estado da Paraíba, das espécies: Mimosa acutistipula (São José do Bonfim), Annona leptopetala, Aspidosperma cuspa, Psidium appendiculatum, Eugenia flavescens, Eugenia stictopetala, Cordiera rigida, Sigmatanthus trifoliatus, Allophylus quercifolius, Stachytarpheta coccínea e Callisthene minor (Itaporanga), Erythroxylum nummularia, Byrsonima vacciniifolia, Eugenia caatingicola, Eugenia flavescens, Myrciaria floribunda, Eugenia stictopetala, Cordiera rigida, Pouteria reticulata e Callisthene minor (Lagoa). Para as três áreas de estudo as espécies estruturantes do estrato adulto são Poincianella pyramidalis e Croton blanchetianus. As áreas de Itaporanga e de Lagoa abrigam espécies ameaçadas de extinção - Astronium fraxinifolium e Schinopsis brasiliensis (Itaporanga); Amburana cearenses e Myracrodruon urundeuva (Itaporanga e Lagoa). Foram consideradas como espécies mais importantes no processo de sucessão: Croton blanchetianus, Poincianella pyramidalis, Combretum leprosum e Aspidosperma pyrifolium (São José do Bonfim); Croton blanchetianus e Amburana cearenses (Itaporanga); Croton blanchetianus, Croton nepetifolius, Aspidosperma riedelii, Myrciaria floribunda e Gymnanthes boticario (Lagoa). $\mathrm{O}$ padrão agregado de distribuição de espécies predomina nas três áreas de estudo. $\mathrm{Na}$ vegetação de Caatinga, de São José do Bonfim e de Lagoa, predomina a bifurcação de fuste, e para Itaporanga predomina fuste único. Das 14 espécies comuns nas três áreas, dez apresentam o mesmo comportamento em relação à bifurcação, sendo de fuste único Handroanthus impetiginosus, Commiphora leptophloeos, Jatropha molissima, Manihot carthaginensis subsp. Glaziovii e Mimosa ophthalmocentra. Por sua vez, as espécies 
Combretum leprosum, Erythroxylum Caatinga, Libidibia ferrea, Poincianella pyramidalis e Mimosa tenuiflora apresentaram bifurcação. A vitalidade/sanidade de fustes é baixa em São José do Bonfim e Itaporanga, e superior em Lagoa. As três áreas de estudo apresentam distribuição de fustes sem descontinuidade e em J Invertido. As espécies de maior densidade de indivíduos e, ou, de fustes e de maior gama de categorias de usos são: São José do Bonfim: Poincianella pyramidalis, Croton blanchetianus, Mimosa tenuiflora, Bauhinia cheilantha, Aspidosperma pyrifolium, Combretum leprosum e Mimosa ophthalmocentra; Itaporanga: Croton blanchetianus, Myracrodruon urundeuva, Amburana cearenses, Poincianella pyramidalis, Combretum leprosum, Mimosa ophthalmocentra, Annona leptopetala, Callisthene minor e Sigmatanthus trifoliatus; Lagoa: Croton blanchetianus, Peltogyne pauciflora, Aspidosperma riedelii, Gymnanthes boticário, Myrciaria floribunda, Luehea ochrophylla, Senegalia polyphylla, Eugenia stictopetala, Croton nepetifolius, Erythroxylum nummularia, Maytenus erythroxyla, Eugenia flavescens, Helicteres heptandra, Senna macranthera e Croton heliotropiifolius. A vegetação de Lagoa é a de maior produção de biomassa, e melhor relação de biomassa e vitalidade/qualidade de fustes. Das frações interpretadas na relação vegetação, ambiente e distribuição espacial, 4\% foram explicadas por meio das variáveis ambientais, $11 \%$ por meio das variáveis espaciais e $27 \%$ por meio da interação espaço e ambiente, tendo $58 \%$ de resíduo. Os preditores espaço e ambiente relacionados entre si, foram mais importantes para explicar a distribuição florística estrutural da vegetação de Caatinga arbustivoarbórea, nas áreas estudas, e explicam pouco quando ocorre apenas o ambiente ou apenas o espaço.

Palavras-chave: Fitossociologia, diversidade, indivíduos e fustes florestais, manejo florestal. 


\title{
STRUCTURAL FLORISTIC DIAGNOSIS OF CAATINGA IN ALTITUDINAL GRADIENTS IN PARAIBA STATE
}

\author{
Author: Pierre Farias de Souza \\ Supervisor: Mauro Eloi Nappo \\ Programa de Pós-graduação em Ciências Florestais
}

GENERAL ABSTRACT - Taking into account great knowledge gaps on floristic composition and the phytosociological structure of the Caatinga vegetation, this study aimed to contribute to the shrub-tree flora knowledge field by analyzing the internal structure and shrub-tree vegetation autocorrelations, with spatial and environmental variables in three fragments located in the municipalities of São José do Bonfim, Itaporanga and Lagoa, in Paraíba state - Brazil. For this study, a forest inventory of the adult and regenerating strata was carried out, in which 25 plots of $400 \mathrm{~m}^{2}$ were established in each area, systematically distributed in mesh of $150 \times 150 \mathrm{~m}$. As to the plots, all the arboreal and shrub individuals from $6 \mathrm{~cm}$ of CAP to the adult stratum were sampled, divided in subplots of $25 \mathrm{~m}^{2}$, while the regenerating stratum was collected from 0,5 of $\mathrm{CAB}$ until CAP equal to $6 \mathrm{~cm}$. The total height, the bifurcation height, the vitality and the quality were taken to the adult stratum in each stem; and the categories of potential uses of species were identified. As to the biomass quantification, 56 stems were cubed, of which 44 were chosen for the models adjustment and 12 for validating the selected equations. Geographical coordinates were obtained in each plot, and soil samples at a depth of 0-60 $\mathrm{cm}$ were collected. The environmental and spatial data were submitted to Redundancy Analysis (RDA) which related vegetation variables with enviromental and spatial variables by using software " $R$ " version 3.2.5. We measured and identified 3.118, 2. 847 and 3.057 individuals, with richness of 20,70 and 68 species in São José do Bonfim, Itaporanga and Lagoa respectively. The Families Euphorbiaceae and Fabaceae are the richest in number of species and the dominant in number of individuals in the adult stratum regarding the three areas. This study presents the first record of occurrence of Caatinga adult stratum species in shrub-tree flora at Paraíba State, namely: Mimosa acutistipula (São José do Bonfim), Annona leptopetala, Aspidosperma cuspa, Psidium appendiculatum, Eugenia flavescens, Eugenia stictopetala, Cordiera rigida, Sigmatanthus trifoliatus, Allophylus quercifolius, Stachytarpheta coccinea and Callisthene minor (Itaporanga), Erythroxylum nummularia, Byrsonima vacciniifolia, Eugenia caatingicola, Eugenia flavescens, Myrciaria floribunda, Eugenia stictopetala, Cordiera rigida, Pouteria reticulata and Callisthene minor (Lagoa). The structure species from the adult stratum for the three research areas are Poincianella pyramidalis and Croton blanchetianus. Itaporanga and Lagoa areas shelter threatened species - Astronium fraxinifolium and Schinopsis brasiliensis (Itaporanga); Amburana cearenses and Myracrodruon urundeuva (Itaporanga and Lagoa). The following species were considered the most important in the succession process: Croton blanchetianus, Poincianella pyramidalis, Combretum leprosum and Aspidosperma pyrifolium (São José do Bonfim); Croton blanchetianus and Amburana cearenses (Itaporanga); Croton blanchetianus, Croton nepetifolius, Aspidosperma riedelii, Myrciaria floribunda and Gymnanthes boticario (Lagoa). The aggregate pattern of species distribution predominates in the three study areas. Stem bifurcation predominates in the Caatinga vegetation of São José do Bonfim and Lagoa, whereas single stem predominates in Itaporanga. Out of 14 common species in the three areas, ten present the same behavior regarding bifurcation, that is, single stem: Handroanthus impetiginosus, Commiphora leptophloeos, Jatropha molissima, Manihot carthaginensis subspecies. Glaziovii and Mimosa ophthalmocentra. In turn, the species Combretum leprosum, Erythroxylum Caatinga, Libidibia ferrea, 
Poincianella pyramidalis and Mimosa tenuiflora exhibit bifurcation. Stem vitality/health is low in São José do Bonfim and Itaporanga, and superior in Lagoa. The three study area display stem distribution without descontinuity and in inverted J. The following species show higher density of individuals and/or stems and a wider range of uses categories: in São José do Bonfim: Poincianella pyramidalis, Croton blanchetianus, Mimosa tenuiflora, Bauhinia cheilantha, Aspidosperma pyrifolium, Combretum leprosum and Mimosa ophthalmocentra; Itaporanga: Croton blanchetianus, Myracrodruon urundeuva, Amburana cearenses, Poincianella pyramidalis, Combretum leprosum, Mimosa ophthalmocentra, Annona leptopetala, Callisthene minor and Sigmatanthus trifoliatus; Lagoa: Croton blanchetianus, Peltogyne pauciflora, Aspidosperma riedelii, Gymnanthes boticario, Myrciaria floribunda, Luehea ochrophylla, Senegalia polyphylla, Eugenia stictopetala, Croton nepetifolius, Erythroxylum nummularia, Maytenus erythroxyla, Eugenia flavescens, Helicteres heptandra, Senna macranthera and Croton heliotropiifolius. The vegetation pertaining to Lagoa displays a bigger biomass production as well as a better relation between biomass and stems vitality/quality. With regard to the fractions interpreted in light of the relation among vegetation, environment and spatial distribution, $4 \%$ were explained through environmental variables, $11 \%$ through spatial variables and $27 \%$ through the space and environment interaction, presenting $58 \%$ of residue. The predictors space and environment, related amongst themselves, were more important to explain the structural floristic distribution of shrub-tree Caatinga vegetation in the studied areas, and they explain little when only the environment occur or the space only.

Key words: Phytosociology, diversity, forest individuals and stems, forest handling. 


\section{SUMÁRIO}

$\begin{array}{ll}\text { INTRODUÇÃO GERAL } & 01\end{array}$

$\begin{array}{ll}\text { Referências } & 05\end{array}$

CAPÍLUTO 1

FLORÍSTICA E FITOSSOCIOLOGIA DOS ESTRATOS ADULTO E REGENERANTE EM TRÊS ÁREAS DE CAATINGA SETENTRIONAL NO ESTADO DA PARAÍBA - BRASIL

1.1 Introdução

1.2 Material e Métodos

1.2.1 Áreas de Estudo

1.2.2 Coleta de Dados

1.2.3 Parâmetros Florísticos e Fitossociológicos

1.3 Resultados e Discussão

1.3.1 Parâmetros Florísticos e Fitossociológicos 20

1.4 Conclusões

Referências

\section{CAPÍTULO 2}

ESTRUTURA INTERNA E PRODUÇÃO DE BIOMASSA EM TRÊS ÁREAS DE CAATINGA SETENTRIONAL NO ESTADA DA PARAÍBA - BRASIL

2.1 Introdução

2.2 Material e Métodos 54

2.2.1 Áreas de estudo $\quad 54$

2.2.2 Coleta de dados 54

2.2.3 Estrutura interna: Bifurcação, vitalidade e qualidade de fuste 54

2.2.4 Estrutura paramétrica $\quad 55$

2.2.5 Grupos de usos $\quad 55$

2.2.6 Quantificação de biomassa 56

2.3 Resultados e Discussão 
2.3.1 Bifurcação, vitalidade e qualidade de fuste

$\begin{array}{lll}\text { 2.3.2 Estrutura paramétrica } & 61\end{array}$

2.3.3 Categorias de uso de espécies 66

2.3.4 Estimativa do estoque de biomassa seca 72

$\begin{array}{lll}2.4 \text { Conclusões } & 77\end{array}$

$\begin{array}{ll}\text { Referências } & 78\end{array}$

\section{CAPÍTULO 3}

ANÁLISE DE GRADIENTES AMBIENTAIS EM TRÊS ÁREAS DE CAATINGA SETENTRIONAL NO ESTADO DA PARAÍBA - BRASIL

3.1 Introdução

3.2 Material e Métodos 88

3.2.1 Áreas de estudo $\quad 88$

3.2.2 Coleta de dados 88

$\begin{array}{lll}\text { 3.2.3 Análise das variáveis } & 88\end{array}$

3.3 Resultados e Discussão 90

3.4 Conclusões 96

Referências $\quad 97$ 


\section{LISTA DE TABELAS}

\section{CAPÍTULO 1}

Tabela 1 Relação florística em uma área de Caatinga arbustivo-arbórea dos estratos superior e regenerante, listada por ordem alfabética de famílias e espécies no município de São José do Bonfim, no estado da Paraíba Brasil.

Tabela 2 Relação florística em uma área de Caatinga arbustivo-arbórea dos estratos superior e regenerante, listada por ordem alfabética de famílias e espécies no município de Itaporanga, no estado da Paraíba - Brasil.

Tabela 3 Relação florística em uma área de Caatinga arbustivo-arbórea dos estratos superior e regenerante, listada por ordem alfabética de famílias e espécies no município de Lagoa, no estado da Paraíba - Brasil.

Tabela 4 Informações referentes às espécies arbustivo-arbóreas presentes nos estratos superior e de regeneração em vegetação de Caatinga para as áreas de estudo em São José do Bonfim (SJB), Itaporanga (ITA) e Lagoa (LAG), no estado da Paraíba e demais trabalhos desenvolvidos em vegetação de Caatinga nos estados do Ceará (CE), Pernambuco (PB) e Rio Grande do Norte (RN) - Brasil.

\section{CAPÍTULO 2}

Tabela 1 Categorias e respectivos tipos de usos utilizados para avaliação das espécies arbustivas e arbóreas de ocorrência nas áreas de São José do Bonfim, Itaporanga e Lagoa, no estado da Paraíba - Brasil.

Tabela 2 Modelos matemáticos a serem ajustados para estimativa da biomassa seca da vegetação lenhosa de Caatinga arbustivo-arbórea nas áreas de São José do Bonfim, Itaporanga e Lagoa, no estado da Paraíba - Brasil.

Tabela 3 Densidades de indivíduos e de fustes da vegetação de Caatinga arbustivo-arbórea para as áreas de São José do Bonfim, Itaporanga e Lagoa, no estado da Paraíba - Brasil.

Tabela 4 Comportamento de fustes em relação a comprimento de seção e diâmetro de fustes da vegetação de Caatinga arbustivo-arbórea para as áreas de São José do Bonfim, Itaporanga e Lagoa, no estado da Paraíba - Brasil.

Tabela 5 Densidades de indivíduos e de fustes em vegetação de Caatinga arbustivo-arbórea presentes na área de São José do Bonfim, no estado da Paraíba - Brasil.

Tabela 6 Densidades de indivíduos e de fustes em vegetação de Caatinga arbustivo-arbórea presentes na área de Itaporanga, no estado da Paraíba - Brasil. 
Tabela 7 Densidades de indivíduos e de fustes em vegetação de Caatinga arbustivo-arbórea presentes na área de Lagoa, no estado da Paraíba Brasil.

Tabela 8 Estimativas dos parâmetros e medidas de precisão das equações de biomassa seca ajustadas para fuste, em vegetação de Caatinga arbustivo-arbórea nas áreas de São José do Bonfim, Itaporanga e Lagoa, no estado da Paraíba - Brasil.

Tabela 9 Estimadores dos parâmetros da variável biomassa seca em t.ha ${ }^{-1}$ das vegetações de Caatinga arbustivo-arbóreas, amostradas nas áreas de São José do Bonfim, Itaporanga e Lagoa, no estado da Paraíba - Brasil.

\section{CAPÍTULO 3}

Tabela 1 Variáveis ambientais obtidas para as áreas de São José do Bonfim, Itaporanga e Lagoa, no estado da Paraíba - Brasil.

\section{ANEXOS}

Anexo 1 Parâmetros da estrutura horizontal das espécies arbustivo-arbóreas do estrato adulto de vegetação de Caatinga, em ordem decrescente pelo IVI (\%), presentes na área de São José do Bonfim, no estado da Paraíba - Brasil.

Anexo 2 Parâmetros da estrutura horizontal das espécies arbustivo-arbóreas do estrato adulto de vegetação de Caatinga, em ordem decrescente pelo IVI (\%), presentes na área de Itaporanga, no estado da Paraíba - Brasil.

Anexo 3 Parâmetros da estrutura horizontal das espécies arbustivo-arbóreas do estrato adulto de vegetação de Caatinga, em ordem decrescente pelo IVI (\%), presentes na área de Lagoa, no estado da Paraíba - Brasil.

Anexo 4 Estimativas de indivíduos.ha ${ }^{-1}$ no estrato de regeneração natural em vegetação de Caatinga presentes na área de São José do Bonfim, no estado da Paraíba - Brasil.

Anexo 5 Estimativas de indivíduos.ha ${ }^{-1}$ no estrato de regeneração natural em vegetação de Caatinga presentes na área de Itaporanga, no estado da Paraíba - Brasil.

Anexo 6 Estimativas de indivíduos.ha ${ }^{-1}$ no estrato de regeneração natural em vegetação de Caatinga presentes na área de Lagoa, no estado da Paraíba - Brasil. 


\section{LISTA DE FIGURAS}

\section{CAPÍTULO 1}

Figura 1 Área útil das parcelas do inventário das espécies arbustivo-arbóreas do estrato adulto $\left(400 \mathrm{~m}^{2}\right)$ e sub-parcelas para inventário das espécies do estrato regenerante $\left(25 \mathrm{~m}^{2}\right)$, utilizadas neste estudo.

Figura 2 Determinação da suficiência amostral utilizando a curva espécie-área, com determinação do ponto de inflexão pela REGRELRP, em vegetação de Caatinga arbustivo-arbórea para as áreas de São José do Bonfim (SJB), Itaporanga (ITA) e Lagoa (LAG), no estado da Paraiba Brasil

Figura 3 Perfis de diversidade para espécies arbustivo-arbóreas em vegetação de Caatinga para os estratos superior e regeneração presentes nas áreas de São José do Bonfim, Itaporanga e Lagoa, no estado da Paraíba - Brasil.

Figura 4 Dendrograma de similaridade florística de Jaccard em vegetação de Caatinga arbustivo-arbórea, nos estratos superior e regeneração para as áreas de São José do Bonfim (SJB), Itaporanga (ITA) e Lagoa (LAG), no Estado da Paraíba - Brasil.

Figura 5 Índice de Valor de Importância - IVI\% para o estrato adulto em vegetação de Caatinga arbustivo-arbórea, no estado da Paraíba - Brasil.

Figura 6 Estimativas da regeneração natural relativa $(\%)$ em vegetação de Caatinga arbustivo-arbórea, presentes na área de São José do Bonfim, Itaporanga e Lagoa, no estado da Paraíba - Brasil.

\section{CAPÍTULO 2}

Figura 1 Distribuição do número de fustes.ha ${ }^{-1}$ para as classes de vitalidade e de qualidade de fuste em vegetação de Caatinga arbustivo-arbórea, para as áreas de São José do Bonfim, Itaporanga e Lagoa, no estado da Paraíba - Brasil. Em que: para sanidade de fuste V 1 = Sadio, V $2=$ Danificado e V 3 = Morto; para qualidade de fuste Q $1=$ Reto, Q $2=$ Levemente torto e Q 3 = Tortuoso.

Figura 2 Distribuição diamétrica de fustes para a vegetação de Caatinga arbustivo-arbórea para as áreas de São José do Bonfim, Itaporanga e Lagoa, no estado da Paraíba - Brasil.

Figura 3 Distribuição da dominância absoluta $\left(\mathrm{m}^{2} \cdot \mathrm{ha}^{-1}\right)$ em classes diamétricas para a vegetação de Caatinga arbustivo-arbórea para as áreas de São José do Bonfim, Itaporanga e Lagoa, no estado da Paraíba - Brasil.

Figura 4 Distribuição do número de fustes com comprimento de seção acima de 2,50 m por classe diamétrica para as áreas de São José do Bonfim, Itaporanga e Lagoa, no estado da Paraíba - Brasil. Em que CD = classe 
Figura 5 Estimativas do estoque de biomassa seca de fuste em (t.ha ${ }^{-1}$ ), distribuídas em classes diamétricas para as vegetações de Caatinga arbustivo-arbóreas, amostradas nas áreas de áreas de São José do Bonfim, Itaporanga e Lagoa, no estado da Paraíba - Brasil.

Figura 6 Estimativas do estoque de biomassa seca de fuste em (t.ha ${ }^{-1}$ ), distribuída para as classes de vitalidade e qualidade de fuste em vegetação de Caatinga arbustivo-arbórea, para as áreas de São José do Bonfim, Itaporanga e Lagoa, no estado da Paraíba - Brasil. Em que: para sanidade de fuste V 1 = Sadio, V 2 = Danificado e V 3 = Morto; para qualidade de fuste $\mathrm{Q} 1=$ Reto, Q $2=$ Levemente torto e Q $3=$ Tortuoso.

\section{CAPÍTULO 3}

Figura 1 Diagrama de ordenação (RDA) das variáveis preditoras ambientais e espaciais para a densidade de indivíduos das espécies arbustivas e arbóreas da vegetação de Caatinga nas áreas de São José do Bonfim (SJB), Itaporanga (ITA) e Lagoa (LAG), no estado da Paraíba - Brasil.

Figura 2 Partição da variância das frações que explicam a variação da densidade de indivíduos para as espécies arbustivas e arbóreas de vegetação de Caatinga nas áreas de São José do Bonfim, Itaporanga e Lagoa, no estado da Paraíba - Brasil.

Figura 3 Composição florística selecionada pelas variáveis espaciais e ambientais significativas e selecionadas pela RDA para a vegetação arbustivo-arbórea de Caatinga nas áreas de São José do Bonfim, Itaporanga e Lagoa, no estado da Paraíba - Brasil. PCNM = filtros espaciais. 


\section{INTRODUÇÃO GERAL}

\section{CAATINGA}

A origem do termo Caatinga vem do tupi-guarani, CAA = mata e TINGA= branca, mata branca, o que caracteriza a paisagem no período de estiagem quando a vegetação perde as folhas e fica com um aspecto seco e sem vida (ALVES, 2007).

A descrição da fitogeografia brasileira iniciou-se com Martius, que teve seu mapa fitogeográfico anexado no volume XXI da Flora Brasiliensis em 1824. Nesse mapa, ele separou o território brasileiro em cinco regiões florísticas distintas. O mesmo se referiu às Caatingas como "Hamadryades" usando, ainda, as palavras "sylvahorrida" e "sylvaaestuaphylla". Estes termos destacam os seus traços principais: plantas lenhosas (sylva), que apresentam perda total das folhas (aphylla) durante a estação seca (aestu). O último termo, inclusive, traz consigo um valor conceitual, entendendo a Caatinga como uma floresta sem folhas no verão (MARTIUS, 1996).

O bioma Caatinga ocupa uma área de aproximadamente 826.411,23 km² (MMA, 2010) do território brasileiro. A Caatinga estende-se desde os limites ao norte, nos estados do Ceará e Rio Grande do Norte, até os limites ao sul, no região norte do estado de Minas Gerais, (AB’SABER, 1974), e os demais estados do Maranhão, Piauí, Pernambuco, Paraíba, Alagoas, Sergipe, Bahia (ALVES et al., 2009a) sendo o único bioma exclusivamente brasileiro (AB'SABER, 1974).

Na maior parte de sua extensão territorial, o Bioma Caatinga é caracterizado por um clima quente e semiárido. Apresenta distribuição sazonal da temperatura, umidade, fatores edáficos, bióticos e abióticos, com menos de $1.000 \mathrm{~mm}$ de precipitação anual, tendo a sua distribuição em um período de três a seis meses. Os totais de chuva variam ao longo do ano e de ano para ano e, em intervalos de dez a vinte anos, a precipitação é menor que a metade da média de todos os anos anteriores analisados, (às vezes durante três a cinco anos seguidos); fenômeno conhecido como "a seca" (VELLOSO et al., 2002).

Com base na interação entre vegetação, solo e clima, a região pode ser dividida nas seguintes zonas ecogeográficas: domínio da vegetação hiperxerófila (34,3\%); domínio da vegetação hipoxerófila (43,2\%); ilhas úmidas $(9,0 \%)$; agreste e área de transição $(13,4 \%)$ (BRASIL, 2003). Segundo Cordeiro; Oliveira (2010), a Caatinga hiperxerófila pode ser encontrada nos setores mais secos e de baixas altitudes presentes nas mesorregiões do Cariri, Curimataú e Sertão, no estado da Paraíba, e a Caatinga hipoxerófila nos setores que 
apresentam melhores condições de clima, umidade, precipitação como em áreas com maiores altitudes.

A cobertura vegetal representada por formações hiperxerófilas é formada por Caatingas muito diversificadas por razões climáticas (clima semiárido), edáficas (solos jovens e férteis, porém rasos) topográficas e antrópicas. Com estas formações vegetais dominantes, ocorrem também as florestas dos relevos (florestas perenifólias e subperenifólias dos brejos de altitude e encostas expostas aos fluxos úmidos de ar e de florestas semi-decíduas) e as florestas ripárias e os cerrados (ALVES et al., 2009b).

Entende-se, então, que a Caatinga está integrada, pelo determinismo dos fatores climáticos, edáficos e antrópicos. As suas diferenças fisionômicas se devem não apenas às variações climáticas regionais ou locais e à composição florística, mas, sobretudo, a certos fatores estacionais, como compartimentação topográfica, fenômenos de exposição e abrigo, condições edáficas e impactos das atividades humanas. Alguns estudos afirmam que todas as formas da Caatinga atual são oriundas da degradação antrópica, onde o clímax sendo a floresta seca. Outros estudos, sem negar o papel das ações humanas diretas e indiretas, consideram as florestas secas como formações clímáceas, sendo estas mesoclimáticas e/ou edáficas (ALVES et al., 2008).

No estado da Paraíba a Caatinga se estende desde as áreas de maior altitude no Planalto da Borborema, distribuindo-se em maior abrangência por toda a região oeste do estado. Apesar disso, apenas 7,5\% de seu território está protegido em Unidades de Conservação, das quais apenas $1,4 \%$ são áreas de proteção integral e estima-se que cerca de $41 \%$ de suas áreas nunca foram estudas. No estado da Paraíba, são 34 Unidades de Conservação, cuja área de preservação é de aproximadamente $0,01 \%$ de seu território (ZILAH, 2011; CALLADO, 2013).

A heterogeneidade florística e da fisionomia da cobertura vegetal pertencente a fitofisionomia Caatinga decorre de dois gradientes de umidade, um no sentido Norte - Sul, que se manifesta em uma diminuição das precipitações e outro Oeste - Leste, que se expressa com um aumento do efeito da continentalidade (RODAL et al., 2008b). Segundo Sales (2003), as maiores limitações naturais nessas áreas estão estabelecidas, principalmente por meio da instabilidade climática, gerando problemas de disponibilidade hídrica que comprometem todo o sistema de regeneração e crescimento da floresta nativa. Todavia, aspectos básicos para o conhecimento dessa vegetação, como, por exemplo, as diferenças entre as tipologias fisionômicas da Caatinga, ainda não são claros. No entanto, 
de um modo geral, a flora vai tornando-se menos rica no sentido Sul - Norte (ALVES, 2009a; RODAL et al., 2008a; 2008b).

O setor florestal no Nordeste brasileiro gera cerca de 170 mil empregos diretos e 500 mil indiretos, além de contribuir com 15\% da renda global dos produtores. Destaca-se também pela sua produção de lenha, uma vez que 35\% do seu parque industrial têm a lenha como sua fonte de energia primária, atendendo a $70 \%$ da demanda energética dos domicílios da região (CAMPELLO et al., 2000).

Segundo Moura et al. (2006), todo este aparato financeiro tem feito com que o produto florestal desempenhe papel fundamental na economia informal das pessoas desfavorecidas, sendo uma das poucas alternativas econômicas para a geração de renda das famílias rurais nos períodos de estiagens na Caatinga.

Em muitas áreas, a exploração da vegetação de Caatinga se dá de forma desordenada. O uso inadequado dos recursos naturais tem sido motivo de muita preocupação e discussão pela mídia e sociedade em geral. No mundo, muitas áreas já estão desertificadas e outras sendo levadas ao mesmo processo. No Brasil, as áreas que estão susceptíveis a desertificação se encontram dentro do Polígono da Secas, que abrange a maior parte do Nordeste brasileiro e uma pequena parte do Sudeste (ALVES et al., 2009b). Há muitos séculos o homem vem usando a área recoberta pela Caatinga com pecuária intensiva e agricultura nas partes mais úmidas, fomentando a retirada da vegetação tanto para o uso da madeira quanto para outros fins de menor interesse socioeconômico (BARBOSA et al., 2012).

A conservação da biodiversidade representa um dos maiores desafios, em função do elevado nível de perturbações antrópicas dos ecossistemas naturais (CHAVES et al., 2013). O desafio de conservar a biodiversidade regional tem como principais limitantes o processo de degradação de fragmentos florestais, tamanho, forma, grau de isolamento e, histórico de perturbações, os quais estão relacionados a fenômenos biológicos e, consequentemente, afetam a dinâmica dos fragmentos florestais. Estes limitantes refletem no mosaico de eco-unidades que diferem entre si quanto à diversidade, mortalidade, natalidade de espécies vegetais dentre outros fatores (VIANA; PINHEIRO, 1998).

Segundo Rodal et al. (2008b) não existem ainda trabalhos que forneçam uma informação completa sobre o potencial florístico da Caatinga e sobre quais setores merecem maior atenção. O conhecimento sobre a distribuição da vegetação e das comunidades de vegetação tem implicações importantes para a conservação da diversidade biológica. No entanto, a distribuição dos estudos realizados até o momento parece estar 
concentrada em áreas ou regiões com longos históricos de perturbações antrópicas (TABARELLI; VICENTE, 2003). Por isso, pouco se conhece sobre comunidades arbustivas, arbustivo-arbóreas e arbóreas em mais de uma fitofisionomia de vegetação de Caatinga (CALIXTO JÚNIOR; DRUMOND, 2014; MENDONÇA et al., 2013; SOUZA; MEDEIROS, 2013; SILVA; SAMPAIO, 2008; FABRICANTE, 2007; SILVA, 2005).

Assim, foi verificada a necessidade da realização de trabalhos voltados para análises de vegetação de Caatinga na região do Sertão Paraibano, mais precisamente em ambientes conservados. De acordo com Souza; Medeiros (2013), é notória uma deficiência em relação à levantamentos das espécies vegetais em vegetação de Caatinga, tendo como necessidade principal a formação de lista Florística, caracterização estrutural das espécies arbustivo-arbóreas, estrutura interna dentre outros aspectos importante para a preservação e conservação dos recursos naturais.

Considerando que a Caatinga é proporcionalmente a fitofisionomia menos estudada entre as de ocorrência no Brasil, que é a região menos protegida em unidades de conservação, que o processo intenso de alteração do uso e ocupação do solo tem levado à rápida perda de diversidade, e por consequência, alterações em processos ecológicos importantes para a região do semiárido. É apresentado a seguir o estudo de diagnóstico florístico estrutural de Caatinga em gradientes altitudinais no estado da Paraíba - Brasil. 


\section{REFERÊNCIAS}

AB'SÁBER, A. N. O domínio morfoclimático semiárido das Caatingas brasileiras. Geomorfologia, 43. p.1-39, 1974.

ALVES, J. J. A.; ARAÚJO, M. A. de.; NASCIMENTO, S. S. do. Degradação da Caatinga: Uma Investigação Ecogeográfica. Revista Caatinga, Mossoró, v.22, n.3, p.126-135, 2009a.

ALVES, J. J. A. Geoecologia da Caatinga no semiárido do Nordeste brasileiro. CLIMEP: Climatologia e Estudos da Paisagem, v.2, n.1, p.58-71, 2007.

ALVES, J. J. A.; ARAÚJO, M. A. de.; NASCIMENTO, S. S. do. Degradação da Caatinga: Uma Investigação Ecogeográfica. Caminhos de Geografia, v.9, n.27, p.143-155, 2008.

ALVES, J. J. A.; SOUZA, E. N. de.; NASCIMENTO, S. S. do. Núcleos de desertificação no estado da Paraíba. Revista Ra'e Ga, n.17, p.139-152, 2009 b.

BARBOSA, M. D.; MARANGON, L. C.; FELICIANO, A. L. P.; FREIRE, F. J.; DUARTE, G. M. T. Florística e Fitossociologia de Espécies Arbóreas e Arbustivas em uma Área de Caatinga em Arco verde, PE, Brasil. Revista Árvore, v.36, n.5, p.851-858, 2012.

BRASIL, Ministério do Meio Ambiente. Biodiversidade da Caatinga: áreas e ações prioritárias para a conservação. SILVA, J. M. C.; TABARELLI, M.; FONSECA, M. T.; LINS, L. V. (Org.). Brasília - DF: Ministério do Meio Ambiente: Universidade Federal de Pernambuco, 382p, 2003.

CALlaDO, P. 2013. Paraíba terá 15 Unidades de Conservação com o intuito de aumentar áreas de preservação no Estado. Disponível em: < http://www.paraiba.com.br/2013/05/27/02279-paraiba-tera-15-unidades-de-conservacaocom-o-intuito-de-aumentar-areas-de-preservacao-no-estado>. Acesso em: 10/02/2016.

CALIXTO JÚNIOR, J. T.; DRUMOND, M. A. Estudo comparativo da estrutura fitossociológica de dois fragmentos de Caatinga em níveis diferentes de conservação. Pesq.flor. bras., v.34, n.80, p.01-011, 2014.

CAMPEllo, F. C. B.; LEAl-JUNiOR, G.; SILVA, J. A.; CAMPELlO, R. C. B. Avaliação dos recursos florestais de área de proteção Ambiental Chapada do Araripe. Projeto MMAIFAO, UTFIBRA1047, MMA - Ministério do Meio Ambiente, Secretaria da Biodiversidade e Floresta, Diretoria do Programa Nacional de Florestas, Crato-CE, 49p. 2000.

CHAVES, A. D. C. G.; SANTOS, R. M. de. S.; SANTOS, J. O. dos.; FERNANDES, A. de. A.; MARACAJÁ, P. B. A importância dos levantamentos florístico e fitossociológico para a conservação e preservação das florestas. Agropecuária Científica no Semiárido, v.9, n.2, p.42-48, 2013, 2013. 
CORDEIRO, J. M. P.; OLIVEIRA, A. G. de. Levantamento Fitogeográfico em Trecho de Caatinga Hipoxerófila - Sítio Canafístula, Sertãozinho - Paraíba, Brasil. Okara: Geografia em debate, v.4, n.1-2, p.54-65, 2010.

FABRICANTE, J. R.; ANDRADE, L. A. de. Análise estrutural de um remanescente de Caatinga no Seridó paraibano. Oecologia Brasiliensis, v.11, n.3, p.341-349, 2007.

MARTIUS, K. P. Von. A viagem de Von Martius: tabulae physiognice: Rio de Janeiro: Index. v.1, 1840p.1996.

MENDONÇA, A. V. R.; SOUZA, J. S.; GIULIETTI, A. M.; BERG, C. V. D. Estimação de biomassa aérea da Caatinga do norte da Bahia. Pesquisa Florestal Brasileira, v.33, n.76, p.355-368, 2013.

MINISTÉRIO DO MEIO AMBIENTE - MMA. Monitoramento do desmatamento nos biomas brasileiros por satélite acordo de cooperação técnica MMA/IBAMA. Monitoramento do Bioma Caatinga 2002 a 2008. MMA/CSR/IBAMA, Brasília, 58p, 2010.

MOURA, O. N.; PASSOS, M. A. A.; FERREIRA, R. L. C.; MOLICA, S. G.; LIRA JUNIOR, M. de. A.; LIRA, M. de. A.; SANTOS, M. V. F. dos. Distribuição de biomassa e nutrients na parte aérea de Mimosa caesalpiniaefolia Benth. Revista Árvore, v.30, n.6, p.877-884, 2006.

RODAL, M. J. N.; BARBOSA, M. R. V.; THOMAS, W. W. Do the seasonal forests in northeastern Brazil represent a single floristic unit? Braz. J. Biol., v.68, n.3, p.467-475, $2008 b$.

RODAL, M. J. N.; MARTINS, F. R.; SAMPAIO, E. V. de. S. B. Levantamento Quantitativo das Plantas Lenhosas em Trechos de Vegetação de Caatinga em Pernambuco. Revista Caatinga, v.21, n.3, p.192-205, 2008a.

SALES, M. C. L. Evolução dos Estudos de Desertificação no Nordeste Brasileiro. Geousp - Espaço e Tempo, n.14, p.9-19, 2003.

SILVA, G. C.; SAMPAIO, E. V. S. B. Biomassas de partes aéreas em plantas da Caatinga. Revista Árvore, v.32, n.3, p.567-575, 2008.

SILVA, J, A, Fitossociologia e relações alométricas em Caatinga nos estados da Paraíba e Rio Grande do Norte. Tese (Doutorado em Ciência Florestal), Universidade Federal de Viçosa, Viçosa, MG, 81p, 2005.

SOUZA, G. F.; MEDEIROS, J. F. Fitossociologia e Florística em áreas de Caatinga na microbacia hidrográfica do Riacho Cajazeiras-RN. GEOTemas, v.3, n.1, p.161-176, 2013.

TABARELli, M.; VICENTE, A. Conhecimento Sobre Plantas Lenhosas da Caatinga: lacunas geográficas e ecológicas, p.101-112. In: SILVA, J. M. C, M.; TABARELLI, M.; FONSECA, F.; LINS, L. V. Biodiversidade da Caatinga: áreas e ações prioritárias. Ministério do Meio Ambiente, Brasília, DF, 382p, 2003. 
VELLOSO.; A. L.; SAMPAIO, E. V. S. B.; GIULIETTI, A. R. V.; BARBOSA, M. R. V.; CASTRO, A. A.; J. F.; QUEIROZ, L. P. de.; FERNANDES, A.; OREN, D. C.; CESTARO, L. A.; CARVALHO, A. J. E. de.; PAREYN, F. G. C.; SILVA, F. B. R. da.; MIRANDA, E. E. de.; KEEL, S.; GONDIM, R. S. Ecorregiões, Propostas para o Bioma Caatinga. Instituto de Conservação Ambiental The Nature Conservancy do Brasil, Associação Plantas do Nordeste, 76p, 2002.

VIANA, V. M.; PINHEIRO, L. A. F. V. Conservação da biodiversidade em fragmentos florestais. Série Técnica IPEF, v.12, n.32, p.25-42, 1998.

ZILAH, K. 2011. Saiba quais são as Unidades de Conservação ambiental na PB. http://www.jornaldaparaiba.com.br/cidades/noticia/60986_saiba-quais-sao-as-unidades-deconservacao-ambiental-na.pb. Acesso em: 12/02/2016. 


\section{CAPÍTULO 1}

\section{FLORÍSTICA E FITOSSOCIOLOGIA DOS ESTRATOS ADULTO E REGENERANTE EM TRÊS ÁREAS DE CAATINGA SETENTRIONAL NO ESTADO DA PARAÍBA - BRASIL}

RESUMO - Considerando grandes lacunas de conhecimento sobre a composição florística e a estrutura fitossociológica da vegetação de Caatinga, este estudo teve como objetivo contribuir para o conhecimento da flora arbustivo-arbórea da Caatinga, estudando três fragmentos localizados nos municípios de São José do Bonfim, Itaporanga e Lagoa, no estado da Paraíba - Brasil. Para este estudo, foi realizado o inventário florestal dos estratos adulto e regenerante, sendo estabelecidas 25 parcelas de $400 \mathrm{~m}^{2}$ em cada área, sistematicamente distribuídas em malha de $150 \times 150 \mathrm{~m}$. Nas parcelas, foram amostrados todos os indivíduos arbóreos e arbustivos com circunferência na altura do peito a $1,30 \mathrm{~m}$ de altura do solo superior a $6 \mathrm{~cm}$, para o estrato adulto e levantada em subparcelas de $25 \mathrm{~m}^{2}$, dentro de cada parcela o estrato regenerante a partir de $0,5 \mathrm{~m}$ de altura até CAP igual a $6 \mathrm{~cm}$. Foram medidos e identificados nas três áreas de estudo 3.118, 2.847 e 3.057 indivíduos, com riqueza de 20, 70 e 68 espécies respectivamente para cada área. Para as três áreas de estudo, no estrato adulto, as famílias Euphorbiaceae e Fabaceae, são as mais ricas em número de espécies, e as dominantes em número de indivíduos. As áreas de maior altitude, Itaporanga e Lagoa, apresentaram valores elevados de diversidade $\left(\mathrm{H}^{\prime}\right)$ para áreas de Caatinga. Este estudo apresenta o primeiro registro de ocorrência na flora arbustivoarbórea do estrato adulto de Caatinga, para o estado da Paraíba, as espécies: Mimosa acutistipula (São José do Bonfim), Annona leptopetala, Aspidosperma cuspa, Psidium appendiculatum, Eugenia flavescens, Eugenia stictopetala, Cordiera rigida, Sigmatanthus trifoliatus, Allophylus quercifolius, Stachytarpheta coccinea e Callisthene minor (Itaporanga), Erythroxylum nummularia, Byrsonima vacciniifolia, Eugenia caatingicola, Eugenia flavescens, Myrciaria floribunda, Eugenia stictopetala, Cordiera rigida, Pouteria reticulata e Callisthene minor (Lagoa). Para as três áreas de estudo, as espécies estruturantes do estrato adulto são Poincianella pyramidalis e Croton blanchetianus, considerando os parâmetros densidade, frequência e densidade de espécies. As áreas de Itaporanga e de Lagoa são consideradas de relevante importância para estudos florístico/fitossociológicos por abrigarem espécies ameaçadas de extinção, sendo: Astronium fraxinifolium e Schinopsis brasiliensis (Itaporanga); Amburana cearenses e Myracrodruon urundeuva (Itaporanga e Lagoa). Foram consideradas como espécies mais importantes no processo de sucessão: Croton blanchetianus, Poincianella pyramidalis, Combretum leprosum e Aspidosperma pyrifolium para São José do Bonfim; Croton blanchetianus e Amburana cearenses para Itaporanga; Croton blanchetianus, Croton nepetifolius, Aspidosperma riedelii, Myrciaria floribunda e Gymnanthes boticario para Lagoa. O padrão agregado de distribuição de espécies predomina nas três áreas de estudo.

Palavras-chave: Caatinga arbóreo-arbustiva, estrutura de vegetação, semiárido.

\section{FLORISTIC AND PHYTOSOCIOLOGY OF THE ADULT AND REGENERATING STRATA IN THREE AREAS OF NORTHERN CAATINGA IN PARAIBA STATE - BRAZIL}

\footnotetext{
ABSTRACT - Taking into consideration great knowledge gaps on floristic composition and the phytosocyological structure of Caatinga vegetation, the current study aimed at
} 
giving contributions to the knowledge field of the Caatinga shrub-tree flora by studying three fragments located in the municipalities of São José do Bonfim, Itaporanga and Lagoa, Paraiba State - Brazil. In order to achieve this aim, a forest inventory of the adult and regenerating strata was carried out, in which 25 plots of $400 \mathrm{~m}^{2}$ were established in each area, systematically distributed in mesh of $150 x 150 \mathrm{~m}$. As to the plots, all the arboreal and shrub individuals were sampled with chest-height circumference of $1,30 \mathrm{~m}$ of soil height superior to $6 \mathrm{~cm}$ to the adult stratum, and raised in subplots of $25 \mathrm{~m}^{2}$, inside of which the regenerating stratum measured from $0,5 \mathrm{~m}$ high until CAP equal to $6 \mathrm{~cm}$. We measured and identified 3.118, 2.847 and 3.057 individuals in the three study areas, with richness of 20, 70, and 68 species for each area respectively. The families Euphorbiaceae and Fabaceae are the richest in number of species and the dominant in number of individuals of the adult stratum in the three study areas. Itaporanga and Lagoa, the areas of greater altitude, presented high values of diversity $\left(\mathrm{H}^{\prime}\right)$ for the Caatinga areas. This research presents the first record of occurrence of Caatinga adult stratum species in shrub-tree flora at Paraiba State, namely: Mimosa acutistipula (São José do Bonfim), Annona leptopetala, Aspidosperma cuspa, Psidium appendiculatum, Eugenia flavescens, Eugenia stictopetala, Cordiera rigida, Sigmatanthus trifoliatus, Allophylus quercifolius, Stachytarpheta coccinea and Callisthene minor (Itaporanga), Erythroxylum nummularia, Byrsonima vacciniifolia, Eugenia caatingicola, Eugenia flavescens, Myrciaria floribunda, Eugenia stictopetala, Cordiera rigida, Pouteria reticulata and Callisthene minor (Lagoa). The structure species from the adult stratum for the three research areas are Poincianella pyramidalis and Croton blanchetianus, taking into account the following parameters: density, frequency, and species density. Itaporanga and Lagoa areas are considered of high importance to floristic/phytosocyological studies for sheltering the following threatened species: Astronium fraxinifolium and Schinopsis brasiliensis (Itaporanga); Amburana cearenses and Myracrodruon urundeuva (Itaporanga and Lagoa). These were considered the most important species in the process of succession: Croton blanchetianus, Poincianella pyramidalis, Combretum leprosum and Aspidosperma pyrifolium in São José do Bonfim; Croton blanchetianus and Amburana cearenses in Itaporanga; Croton blanchetianus, Croton nepetifolius, Aspidosperma riedelii, Myrciaria floribunda and Gymnanthes boticario in Lagoa. The aggregate pattern of species distribution predominates in the three study areas.

Key words. Shrub-tree Caatinga, vegetation structure, semiarid 


\subsection{INTRODUÇÃO}

Segundo Sampaio (1996), os estudos fitossociológicos fornecem informações acerca da estrutura das comunidades e de algumas populações, bem como o conhecimento da flora regional, subsidiando, dessa forma, o manejo, a recuperação e/ou, a conservação dos ecossistemas. Portanto, pode constituir o ponto de partida para nortear atividades conservacionistas; assim, é necessário conhecer para conservar, conhecer para preservar.

No mundo, $42 \%$ da vegetação tropical e subtropical estão em áreas tropicais sazonalmente secas (MURPHY; LUGO, 1995) como a/as que ocorre no semiárido do Nordeste do Brasil, no qual predomina a Caatinga.

Em particular, a vegetação de Caatinga possui desde formações vegetacionais arbustivas baixas, ralas ou abertas até florestas arbóreas impenetráveis atingindo estratos superiores a oito metros de altura, com a presença de espécies decíduas e macrófitas (DANIEL et al., 2006). Além disso, apresenta proporção significativa de espécies dotadas de espinhos, acúleos, folhas compostas e caules suculentos e o predomínio de ervas anuais adaptadas à deficiência hídrica (ALCOFORADO-FILHO et al., 2003).

A Caatinga está entre as formações vegetais brasileiras menos conhecidas, sendo que os estudos florísticos atualmente existentes, ainda não permitem elaborar uma lista florística completa para as espécies arbustivas e arbóreas (RODAL et al., 2013). É também um dos biomas mais ameaçados quanto à conservação de sua biodiversidade devido a antropização crescente que, entre outros aspectos, vem intensificando a fragmentação e proporcionando altos níveis de degradação, sendo, por isso, considerada área vulnerável (MOONEY et al., 1995; RODAL; SAMPAIO, 2002; VIEIRA; SCARIOT, 2006; PRANCE, 2006).

Associado aos aspectos já relacionados, observa-se grandes lacunas de conhecimento sobre a composição florística e a estrutura fitossociológica da vegetação de Caatinga. Por essa razão, este estudo teve como objetivo contribuir para o conhecimento da flora arbustivo-arbórea da Caatinga, dos estratos superior e de regeneração de três fragmentos localizados nos municípios de São José do Bonfim (SJB), Itaporanga (ITA) e Lagoa (LAG), no estado da Paraíba - Brasil. 


\subsection{MATERIAL E MÉTODOS}

\subsection{1. Áreas de Estudo}

A pesquisa foi conduzida em três áreas de vegetação de Caatinga, no semiárido do estado da Paraíba, localizadas nos municípios de São José do Bonfim, Itaporanga e Lagoa, inseridas na mesma região vegetacional denominada de "Sertão Paraibano". Estas áreas apresentam vegetação nativa representativa localmente (Tabelas 1, 2 e 3).

As três áreas de estudo estão situadas no polígono do semiárido, circunscritas na Depressão Sertaneja Setentrional (VELLOSO et al., 2002). Segundo a classificação de Koppen (RUBEL; KOTTEK, 2010), o clima predominante é do tipo Bsh, muito quente e com presença de semiardidez. A precipitação possui uma distribuição irregular, em que se observam períodos entre 7 e 10 meses sem chuvas. Em geral, a precipitação média anual é da ordem de $800 \mathrm{~mm}$ em áreas de planície e de 800 a $1.200 \mathrm{~mm}$ em áreas elevadas (MAGALHÃES, 2012).

A primeira área está localizada na Fazenda Lagoa Seca no município de São José do Bonfim, Paraíba, nas seguintes coordenadas geográficas: $7^{\circ} 09^{\prime} 18,21$ ”; $7^{\circ} 08^{\prime} 32,85$ ” latitude Sul e $37^{\circ} 17^{\prime} 35,50^{\prime \prime} ; 37^{\circ} 18^{\prime} 13,63$ ” longitude oeste. O fragmento de vegetação selecionado está inserido em altitudes entre 270 a 290 m. A vegetação apresenta Caatinga arbustiva arbórea (Andrade-Lima, 1981), solos do tipo Luvissolos e apresenta restrições quanto à profundidade, (SECTMA-PB, 2006; JACOMINE, 2009) textura de francoarenosa a areia franca e relevo relativamente plano. Apresenta ainda clima AW' - quente e úmido, precipitação média anual de 848,6 mm no período de 1911 a 1990 (UFCG, 2014), com temperatura média mínima nos meses de março e abril, e máxima nos meses de setembro e outubro.

A segunda área está localizada na Fazenda Cafula, município de Itaporanga, Paraíba, inserida nas seguintes coordenadas geográficas: $7^{\circ} 14^{\prime} 18^{\prime \prime} ; 7^{\circ} 13$ '28,20" latitude Sul e $38^{\circ} 09^{\prime} 23,74$ "; $38^{\circ} 08^{\prime}$ 59,87' longitude oeste, ocupando um fragmento inserido em altitudes entre 450 a $530 \mathrm{~m}$, apresentando vegetação arbórea, relevo é relativamente ondulado, solos profundos com presença de afloramentos de rochas do tipo Neossolos litólicos ou Cambissolos (SECTMA-PB, 2006; JACOMINE, 2009), e textura de francoarenosa a areia franca. Esta área apresenta clima AW' - quente e úmido, com precipitação média anual de 876,3 mm no período de 1911 a 1990 (UFCG, 2014), com temperatura média mínima nos meses de março e abril e máxima nos meses de agosto e setembro. 
A terceira área está localizada no assentamento Santa Mônica, município de Lagoa, Paraíba, inserida nas seguintes coordenadas: $6^{\circ} 36^{\prime}$ 51,91"; $6^{\circ} 36^{\prime} 38,94$ " latitude Sul e $37^{\circ}$ 56' 17,51"; $37^{\circ}$ 55' 43,39" longitude oeste. Está presente em uma área inserida em altitudes entre 650 a $730 \mathrm{~m}$, podendo ser considerada área de "brejo de altitude" (ANDRADE et al., 2006). Seu relevo é relativamente ondulado e ocasionalmente declivoso. Os solos, de textura franco-argilo-arenosa, não apresentam restrições de profundidade, sendo classificados como Luvissolos (SECTMA-PB, 2006; JACOMINE, 2009). Próximo a esta área de estudo foi encontrada uma precipitação média anual de 913,6 mm, concentrada entre os meses de março e abril no período de 1911 a 1990 (UFCG, 2014), com temperatura média mínima nos meses de março e abril, e máxima nos meses de setembro e outubro.

\subsubsection{Coleta de Dados}

O inventário florestal foi realizado considerando o estrato adulto e o estrato de regeneração, tendo sido estabelecidas em cada área de estudo 25 parcelas de $400 \mathrm{~m}^{2}(20 \mathrm{x}$ $20 \mathrm{~m}$ ) com sub-parcelas de $25 \mathrm{~m}^{2}(5 \times 5 \mathrm{~m})$ para estudos dos respectivos estratos. A distribuição das parcelas foi sistemática, distantes entre si, em malha retangular de $150 \mathrm{~m}$, demarcadas com auxílio de aparelho de GPS de navegação com altímetro barométrico com precisão de 5 m (Figura 1).

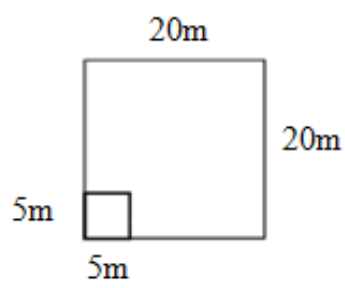

Figura 1. Área útil das parcelas do inventário das espécies arbustivo-arbóreas do estrato adulto $\left(400 \mathrm{~m}^{2}\right)$ e sub-parcelas para inventário das espécies do estrato regenerante $\left(25 \mathrm{~m}^{2}\right)$, utilizadas neste estudo.

Para o estrato adulto (EA), foram medidos e identificados todos os indivíduos arbustivos e arbóreos vivos ou mortos em pé, cuja circunferência a 1,30 m a altura do peito (CAP), fosse superior a $6 \mathrm{~cm}$. Foram tomadas as medidas de CAP, circunferência a 0,3 m 
na altura da base $(\mathrm{CAB})$ e a altura total em metros. Para o estrato regenerante (ER) foram medidos e identificados todos os indivíduos de espécies arbustivas e arbóreas com altura a partir de 0,5 $\mathrm{m}$ até CAP igual a $6 \mathrm{~cm}$, sendo tomadas as medidas de altura total. Estes procedimentos seguem o estabelecido no protocolo de medições de parcelas permanentes da Rede de Manejo Florestal da Caatinga (2005).

O material botânico foi coletado e identificado por especialistas e comparado ao material dos herbários: "Herbário CSTR" da Universidade Federal de Campina Grande; "Herbário Lauro Pires Xavier (JPB)" da Universidade Federal da Paraíba; "Herbário UB", da Universidade de Brasília, Instituto de pesquisa Jardim Botânico do Rio de Janeiro; "Herbário SPF", da Universidade de São Paulo; "Herbário Prisco Bezerra (EAC)", da Universidade Federal do Ceará; e "Herbário da Universidade Estadual de Feira de Santana (HUEFS)", de acordo com o sistema de classificação Angyosperm Phylogeny Group APG III (REVEAL, CHASE, 2011). A lista de táxons florísticos foi atualizada de acordo com a Lista de Espécies da Flora do Brasil (BFG, 2015). As exsicatas foram depositadas nos Herbários do Centro de Saúde e Tecnologia Rural (CSTR) da Universidade Federal de Campina Grande (UFCG) e da Universidade de Brasília (UnB).

Para determinação da suficiência amostral, foi empregada a curva espécie-área, considerando a riqueza de espécies do estrato adulto, identificando o ponto de inflexão da curva pela análise de regressão com resposta em platô - REGRELRP conforme Costa Junior et al. (2008). Para esta análise utilizou-se o Sistema de Análise Estatística e Genética (SAEG, 1997), desenvolvido pela Universidade Federal de Viçosa (UFV).

\subsubsection{Parâmetros Florísticos e Fitossociológicos}

Levantamentos florísticos permitem, além do conhecimento das espécies que ocorrem em uma área, comparações relativamente simples e eficientes entre um grande número de áreas. No entanto diferenças e semelhanças entre áreas de vegetações de mesmo bioma, ou próximas, ou semelhantes floristicamente, ou fisionomicamente, podem ser melhor entendidas por meio de parâmetros obtidos por levantamentos fitossociológicos, pois diferenças quantitativas entre áreas podem ser muito mais marcantes que diferenças florísticas (VAN DEN BERG; OLIVEIRA-FILHO, 2000). Medidas de abundância e de distribuição das espécies, dentre outras, auxiliam no subsídio do manejo segundo diferentes objetivos, sejam estes a conservação, a preservação, a recuperação, ou outros (VILELA et al., 1993). 
Assim, neste estudo foram quantificados os seguintes parâmetros florísticos e fitossociológicos: riqueza florística, perfil de diversidade, similaridade florística, estruturas horizontal e vertical, espécies de baixa densidade e padrão de distribuição espacial de espécies. Cada um deles passará a ser descritos a seguir.

\section{Riqueza florística}

Para o estudo de riqueza florística foi quantificado o número de gêneros, famílias e espécies arbustivo-arbóreas de cada um dos estratos superior e de regeneração, dispondo os dados em ordem alfabética de família, gênero e espécie para as áreas de estudo, de acordo com o sistema de classificação Angyosperm Phylogeny Group APG III (REVEAL, CHASE, 2011), registrando sua ocorrência em cada estrato.

Estimou-se também o índice de equabilidade de Pielou (J) para as três áreas de estudo. Este índice varia de 0 a 1 (em que 1 representa a máxima diversidade, em que todas as espécies são igualmente abundantes) e permite representar a uniformidade da distribuição dos indivíduos entre as espécies na comunidade.

\section{Perfil de diversidade}

O uso de perfis de diversidade, como as séries de Rényi ou de Hill, apresentam uma maneira de estudar os padrões de diversidade de vegetação, tanto para espécies raras, quanto para espécies abundantes presentes em um mesmo perfil de diversidade. Estas séries para as estimativas de diversidade, consideram que as espécies raras e abundantes possuem o mesmo peso, assumindo alfa $(\alpha)$ igual a zero. Conforme se aumenta o parâmetro $\alpha$ nestas séries, maior ênfase é dada às espécies dominantes, já/uma vez que espécies raras praticamente não influenciam nos valores dos índices (MELO, 2008). Os perfis de diversidade dos estratos superior e de regeneração foram estimados usando a série exponencial de Rényi (TÓTHMÉRÉSZ, 1995), dada pela equação 1:

$$
\mathrm{H}_{\alpha}=\left(\ln \left(\mathrm{p}_{1}^{\alpha}+\mathrm{p}_{2}^{\alpha}+\mathrm{p}_{3}^{\alpha} \ldots+\mathrm{p}_{\mathrm{s}}^{\alpha}\right)\right) /(1-\alpha)
$$

Em que: $\mathrm{H}_{\alpha}$ é o Índice de Diversidade para o parâmetro $\alpha(\alpha \geq 0, \alpha \neq 1)$ e $\mathrm{p}_{1}, \mathrm{p}_{2}, \mathrm{p}_{3} \ldots, \mathrm{p}_{n}$, proporções de indivíduos das espécies $1,2,3, \ldots$, e $\mathrm{S}$. 
Para esta análise foi utilizado o Software PAST 2.08 (HAMMER et al., 2001) e foi levado em consideração o número de indivíduos, a presença e a ausência de espécies nos estratos superior e regeneração, para cada área de estudo.

No eixo $\mathrm{Y}$, com $\alpha$ igual a zero, o gráfico mostra toda a riqueza das espécies raras e das abundantes, ambas com o mesmo peso na estimativa da diversidade. O perfil (1 do eixo $\mathrm{X}$ de $\alpha$ ) corresponde ao índice de Shannon-Weaver (o qual dá peso intermediário para espécies raras). O perfil ( 2 do eixo $\mathrm{X}$ de $\alpha$ ) corresponde ao índice de Simpson, que dá pouco peso às espécies raras (MEWS, 2013; MELO, 2008). Esta análise de perfil de diversidade pode ser aplicada simultaneamente em vários levantamentos sobre vegetação, e as estimativas podem ser apresentadas de forma gráfica para comparação entre os levantamentos.

A diversidade florística dos estratos superior e de regeneração foi analisada com base na distribuição dos indivíduos em espécies, por meio do índice de diversidade de Shannon-Weaver (H'), conforme descrito em MAGURRAN (1989) e o índice de diversidade de Simpson (C), conforme descrito (BROWER; ZAR, 1984).

\section{Similaridade Florística}

A este parâmetro permite avaliar possíveis semelhanças e diferenças na composição florística entre diferentes comunidades de vegetação em diferentes regiões (MEIRANETO, MARTINS, 2002; KUNZ et al., 2009).

Para a análise de similaridade florística entre as três áreas para os estratos superior e de regeneração, foi utilizada análise de Cluster levando em consideração o número de espécies presentes nas áreas de estudo, e o número de indivíduos por espécies (abundância). Para a análise de similaridade dentro de cada área de estudo, foi preparada uma matriz de presença/ausência, composta pela abundância (número de plantas por hectare) para cada área, distribuindo o valor da abundância por espécie e por parcela de presença de cada espécie. A métrica utilizada para interpretar a diversidade das espécies foi o coeficiente de similaridade de Jaccard conforme MAGURRAN (1989), por meio do método da ligação simples, associando elementos florísticos que mais se assemelham, utilizando o Software PAST 2.08 (HAMMER et al., 2001). 


\section{Estrutura horizontal}

A estrutura horizontal diz respeito à distribuição espacial das espécies que compõem a comunidade, permitindo quantificar a participação de cada uma delas no ambiente (REZENDE, 1995; CURTIS; McINTOSH, 1951 e LAMPRECHT, 1964).

Foram utilizados os seguintes parâmetros quantitativos estimados para cada espécie: densidade, frequência e dominância, em suas formas absolutas e relativas. Segundo Lamprecht (1962), estes parâmetros estimam com precisão a participação das espécies vegetais no ambiente florestal. A densidade refere-se ao número total de indivíduos $\left(\mathrm{n}_{\mathrm{i}}\right)$ de uma determinada espécie em uma comunidade vegetal amostrada. Este parâmetro foi estimado nas formas absoluta e relativa de acordo com Lamprecht (1964).

A dominância expressa a proporção de volume ou de cobertura de cada espécie, em relação ao espaço ou volume ocupado pela comunidade (MARTINS, 1993). Uma das formas comuns de calcular a dominância para comunidades arbóreo-arbustiva, é a razão entre a área basal total por espécie e a área amostrada. As áreas basais são calculadas a partir dos diâmetros ou circunferências dos caules das árvores e arbustos. Estes parâmetros estimados nas formas absoluta e relativa estão de acordo com Lamprecht (1964).

A frequência representa como os indivíduos de cada espécie estão distribuídos na área amostrada, e é dada em porcentagem das unidades amostrais que contém a espécie. Este parâmetro foi estimado nas formas absoluta e relativa. As expressões utilizadas para esta estimativa estão de acordo com Lamprecht (1964).

Os valores relativos da densidade, da frequência e da dominância por espécie é calculado como Índice de Valor de Importância (IVI\%). Este índice expressa a importância de cada espécie de forma quantitativa no ambiente, expressão interpretada e utilizada por Curtis; McIntosh (1951).

\section{Estrutura vertical}

O termo regeneração natural abarca/compreende todos os descendentes das plantas arbóreas, podendo incluir indivíduos recém-germinados e ou plântulas com altura mínima de $10 \mathrm{~cm}$, presentes no piso da floresta, até o limite de diâmetro estabelecido no levantamento estrutural (FINOL, 1971). Neste estudo, foram consideradas as plantas regenerantes a partir da classe de altura $0,5 \mathrm{~m}$. 
Para o estrato de regenerante, os parâmetros da densidade e frequência foram obtidos utilizando as mesmas expressões para o estrato arbustivo-arbóreo adulto. Foi estimado o índice de regeneração natural relativa para a i-ésima espécie $\left(\mathrm{RNR}_{\mathrm{i}}\right)$, que é dado pela média aritmética dos valores relativos dos parâmetros densidade, frequência e classe relativa de tamanho da regeneração natural de acordo com Finol (1971).

Segundo Finol (1971), as florestas apresentam diferentes características estruturais. Dentre estas, citamos a estrutura vertical, que influencia a riqueza florística, o crescimento e a produção de biomassa, sendo um importante indicador de sustentabilidade ambiental de uma floresta (SOUZA et al., 2003). As estimativas de Posição Sociológica Absoluta (PSAi) e Relativa (PSRi), foram estimadas de acordo com Finol (1971).

\section{Espécies de baixa densidade}

Uma espécie pode ser considerada rara quando seus indivíduos ocorrem em baixa densidade na natureza, associada a uma distribuição mais restrita em termos geográficos (SANO et al., 2014). As espécies raras são as grandes responsáveis pela alta diversidade nas florestas tropicais (VIANA et al., 1992). Além disso, por ocorrerem em baixa densidade, estas espécies se tornam vulneráveis à extinção e a baixa taxa de reprodução, aumentando a importância de conhecer qual o papel que estas espécies exercem nos ambientes (LYONS et al., 2005).

Para este trabalho, foi considerado o conceito de espécies localmente raras segundo Rabinowitz et al. (1986), que as define como aquelas que apresentam apenas um indivíduo na amostragem dos estratos superior e de regeneração. Elas são quantificadas em porcentagem do número total de espécies, de acordo com a equação 2.

$$
\mathrm{EBD}=\frac{\mathrm{n}_{\mathrm{i}}}{\mathrm{N}} \times 100
$$

Em que: $\mathrm{EBD}=$ Espécie de baixa densidade, em \%; ni = número de espécies que apresentaram apenas um indivíduo na amostragem; $\mathrm{N}=$ Número total de espécies encontradas na amostragem. 


\section{Padrão de distribuição espacial de espécies}

O padrão de distribuição espacial de espécies é a forma como os indivíduos de uma espécie estão distribuídos no ambiente físico. Odum (1983) considera que o padrão de distribuição espacial de espécies pode ocorrer em três padrões distintos, aleatório, uniforme e agregado.

Dada a escassez de informações da flora arbustivo-arbórea relacionadas à fitossociologia e à distribuição espacial de espécies vegetais de Caatinga, é importante o entendimento dos mecanismos de distribuição espacial para aplicação adequada do manejo florestal para uso do bioma estudado.

Para identificar o padrão de distribuição espacial das espécies nos estratos superior e de regeneração, foi utilizado o índice de Payandeh (Pi). Este índice, estimado de acordo com Payandeh (1970), é obtido pelo grau de agregação da espécie, por meio da relação entre a variância do número de árvores por parcela, e a média do número de árvores.

A classificação do padrão de distribuição espacial obtida pelo "Índice de Payndeh" (Pi) obedece a seguinte escala: $\mathrm{Pi}<1$, apresenta distribuição aleatória ou nãoagrupamento; $\mathrm{Pi} \geq 1$ e $\leq 1,5$, apresenta tendência ao agrupamento; e $\mathrm{Pi}>1,5$, apresenta distribuição agregada ou agrupada.

As análises dos dados de estrutura horizontal e estrutura vertical da regeneração, distribuição diamétrica, espécies de baixa densidade e distribuição espacial de espécies foram realizadas utilizando o software Mata Nativa 2.0 (CIENTEC, 2006). 


\subsection{RESULTADOS E DISCUSSÃO}

Para as três áreas de estudo a suficiência amostral foi alcançada, conforme pode ser observado nas curvas espécie-área, com a determinação do ponto de inflexão pela REGRELRP. Para a área de São José do Bonfim a suficiência amostral foi obtida com 23 parcelas, para a área de Itaporanga com 16 e para a área de Lagoa com 11 (Figura 2).
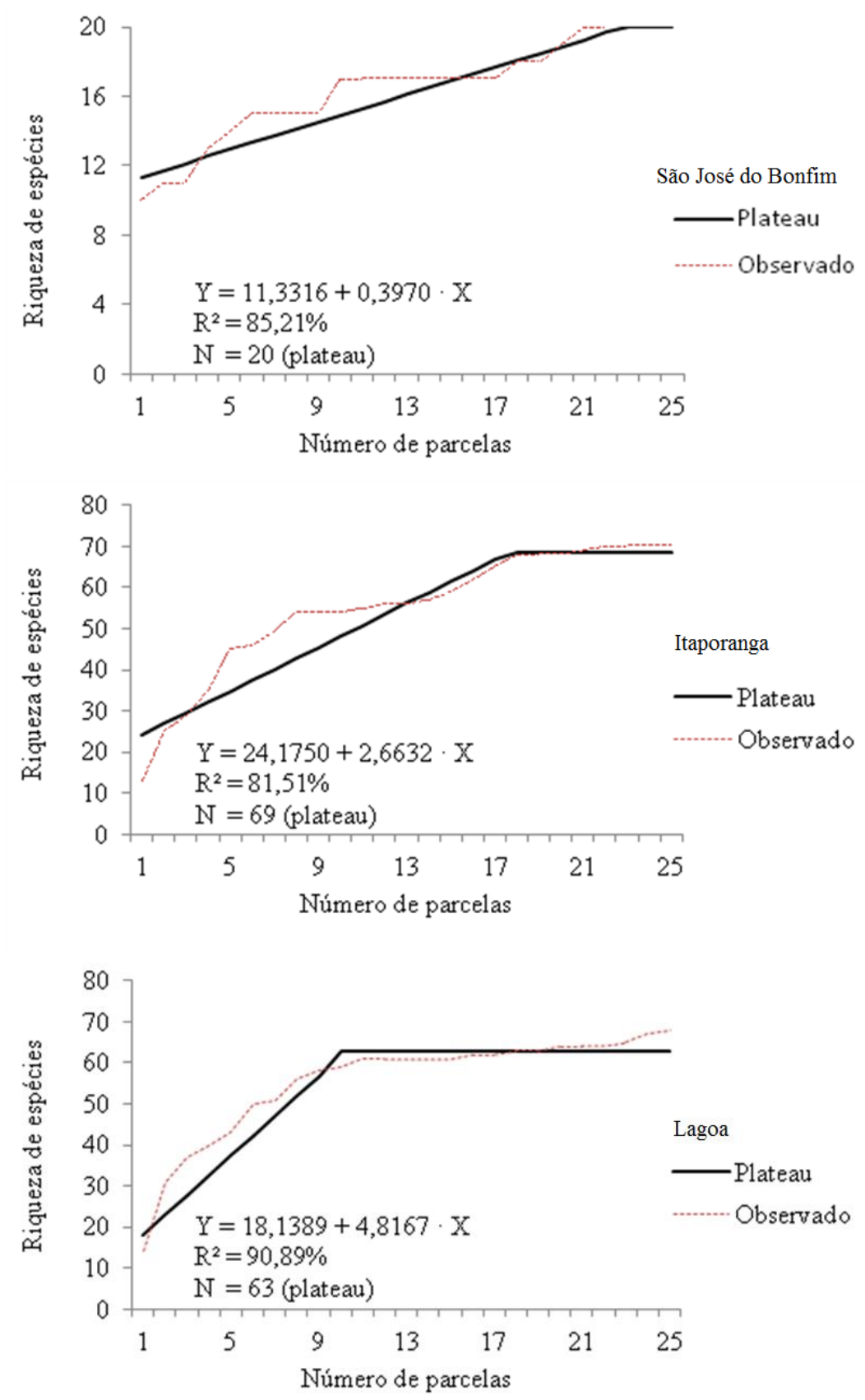

Figura 2. Determinação da suficiência amostral utilizando a curva espécie-área, com determinação do ponto de inflexão pela REGRELRP, em vegetação de Caatinga arbustivo-arbórea para as áreas de São José do Bonfim, Itaporanga e Lagoa, no estado da Paraiba - Brasil. 


\subsubsection{Parâmetros Florísticos e Fitossociológicos}

Nas tabelas 1, 2 e 3 a seguir é apresentada as listas florísticas das espécies arbustivas e arbóreas encontradas no estrato adulto e de regeneração nas áreas de estudo.

Foram encontradas na área de São José do Bonfim 3.118 indivíduos no estrato adulto, pertencentes a nove famílias, 15 gêneros e 20 espécies. As famílias que obtiveram maior número de espécies no estrato adulto foram Fabaceae com 8 espécies e Euphorbiaceae com 4. No estrato de regeneração foram encontrados 284 indivíduos pertencentes a 7 famílias, 11 gêneros e 11 espécies. A família que apresentou o maior número de espécies no estrato de regeneração foi Fabaceae com 5 espécies. As famílias que obtiveram maior número de indivíduos no estrato de regeneração foram Euphorbiaceae e Fabaceae com 45,42\% e 23,94\% respectivamente, totalizando 69,37\% dos indivíduos.

Em Itaporanga foram encontrados 2.847 indivíduos no estrato adulto, pertencentes a 23 famílias, 57 gêneros e 70 espécies, sendo 1 espécie indeterminada. As famílias que obtiveram maior número de espécies no estrato adulto foram Fabaceae com 19 espécies, Euphorbiaceae com 8, Rubiaceae e Bignoniaceae ambas com 5 e Apocynaceae com 4. No estrato de regeneração foram encontrados 437 indivíduos pertencentes a 21 famílias, 50 gêneros e 52 espécies, sendo 1 espécie indeterminada. As famílias com maior número de espécies foram Fabaceae com 14, Euphorbiaceae com 6, Apocynaceae e Bignoniaceae com 3 cada uma. As famílias que obtiveram maior número de indivíduos no estrato de regeneração foram Euphorbiaceae, Fabaceae e Boraginaceae, com índices de 38,44\%, $30,43 \%$ e $5,26 \%$ respectivamente, totalizando $74,14 \%$ dos indivíduos.

Em Lagoa no estrato adulto foram encontrados 3.057 indivíduos, pertencentes a 27 famílias, 55 gêneros e 68 espécies, sendo 3 espécies indeterminadas. As famílias que obtiveram maior número de espécies no estrato adulto foram Fabaceae com 20 espécies, Euphorbiaceae com 7 e Myrtaceae com 5. No estrato de regeneração foram encontrados 428 indivíduos pertencentes a 19 famílias, 39 gêneros e 40 espécies, sendo 1 indeterminada. As famílias com maior número de espécies foram Fabaceae, com 12, Euphorbiaceae e Myrtaceae cada uma com 4. As famílias que obtiveram maior número de indivíduos no estrato de regeneração foram, Euphorbiaceae, Fabaceae, Myrtaceae, Rubiaceae, Malvaceae e Apocynaceae, com índices de 51,87\%, 8,64\%, 8,18\%, 7,24\%, $6,54 \%$ e $5,14 \%$ respectivamente, totalizando $87,62 \%$ dos indivíduos.

As famílias Euphorbiaceae e Fabaceae no estrato adulto são as mais representativas em número de espécies neste estudo. Estas famílias juntas representam, respectivamente, 
para as áreas de SJB, ITA e LAG, 60\%, 38,57\% e 39,71\% do total de espécies encontradas. Estes resultados corroboram com os estudos de Rodal et al. (2008) e Gomes et al. (2006). No que diz respeito especificamente à família Fabaceae, esses resultados alinham-se, em número de espécies, com os estudos de Nascimento; Rodal (2008), Rodal; Nascimento (2006), Rodal et al. (2005) e Melo; Rodal (2003). Já Cunha (2010) e Andrade et al. (2006) com levantamentos em áreas de altitude superior a $600 \mathrm{~m}$ na Paraíba, identificaram que as famílias Fabaceae e Myrtaceae obtiveram o maior número de espécies, resultados estes que corroboram com a área de LAG deste estudo, quanto à incidência das famílias Fabaceae, Myrtaceae e Euphorbiaceae.

As famílias Fabaceae e Euphorbiaceae também obtiveram o maior número de indivíduos nas três áreas estudadas; com $63,73 \%$ e 28,45\% respectivamente, para a área de São José do Bonfim, 43,55\% e 22,30\%, respectivamente, para a área de Itaporanga e $19,30 \%$ e 33,53\% respectivamente, para a área de Lagoa. Do total de indivíduos presentes nas áreas de estudo, as duas famílias juntas representam 92,17\% para a área de São José do Bonfim, 65,86\% para a área de Itaporanga e 52,83\% para a área de Lagoa. Estas estimativas mostram a importância destas famílias botânicas em vegetação de Caatinga.

Os gêneros que obtiveram o maior número de indivíduos no estrato adulto foram: Poincianella (36,98\%), Croton (27,81\%), Mimosa (15,59\%) e Bauhinia (8,08\%). Estes gêneros representam $88,45 \%$ dos indivíduos presentes na área de São José do Bonfim (Anexo 1). Para a área de Itaporanga foram os gêneros: Croton (35,05\%), Mimosa $(6,36 \%)$ e Combretum (6,04\%), representando um total de 47,45\% dos indivíduos (Anexo 2). Finalmente, para a área de Lagoa foram os gêneros: Croton (22,21\%), Gymnanthes (9,09\%), Aspidosperma (8,86\%), Eugenia (7,10\%), Peltogyne (6,18\%) e Myrciaria $(5,82 \%)$, sendo um total de 59,27\% dos indivíduos presentes nesta área (Anexo 3). Destes gêneros levantados, apenas o gênero Croton teve presença nas três áreas de estudo e o gênero Mimosa presente em duas áreas, estes são pertencentes às famílias Euphorbiaceae e Fabaceae. 
Tabela 1. Relação florística em uma área de Caatinga arbustivo-arbórea dos estratos superior e regenerante, listada por ordem alfabética de famílias e espécies no município de São José do Bonfim, no estado da Paraíba - Brasil.

Família/Espécie PR ES ER

\section{Apocynaceae}

Aspidosperma pyrifolium Mart.

\section{Bignoniaceae}

Dolichandra sp.

Handroanthus impetiginosus (Mart.ex DC.)Mattos

\section{Burseraceae}

Commiphora leptophloeos (Mart.) J.B.Gillet

\section{Capparaceae}

Cynophalla hastata (Jacq.) J.Presl

\section{Combretaceae}

Combretum leprosum Mart.

\section{Erythroxylaceae}

Erythroxylum Caatinga Plowman

\section{Euphorbiaceae}

Cnidoscolus quercifolius Pohl

Croton blanchetianus Baill

Jatropha mollissima (Pohl) Baill.

Manihot carthaginensis subsp. Glaziovii (Müll.Arg.) Allem

Fabaceae-Caesalpinoideae

Bauhinia cheilantha (Bong.) D. Dietr.

Libidibia ferrea (Mart. ex.Tul.) L.P. Queiroz

Poincianella pyramidalis (Tul.) L. P. Queiroz.

Senna macranthera (DC. ex Collad.) H.S. Irwin \&Barneby

$\begin{array}{ll}\mathrm{X} & \mathrm{X} \\ \mathrm{X} & \mathrm{X} \\ \mathrm{X} & \mathrm{X} \\ \mathrm{X} & \end{array}$

\section{Fabaceae-Mimosoideae}

Anadenanthera colubrina (Vell.) Brenan

Mimosa acutistipula (Mart.) Benth.

Mimosa tenuiflora (Willd.) Poir

\section{Rhamnaceae}

Ziziphus joazeiro Mart. 
Tabela 2. Relação florística em uma área de Caatinga arbustivo-arbórea dos estratos superior e regenerante, listada por ordem alfabética de famílias e espécies no município de Itaporanga, no estado da Paraíba - Brasil.

\section{Família/Espécie}

PR ES ER

\section{Anacardiaceae}

Astronium fraxinifolium Schott

Myracrodruon urundeuva M. Allemão

Schinopsis brasiliensis Engl.

$\mathrm{X} \quad \mathrm{X}$

$\mathrm{X} \quad \mathrm{X}$

\section{Annonaceae}

Annona leptopetala (R.E.Fr.) H.Rainer

$\mathrm{X} \quad \mathrm{X} \quad \mathrm{X}$

\section{Apocynaceae}

Allamanda blanchetii A. DC.

Aspidosperma cuspa (Kunth) S.F.Blake

Aspidosperma pyrifolium Mart.

Aspidosperma riedelii Müll.Arg.

$\begin{array}{lll} & \text { X } & \\ \text { X } & \text { X } & \text { X } \\ & \text { X } & \text { X } \\ & \text { X } & \text { X }\end{array}$

X X

Fridericia dichotoma (Jacq.) L.G.Lohmann

Handroanthus impetiginosus (Mart.ex DC.)Mattos

Handroanthus serratifolius (Vahl) S.Grose

Jacaranda jasminoides (Thunb.) Sandwith

X

X X

X X
X X

Cochlospermum vitifolium (Willd.) Spreng.

Boraginaceae

Cordia trichotoma (Vell.) Arráb. exSteud.

Varronia curassavica Jacq.

\section{Burseraceae}

Commiphora leptophloeos (Mart.) J.B.Gillet

\section{Capparaceae}

Cynophalla hastata (Jacq.) J.Presl

\section{Combretaceae}

Combretum duarteanum Cambess.

Combretum leprosum Mart.

X

X X

X X

Erythroxylum Caatinga Plowman
X X

X X

X

X X

$\mathrm{X}$

X X

X X 
Tabela 2. Cont.

\section{Euphorbiaceae}

Stillingia trapezoidea Ule

X $\quad \mathrm{X}$

Fabaceae-Caesalpinoideae

Bauhinia cheilantha (Bong.) D. Dietr.

Hymenaea courbaril L.

Libidibia ferrea (Mart. ex.Tul.) L.P. Queiroz

Poincianella pyramidalis (Tul.) L. P. Queiroz.

Senna trachypus (Benth.) H.S.Irwin \& Barneby

Senna macranthera (DC. ex Collad.) H.S. Irwin \&Barneby

X X

$\mathrm{X}$

$\mathrm{X}$

X X

$\mathrm{X} \quad \mathrm{X}$

$\mathrm{X} \quad \mathrm{X}$
$\mathrm{X} \quad \mathrm{X}$

$\mathrm{X}$

$\mathrm{X} \quad \mathrm{X}$

$\mathrm{X} \quad \mathrm{X}$

Luetzelburgia auriculata (Allemão) Ducke

$\begin{array}{ll}\mathrm{X} & \mathrm{X} \\ \mathrm{X} & \mathrm{X} \\ \mathrm{X} & \mathrm{X} \\ \mathrm{X} & \mathrm{X} \\ \mathrm{X} & \mathrm{X} \\ \mathrm{X} & \\ \mathrm{X} & \\ \mathrm{X} & \mathrm{X} \\ \mathrm{X} & \mathrm{X}\end{array}$

X $\quad \mathrm{X}$

$\mathrm{X} \quad \mathrm{X}$

$\mathrm{X}$

$\mathrm{X} \quad \mathrm{X}$

$\mathrm{X} \quad \mathrm{X}$

Brosimum gaudichaudii Trécul

$\mathrm{x}$ $x$ $\mathrm{X}$ X

Malvaceae

Helicteres heptandra L.B.Sm. Luehea ochrophylla Mart.

Pseudobombax marginatum (A.St.-Hil.) A. Robyns

\section{Moraceae}

Myrtaceae

Eugenia flavescens DC.

Eugenia stictopetala Mart. ex DC.

Psidium appendiculatum Kiaersk.

$\begin{array}{lll}\mathrm{X} & \mathrm{X} & \mathrm{X} \\ \mathrm{X} & \mathrm{X} & \\ \mathrm{X} & \mathrm{X} & \mathrm{X}\end{array}$

\section{Nyctaginaceae Juss.}

Guapira laxa (Netto) Furlan $\quad$ X

\section{Olacaceae}


Tabela 2. Cont.

\section{Polygonaceae}

Triplaris gardneriana Wedd.

$\mathrm{X}$

Rubiaceae

Cordiera rigida (K.Schum.) Kuntze

Coutarea hexandra (Jacq.) K. Schum.

Guettarda angelica Mart. exMüll.Arg.

Randia armata (Sw.) DC.

Tocoyena formosa (Cham. \&Schltdl.) K.Schum.

Rutaceae

Sigmatanthus trifoliatus Huber ex. Emmerich

Zanthoxylum syncarpum Tul.

X $\quad$ X $\quad$ X

\section{Sapindaceae}

Allophylus quercifolius (Mart.) Radlk.

Talisia esculenta (Cambess.) Radlk.

X X X

X X

\section{Verbenaceae}

Lantana camara L.

Stachytarpheta coccinea Schauer

$\begin{array}{lll} & & \text { X } \\ \text { X } & \text { X } & \text { X }\end{array}$

\section{Vochysiaceae}

Callisthene minor Mart.

X $\quad \mathrm{X}$

Morfo espécie 1

$\mathrm{x}$

Morfo espécie 4

$\mathrm{x}$

Em que: $P R$ = Primeiro Relato em vegetação de Caatinga no estado da Paraíba; ES = Estrato superior; $E R=$ Estrato regenerante. 
Tabela 3. Relação florística em uma área de Caatinga arbustivo-arbórea dos estratos superior e regenerante, listada por ordem alfabética de famílias e espécies no município de Lagoa, no estado da Paraíba - Brasil.

\begin{tabular}{lll}
\hline Família/Espécie & PR & ES ER \\
\hline
\end{tabular}

\section{Anacardiaceae}

Astronium fraxinifolium Schott

Myracrodruon urundeuva M. Allemão

Schinopsis brasiliensis Engl.

\section{Annonaceae}

Annona leptopetala (R.E.Fr.) H.Rainer

\section{Apocynaceae}

Aspidosperma riedelii Müll.Arg.

Arecaceae

Syagrus cearensis Noblick

\section{Bignoniaceae}

Dolichandra sp.

$\mathrm{X}$

Handroanthus impetiginosus (Mart.ex DC.)Mattos

Handroanthus serratifolius (Vahl) S.Grose

\section{Bixaceae}

Cochlospermum vitifolium (Willd.) Spreng.

\section{Boraginaceae}

Cordia trichotoma (Vell.) Arráb. exSteud.

Varronia curassavica Jacq.

Burseraceae

Commiphora leptophloeos (Mart.) J.B.Gillet

\section{Capparaceae}

Cynophalla hastata (Jacq.) J.Presl $\quad$ X $\quad$ x

\section{Celastraceae}

Maytenus erythroxyla Reissek

\section{Combretaceae}

Combretum leprosum Mart.

\section{Erythroxylaceae}

Erythroxylum nummularia Peyr.

Erythroxylum Caatinga Plowman

\section{Euphorbiaceae}

Croton blanchetianus Baill

Croton heliotropiifolius Kunth.

Croton nepetifolius Baill.

Gymnanthes boticario Esser, M. F. A. Lucena \& M. Alves

Jatropha mollissima (Pohl) Baill. 
Tabela 3. Cont.

\section{Euphorbiaceae}

Manihot carthaginensis subsp. Glaziovii (Müll.Arg.) Allem x

Sapium glandulosum (L.) Morong

\section{Fabaceae-Caesalpinoideae}

Bauhinia cheilantha (Bong.) D. Dietr. $\quad$ x $\quad \mathrm{x}$

Hymenaea courbaril L.

Libidibia ferrea (Mart. ex.Tul.) L.P. Queiroz

Peltogyne pauciflora Benth.

Poincianella pyramidalis (Tul.) L. P. Queiroz.

Senna trachypus (Benth.) H.S.Irwin \& Barneby

Senna macranthera (DC. ex Collad.) H.S. Irwin \&Barneby

Senna spectabilis (DC.) H.S. Irwin \& Barneby

$\begin{array}{ll}\mathrm{X} & \mathrm{X} \\ \mathrm{X} & \mathrm{X} \\ \mathrm{X} & \\ \mathrm{X} & \mathrm{X} \\ \mathrm{X} & \mathrm{X} \\ \mathrm{X} & \\ \mathrm{X} & \mathrm{X} \\ \mathrm{X} & \mathrm{X}\end{array}$

\section{Fabaceae-Faboideae}

Amburana cearensis (Allemão) A.C.Sm.

Dahlstedtia araripensis (Benth.) M.J. Silva \& A.M.G. Azevedo

Dalbergia cearensis Ducke

Luetzelburgia auriculata (Allemão) Ducke

\section{Fabaceae-Mimosoideae}

Chloroleucon foliolosum (Benth.) G.P.Lewis $\quad \mathrm{x}$

Enterolobium contortisiliquum (Vell.) Morong x

Mimosa ophthalmocentra Mart. exBenth. $\quad \mathrm{x}$

Mimosa paraibana Barneby $\quad x$

Mimosa tenuiflora (Willd.) Poir

Parapiptadenia zehntneri (Harms) M.P.Lima\& H.C. Lima $\quad$ x $\quad$ x

Senegalia polyphylla (DC.) Britton \& Rose

Senegalia riparia (Kunth) Britton \& Rose ex Britton \& Killip

$x$

$$
x
$$

$$
\mathrm{X}
$$$$
x
$$$$
\mathrm{X}
$$

Lamiaceae

Vitex megapotamica (Spreng.) Moldenke

\section{Malvaceae}

Helicteres heptandra L.B.Sm. $\quad \mathrm{x} \quad \mathrm{x}$

Luehea ochrophylla Mart. $\quad$ x $\quad$ x

Pseudobombax marginatum (A.St.-Hil.) A. Robyns $\quad$ x

\section{Moraceae}

Brosimum gaudichaudii Trécul $\quad$ x $\quad$ x

\section{Myrtaceae}

Eugenia flavescens DC.

Eugenia ligustrina (Sw.) Willd.

Eugenia stictopetala Mart. ex DC.

Eugenia caatingicola Coutinho \& M. Ibrahim

X $\mathrm{X}$ X

$\mathrm{X}$

X $\mathrm{X} \quad \mathrm{X}$

X X X

Myrciaria floribunda (H.WestexWilld.) O.Berg

$\begin{array}{ccc}\mathrm{X} & \mathrm{X} & \mathrm{X} \\ \text { Continuação... }\end{array}$ 
Tabela 3. Cont.

Nyctaginaceae Juss.

Guapira laxa (Netto) Furlan

\section{Olacaceae}

Ximenia americana $\mathrm{L}$.

\section{Rubiaceae}

Cordiera rigida (K.Schum.) Kuntze

Guettarda angelica Mart. exMüll.Arg.

Randia armata (Sw.) DC.

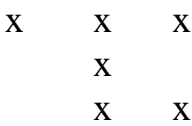

\section{Rutaceae}

Zanthoxylum syncarpum Tul.

\section{Salicaceae}

Xylosma prockia (Turcz.) Turczaninov

X X

\section{Sapindaceae}

Talisia esculenta (Cambess.) Radlk.

\section{Sapotaceae}

Pouteria reticulata (Engl.)Eyma

\section{Turneraceae}

Turnera calyptrocarpa Urb.

\section{Verbenaceae}

Lantana camara $\mathrm{L}$.

\section{Vochysiaceae}

Callisthene minor Mart.

Morfo espécie 1

Morfo espécie 2

X

X X

Morfo espécie 3

Em que: PR = Primeiro Relato em vegetação de Caatinga no estado da Paraíba; ES = Estrato superior; ER = Estrato regenerante.

No Nordeste do Brasil, a maior parte das Caatingas estão localizadas nas depressões interplanálticas (Ab'Sáber, 1974). No entanto, há algumas áreas neste bioma como faixas da Borborema e ilhas de vegetação de altitude, nas quis a vegetação de Caatinga é encontrada não apenas nas depressões, mas também em áreas de planaltos (ANDRADE-LIMA, 1981), apresentando alta riqueza de espécies, referências que corroboram com os resultados encontrados nas áreas de Itaporanga (Tabela 2) e Lagoa (Tabela 3), as quis apresentaram alta riqueza de espécies. Confirmando estas informações, 
Giulietti et al. (2004) afirmaram que a flora da Caatinga apresenta maior diversidade e riqueza de espécies quando está associada à vegetação inserida em áreas com as maiores altitudes. Estas áreas atuam como refúgio para as espécies florestais, como pode ser visto em áreas de florestas de altitudes dentro da região do Bioma Caatinga.

Os números de espécies vegetais encontradas nos estratos adulto e de regeneração nas áreas de Itaporanga e Lagoa representam formações de florestas de matas secas, presentes nos topos de áreas altitudinais, obtendo maior número de espécies quando comparado com vegetação de Caatinga do entorno. De acordo com Sales et al. (1998), a vegetação de Caatinga presente em ambientes altitudinais são as menos conhecidas, ou pouco catalogadas nos estados do Nordeste, e praticamente não existem dados florísticos nem estruturais que permitam a caracterização dessas formações florestais como uma vegetação de transição entre a floresta atlântica e a vegetação de Caatinga, ocupando o ambiente entre essas duas formações.

Em relação às riquezas de espécies encontradas nas áreas de estudo e à comparação delas com demais trabalhos realizados na Caatinga, exemplificados na tabela 4 a seguir, pode-se dizer que há grande heterogeneidade em número de famílias, gêneros e espécies botânicas, nos diferentes trabalhos realizados. Esta grande heterogeneidade reforça a ideia de que peculiaridades ambientais locais, como altitude, topografia, umidade, entre outros e associações dos mesmos façam com que cada fragmento seja colonizado de forma muito particular. Para entender estas relações, é necessário estabelecer, de forma mais padronizada, mais detalhada e em maior escala, os estudos da flora arbustivo-arbórea da Caatinga.

Neste estudo, 16 espécies botânicas foram registradas pela primeira vez, ocorrendo na flora arbustivo-arbórea no estrato adulto no estado da Paraíba, conforme comparação feita com a Lista de Espécies da Flora do Brasil (BFG, 2015), e revisão minuciosa de trabalhos científicos da área em questão. São elas, primeiro na área de São José do Bonfim (Tabela 1): Mimosa acutistipula, depois, na área de Itaporanga (Tabela 2): Annona leptopetala, Aspidosperma cuspa, Psidium appendiculatum, Eugenia flavescens, Eugenia stictopetala, Cordiera rigida, Sigmatanthus trifoliatus, Allophylus quercifolius, Stachytarpheta coccinea e Callisthene minor, e, por fim, na área Lagoa (Tabela 3): Erythroxylum nummularia, Byrsonima vacciniifolia, Eugenia caatingicola, Eugenia flavescens, Myrciaria floribunda, Eugenia stictopetala, Cordiera rigida, Pouteria reticulata e Callisthene minor. Destas, quatro espécies foram observadas simultaneamente nas áreas Itaporanga e Lagoa, sendo as espécies: Eugenia flavescens, Eugenia stictopetala, 
Cordiera rigida e Callisthene minor. Destas espécies, apenas as espécies Mimosa acutistipula na área de São José do Bonfim e Byrsonima vacciniifolia na área de Lagoa não estiveram presentes nos estratos superior e regenerante nas áreas estudadas.

A espécie Eugenia caatingicola foi publicada como nova espécie de Eugenia (Myrtaceae) para a Caatinga, com registro apenas para Bahia e Piauí, Coutinho et al. (2015). Agora, pela primeira vez, com ocorrência registrada para o estado da Paraíba, tendo sido encontrada apenas na área de Lagoa, de maior altitude. 
Tabela 4. Informações referentes às espécies arbustivo-arbóreas presentes nos estratos superior e de regeneração em vegetação de Caatinga para as áreas de estudo em São José do Bonfim (SJB), Itaporanga (ITA) e Lagoa (LAG), no estado da Paraíba e demais trabalhos desenvolvidos em vegetação de Caatinga nos estados do Ceará (CE), Pernambuco (PB) e Rio Grande do Norte (RN) - Brasil.

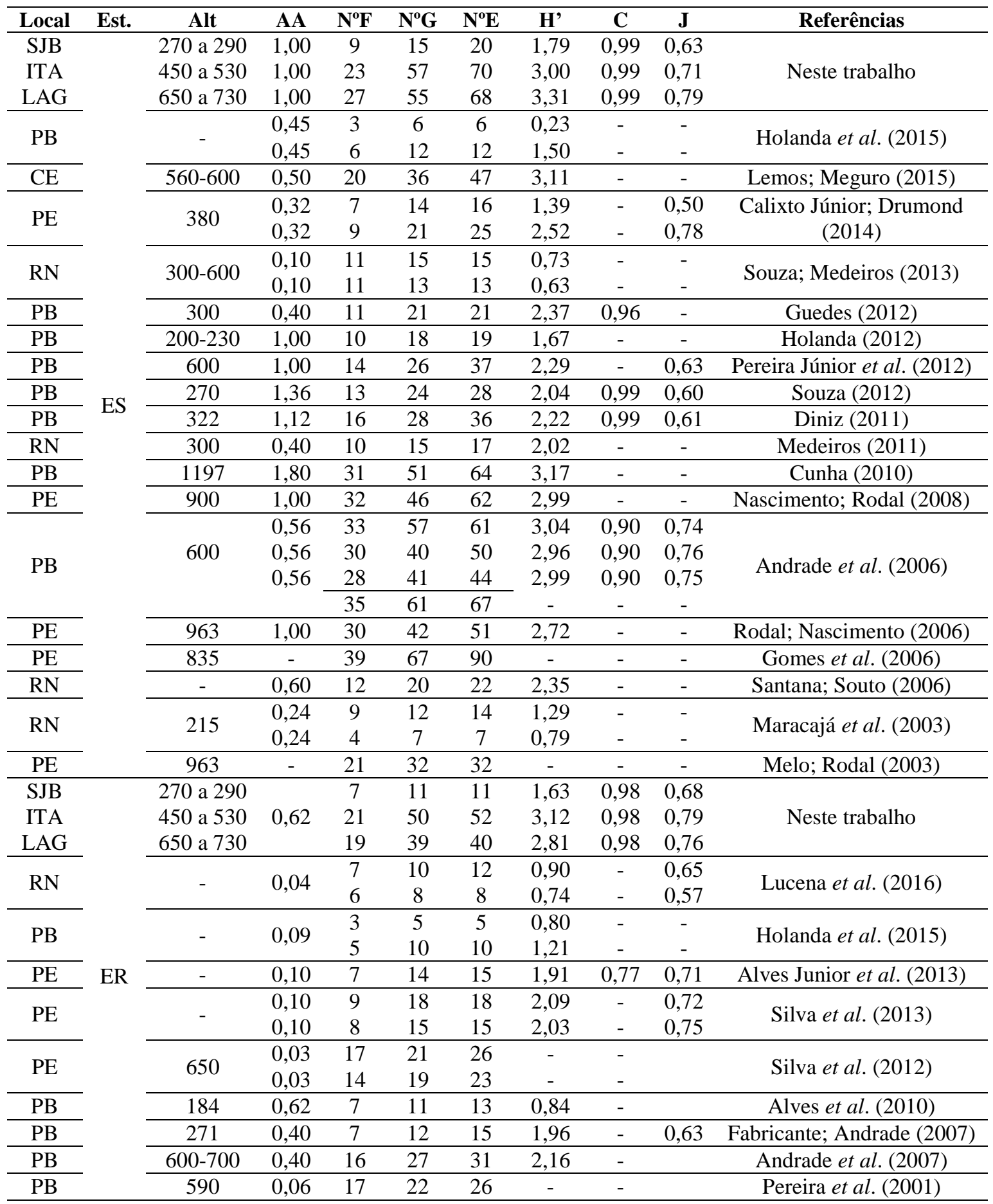

Em que: Est $=$ Estrato $; \mathrm{ES}=$ Estrato adulto $; \mathrm{ER}=$ Estrato de regeneração; Alt $=$ Altitude em metros; $\mathrm{AA}=$ Área amostral em hectare; $\mathrm{N}^{\circ} \mathrm{F}=$ Número de famílias; $\mathrm{N}^{\circ} \mathrm{G}=$ Número de Gêneros; $\mathrm{N}^{\mathrm{o}} \mathrm{E}=$ Número de espécies; H’ = índice de Shannon-Weaver; C = índice de Simpson e J = índice de equabilidade de Pielou. 


\section{Perfil de Diversidade}

A estimativa de diversidade de uma comunidade vegetal pode expressar a medida de sua riqueza florística, em maior ou menor número de espécies. A vegetação da área de São José do Bonfim apresentou a menor diversidade de espécies para a vegetação de Caatinga arbustivo-arbórea dos estratos superior e de regeneração, quando comparada às áreas de Itaporanga e Lagoa (Figura 3).
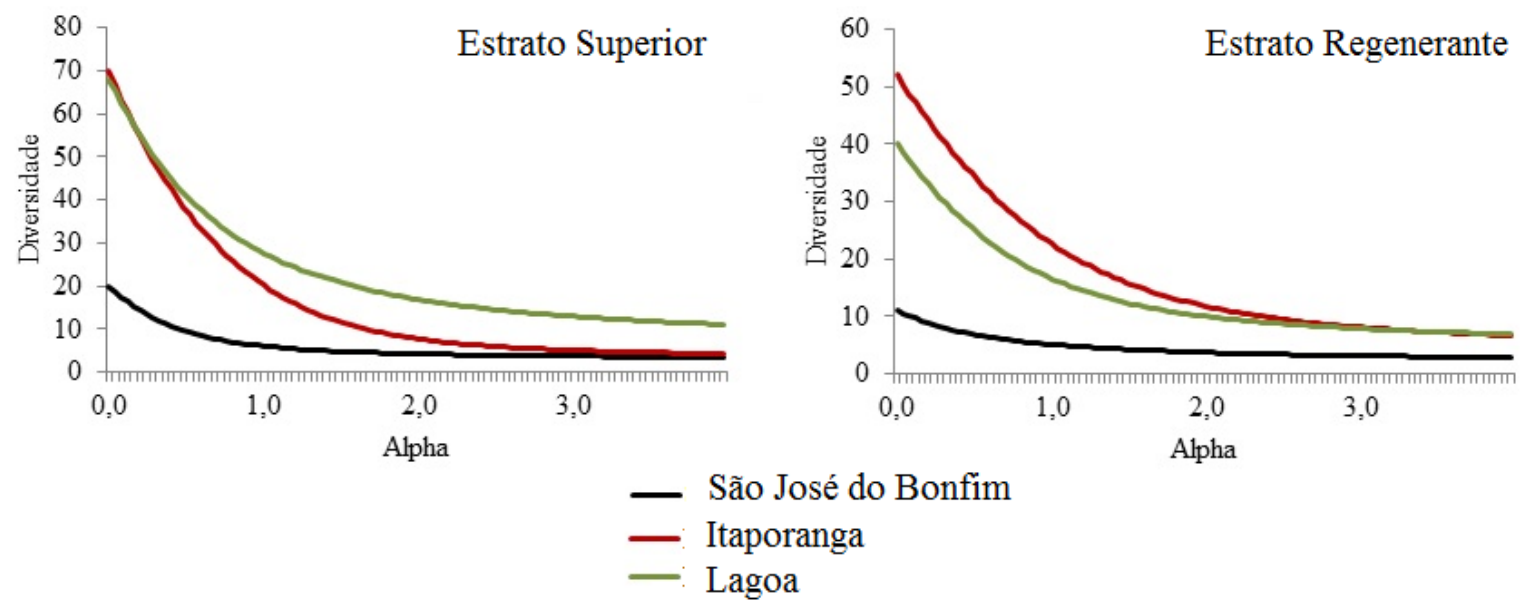

Figura 3. Perfis de diversidade para espécies arbustivo-arbóreas em vegetação de Caatinga para os estratos superior e regeneração presentes nas áreas de São José do Bonfim, Itaporanga e Lagoa, no estado da Paraíba - Brasil.

No eixo $\mathrm{X}$ em que Alfa $=0$, o gráfico mostra a riqueza de espécies, instante este que as espécies raras (localmente pouco abundante) possuem peso máximo no conjunto da diversidade, sendo assim, as áreas de Itaporanga e Lagoa apresentaram os maiores valores de diversidade para plantas arbustivo-arbóreas dos estratos superior e de regeneração (Figura 3).

No eixo $\mathrm{X}$ em que Alfa $=1$, correspondente ao índice de Shannon-Weaver, com peso intermediário às espécies raras, e no eixo $\mathrm{X}$ em que Alfa $=2$, correspondente ao índice de Simpson, com pouco peso às espécies raras, observa-se que as áreas de estudo de Itaporanga e Lagoa apresentaram as melhores estimativas de diversidade para as espécies arbustivo-arbóreas dos estratos adulto e de regeneração no eixo X para Alfa 1 e 2, com destaque para a área de Lagoa no estrato adulto, mesmo esta área não obtendo maior riqueza de espécies (Figura 3). Além disso, quanto ao estrato de regeneração, a área de 
Itaporanga foi a que apresentou as melhores estimativas de diversidade para Alfa 1 e 2 (Figura 3).

Os valores encontrados para o índice de diversidade de Shannon-Weaver - H', para vegetação no estrato adulto da vegetação arbustivo-arbórea, nas três áreas de estudo foram: área de São José do Bonfim = 1,79; área de Itaporanga $=3,0$ e área de Lagoa $=3,31$. Os valores de índice de Shannon-Weaver das áreas de Itaporanga e Lagoa estão entre os maiores encontrados em estudo de vegetação arbustivo-arbórea na Caatinga, tendo sido encontrados valores próximos nos estudos de uma área não antropizada realizados por Lemos; Meguro (2015) da ordem de 3,11 (Tabela 4).

Para São José do Bonfim, o índice de Shannon-Weaver é baixo, mas, ainda é superior aos encontrados em trabalhos realizados em vegetação de Caatinga como os de Holanda et al. (2015), Calixto Júnior; Drumond (2014), Souza; Medeiros (2013), Holanda (2012), Andrade et al. (2005), e Maracajá et al. (2003), dentre outros. Estes valores baixos estão principalmente associados à baixa riqueza de espécies encontradas nestas áreas (Tabela 4).

Para o estrato de regeneração, os valores encontrados para o índice de diversidade Shannon-Weaver para as áreas de estudos foram de 1,63 para São José do Bonfim, 3,12 para Itaporanga e 2,81 para Lagoa, semelhantes aos obtidos nos respectivos estratos superiores.

A equabilidade de Pielou (J) para as áreas de São José do Bonfim, Itaporanga e Lagoa para o estrato adulto foi de 0,$63 ; 0,71$ e 0,79 , respectivamente, e para o estrato de regeneração foi de 0,$68 ; 0,79$ e 0,76 , respectivamente. Estes valores ratificam o observado em relação ao número de espécies de cada área e a densidade de indivíduos, sendo que em São José do Bonfim, encontramos menor equabilidade, uma vez que $64 \%$ do número de indivíduos desta área são das espécies Poincianella pyramidalis e Croton blanchetianus. Nas demais áreas, não é observada uma dominância em termos de densidade, por um número pequeno de espécies. Estes valores de $\mathrm{J}$ são semelhantes aos encontrados nos estudos apresentados na Tabela 4.

\section{Similaridade Florística}

A similaridade florística explica o quanto, floristicamente, áreas são similares ou dissimilares em relação ao número de espécies. Segundo Mueller-Dombois; Ellenberg (1974), áreas vegetacionais são consideradas similares em composição florística quando 
apresentam um valor mínimo de $25 \%$ de espécies comuns. Estas estimativas estão de acordo com as encontradas em trabalhos sobre vegetação de Caatinga (LEMOS; MEGURO, 2010; FERRAZ et al., 1998).

A similaridade florística entre as áreas de Itaporanga e Lagoa, estimada pelo índice de Jaccard, foi igual a 0,53 para o estrato adulto, e 0,27 para o estrato de regeneração, revelando grande similaridade florística entre estas áreas (Figura 4). Estas áreas também apresentam as maiores altitudes. A área de São José do Bonfim apresenta baixa similaridade florística com as demais, para os dois estratos, e também está associada a valores de altitudes mais baixas (Figura 4). São José do Bonfim é a área menos rica em espécies, com menor densidade de indivíduos, e esta possui a menor altitude, corroborando com os estudos apresentados por Andrade-Lima (1981), confirmados também por Ferraz et al. (1998); e Giulietti et al. (2004); Rodal et al. (2008) e Lemos; Meguro (2015). Para estes autores, existe um gradiente ambiental na Caatinga, caracterizado por apresentar fisionomias de vegetação (densidade e riqueza) orientadas pela altitude.
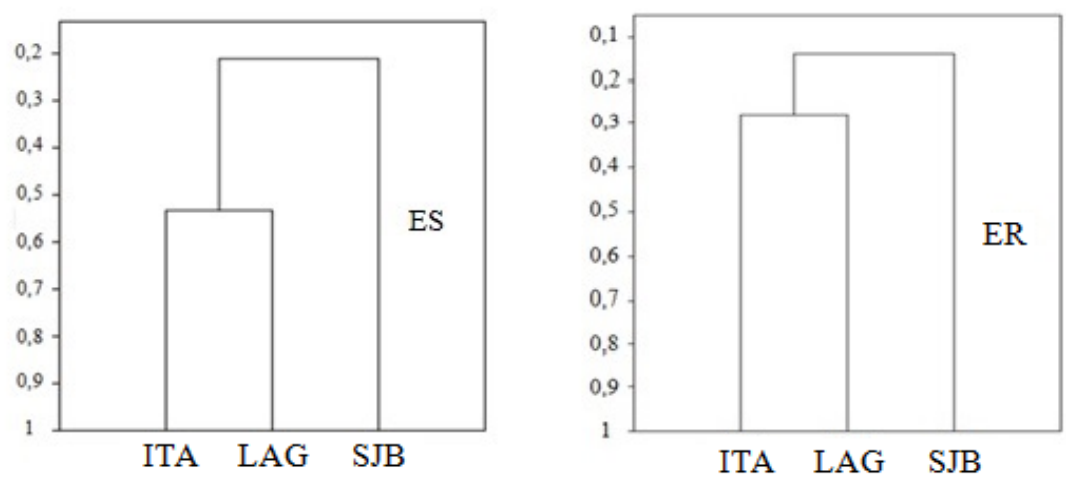

Figura 4. Dendrograma de similaridade florística de Jaccard em vegetação de Caatinga arbustivo-arbórea, nos estratos superior e regeneração para as áreas de São José do Bonfim (SJB), Itaporanga (ITA) e Lagoa (LAG), no estado da Paraíba - Brasil.

\section{Estrutura horizontal}

Os parâmetros quantitativos da estrutura horizontal por área de estudo, por espécies, para o estrato adulto, foram calculados e são apresentados na figura 5 e nos anexos 1,2 e 3.

Na área de São José do Bonfim, cinco espécies sendo Poincianella pyramidalis, Croton blanchetianus, Mimosa tenuiflora, Anadenanthera colubrina e Bauhinia 
cheilantha, respondem por 75,23\% do IVI\%. Destas, é observado o amplo predomínio de Poincianella pyramidalis que sozinha representa $28,86 \%$ do IVI\%.

Para a área de Itaporanga, as espécies Croton blanchetianus, Myracrodruon urundeuva, Amburana cearenses, Poincianella pyramidalis, Combretum leprosum, Mimosa tenuiflora, Commiphora leptophloeos, Sapium glandulosum, Mimosa ophthalmocentra e Manihot carthaginensis respondem por $57,11 \%$ do IVI\% desta área. A espécie Croton blanchetianus é a de maior IVI\%, representando 20,91\%.

Para a área de Lagoa, as espécies Croton blanchetianus, Peltogyne pauciflora, Aspidosperma riedelii, Gymnanthes boticario, Myrciaria floribunda, Luehea ochrophylla, Senegalia polyphylla, Eugenia stictopetala, Brosimum gaudichaudii e Poincianella pyramidalis respondem por 50,55\% do IVI\% desta área. A espécie Croton blanchetianus é a de maior IVI\%, representando 9,39\%.

Nas áreas de estudo, o comportamento das espécies estruturantes em relação ao IVI\% é bastante distinto. Há espécies que marcam sua importância na estrutura horizontal da vegetação da Caatinga pela maior predominância em densidade, e outras que se destacam pela maior predominância em frequência e indivíduos com maiores diâmetros. De maneira geral, todas estas apresentam de média a alta frequência de distribuição nas áreas de estudo.

Nas três áreas de estudo, as espécies Poincianella pyramidalis e Croton blanchetianus estão entre as de maior participação nos parâmetros, frequência e densidade de espécies, sendo consideradas espécies estruturantes para as três áreas de estudo.

Para as áreas de Itaporanga e Lagoa, a espécie Croton blanchetianus Baill apresentou maior densidade relativa de indivíduos, com 33,83\% e 15,57\% respectivamente. Estes resultados corroboram com os encontrados por Souza; Medeiros (2013); Costa et al. (2009); Fabricante; Andrade (2007); Araújo (2007); Santana; Souto (2006) e Silva (2005). Maracajá et al. (2003), estudando um extrato arbustivo-arbóreo em dois ambientes de vegetação de Caatinga, constataram um elevado número de indivíduos desta espécie em relação a outras encontradas em vegetação de Caatinga, atribuindo esse predomínio à facilidade de rebrota da mesma. Tal fato mostra a facilidade de colonização desta espécie em relação às demais.

Para a área de estudo de São José do Bonfim, a espécie Poincianella pyramidalis, obteve o maior IVI\% com $28,86 \%$; tais resultados são semelhantes aos encontrados nos estudos realizados em áreas de Caatinga por Oliveira et al. (2009); Araújo (2007); Fabricante; Andrade (2007); Santana; Souto (2006); Andrade et al. (2005); Silva (2005) e 

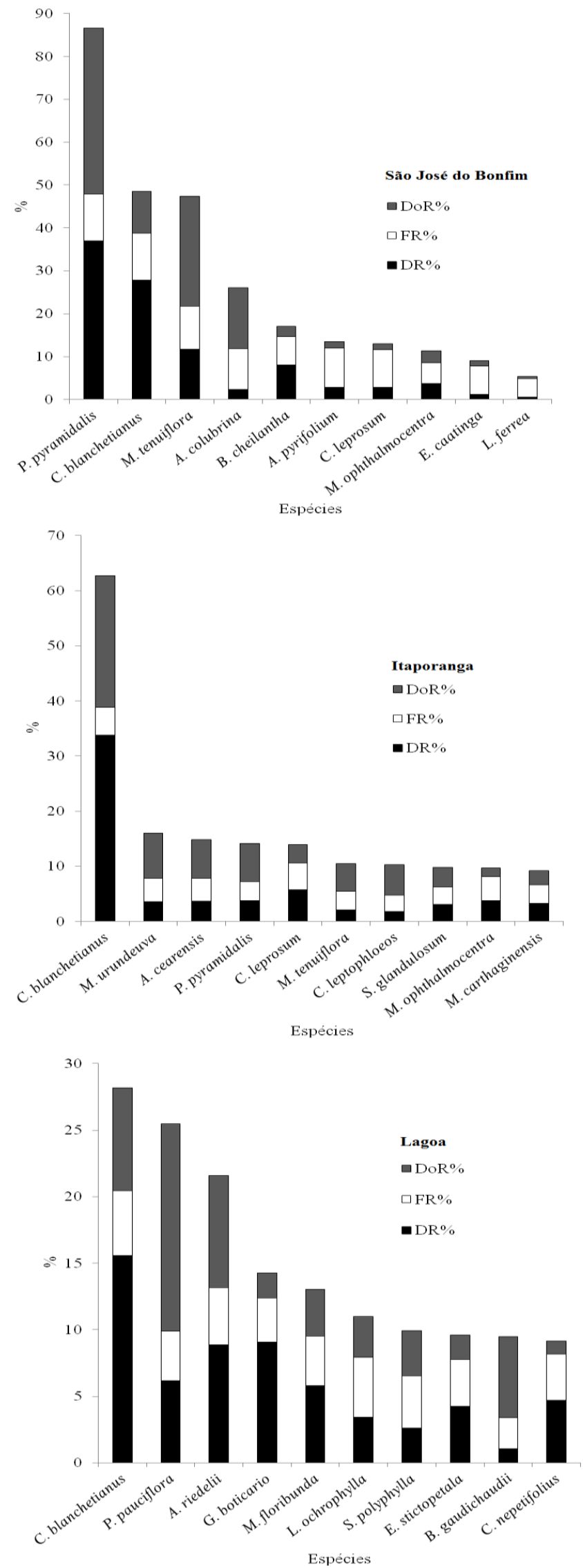

Figura 5. Índice de Valor de Importância - IVI\% para o estrato adulto em vegetação de Caatinga arbustivo-arbórea, no estado da Paraíba - Brasil. 
Alcoforado-Filho et al. (2003). Nestes trabalhos, esta espécie é uma das que possuem os maiores IVI\%.

A espécie Gymnanthes boticario foi descrita por Lucena (2009) como uma nova espécie de Euphorbiaceae para o Nordeste brasileiro. Ela foi observada na área de Lagoa, sendo a segunda de maior densidade de indivíduos, tendo alta frequência de distribuição e baixa dominância, sendo a $4^{\mathrm{a}}$ espécie de maior IVI\%.

As densidades constatadas nas áreas de estudo são elevadas, sendo 3.118 ind.ha $^{-1}$ na área de São José do Bonfim, 2.847 ind.ha $^{-1}$ na área de Itaporanga e 3.057 ind.ha ${ }^{-1}$ na área de Lagoa, quando comparadas aos resultados obtidos por Pessoa et al. (2008) em um trabalho realizado em vegetação de Caatinga no Rio Grande do Norte, com densidades de 538 e 1017 ind.ha ${ }^{-1}$. Costa et al. (2002), em um trabalho realizado na região do Seridó, no Rio Grande do Norte, constataram densidades em 10 locais entre 360 e 2.290 ind.ha $^{-1}$. Por sua vez, Guedes et al. (2012) encontrou, em área preservada da mesma natureza, densidades de 1.622,5 ind.ha $^{-1}$. A elevada densidade de indivíduos nas áreas de estudo pode ser explicada como um reflexo da baixa ação antrópica dos últimos anos, refletindo em uma maior conservação destes remanescentes florestais.

\section{Estrutura vertical}

O número de espécies presentes no estrato de regeneração, para as três áreas de estudo (Anexos 4, 5 e 6) foi de: 11 espécies para São José do Bonfim, 52 espécies para Itaporanga e 40 espécies para Lagoa (Tabela 4 e Figura 6), o número de espécies no estrato de regeneração foi inferior ao observado no estrato adulto.

Apenas a espécie Lantana camara L. na área de Lagoa (Anexo 6) e a Morfo espécie 4 na área de Itaporanga (Anexo 5) apresentam indivíduos unicamente no estrato regenerante.

Foi estimado no estrato de regeneração para as áreas de estudo, uma densidade de 4.544 ind.ha ${ }^{-1}$, 6.992 ind.ha $^{-1}$ e 6.848 ind.ha $^{-1}$ (Anexos 4, 5 e 6). Estas estimativas corroboraram com as encontradas por Pereira et al. (2001) em áreas de Caatinga bem preservadas. Em outros trabalhos realizados em Caatinga com características de antropização, como corte seletivo e ocorrência de incêndios florestais, Alves Junior et al. (2013), Alves et al. (2010), Fabricante; Andrade (2007), encontraram estimativas de densidade muito inferiores às estimadas neste estudo. 
Na área de São José do Bonfim, as espécies Croton blanchetianus, Poincianella pyramidalis, Combretum leprosum e Aspidosperma pyrifolium são as de maior valor de regeneração natural relativa (RNR) e densidade no estrato regenerante, assim como estão entre as de maior IVI\%, no estrato adulto.

$\mathrm{Na}$ área de Itaporanga, Croton blanchetianus e Amburana cearenses são as de maior valor de regeneração natural relativa (RNR) e densidade no estrato regenerante, assim como estão entre as de maior IVI\% do estrato adulto; o que nos permite inferir que estas espécies apresentam comportamento mais estável no processo de sucessão natural desta área. Fabricante; Andrade (2007); Alves et al. (2010), estudando a regeneração natural em vegetação de Caatinga, observaram em seus estudos que Croton blanchetianus Baill também foi uma das espécies que apresentou as maiores densidades de indivíduos regenerantes assim como o observado neste estudo em Itaporanga. Por sua vez, Varronia curassavica, Croton rhamnifolioides, Senegalia polyphylla e Erythroxylum Caatinga apresentaram grande participação na RNR, mas, não apresentam comportamento similar no estrato adulto, e não demonstram participação efetiva no processo de sucessão ecológica desta área.

$\mathrm{Na}$ área de Lagoa, por sua vez, as espécies Croton blanchetianus, Croton blanchetianus, Croton nepetifolius, Aspidosperma riedelii, Myrciaria floribunda e Gymnanthes boticario são as de maior valor de regeneração natural relativa (RNR) e densidade no estrato regenerante, bem como estão entre as de maior IVI\% no estrato adulto. Estas espécies apresentam comportamento mais estável no processo de sucessão natural desta área. As espécies Croton heliotropiifolius e Helicteres heptandra apresentaram participação de destaque na RNR, mas, não apresentaram comportamento similar no estrato adulto, indicando que no presente momento, não demonstram sua participação efetiva no processo de sucessão ecológica desta área.

A análise da regeneração natural permite que sejam feitas inferências sobre a origem da floresta, bem como previsões sobre seu desenvolvimento e aproveitamento sob diferentes formas de tratamento (NAPPO et al., 2004). Os conhecimentos propiciados pelos estudos que envolvem o estrato regenerante e o estrato adulto são essenciais para a elaboração e aplicação correta dos planos de manejo e tratamentos silviculturais, permitindo uma exploração racional da vegetação da Caatinga (ALVES JÚNIOR et al., 2013). Neste sentido, este estudo representa uma contribuição significativa para o manejo conservacionista ou de preservação dos fragmentos de Caatinga, hora estudados em São José do Bonfim, Itaporanga e Lagoa, na Paraíba. 

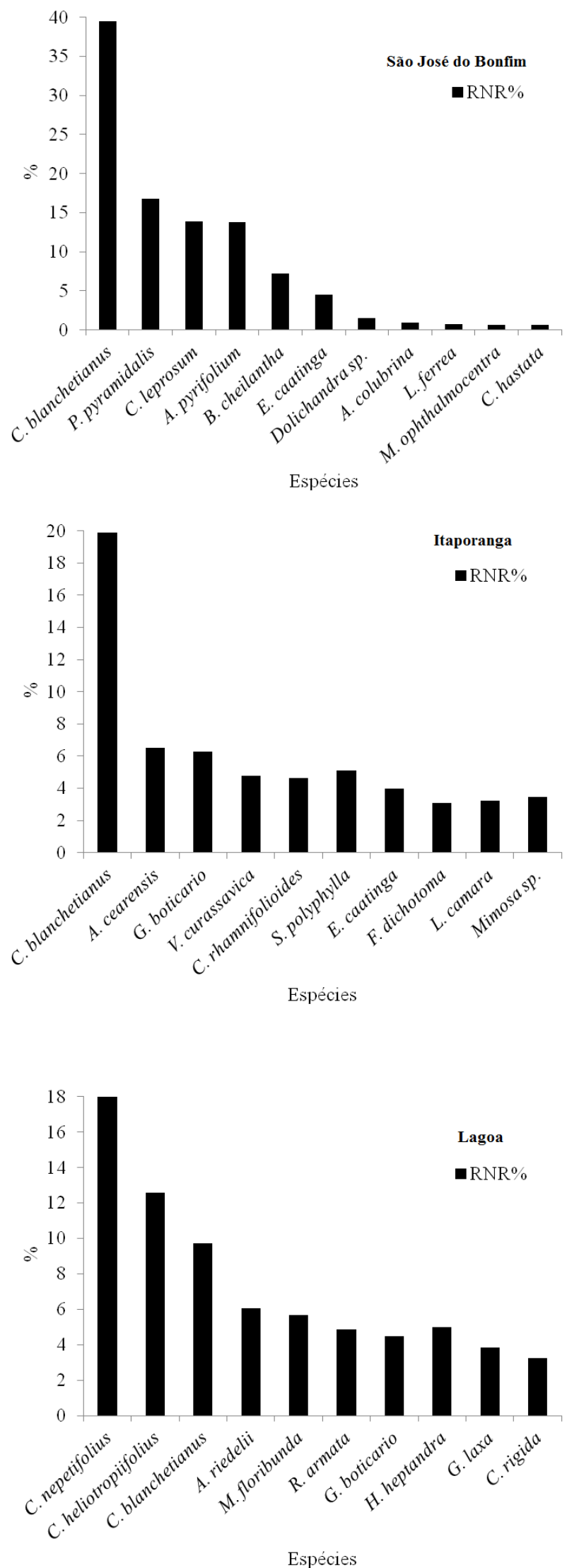

Figura 6. Estimativas da regeneração natural relativa (\%) em vegetação de Caatinga arbustivo-arbórea, presentes na área de São José do Bonfim, Itaporanga e Lagoa, no estado da Paraíba - Brasil. 


\section{Espécies de baixa densidade}

Na área de São José do Bonfim, não foi observada nenhuma espécies de baixa densidade, tanto no estrato adulto (Anexo 1) quanto no estrato de regeneração (Anexo 4).

$\mathrm{Na}$ área de Itaporanga, foram observadas 6 espécies de baixa densidade, sendo: Zanthoxylum syncarpum, Cordiera rigida, Handroanthus impetiginosus, Triplaris gardneriana, Coutarea hexandra e Stachytarpheta coccinea, e no estrato adulto (Anexo 2) e no estrato de regeneração não foi observada nenhuma espécie de baixa densidade (Anexo $5)$.

$\mathrm{Na}$ área de Lagoa, foram observadas 5 espécies de baixa densidade: Mimosa tenuiflora, Xylosma prockia, Dolichandra sp., Turnera calyptrocarpa e Varronia curassavica no estrato adulto (Anexo 3) e nenhuma no estrato de regeneração (Anexo 6).

Nenhuma das espécies citadas acima, consideradas de baixa densidade pelo parâmetro estabelecido neste estudo, estão na lista oficial das espécies da flora brasileira ameaçadas de extinção, conforme BRASIL (2008) e Martinelli; Moraes (2013). Segundo Costa et al. (2009), espécies de baixa densidade da vegetação de Caatinga, têm se mostrado muito sensíveis à antropização, estando presentes apenas em fragmentos conservados, nos quais o empobrecimento da flora por meio da degradação ambiental, tem ocorrido em todos os estratos (SANTOS et al., 2009). Espécies de baixa densidade são mais vulneráveis à extinção por serem adaptadas a um conjunto restrito de fatores ambientais e por apresentarem limitações de dispersão para outros ambientes (OLIVEIRA; AMARAL, 2005).

As espécies Astronium fraxinifolium na área de Itaporanga (5 indivíduos no estrato adulto), Amburana cearensis em Itaporanga (104 indivíduos no estrato adulto e 60 no estrato regenerante) e em Lagoa (11 indivíduos no estrato adulto e 4 no estrato regenerante), Myracrodruon urundeuva em Itaporanga (103 indivíduos no estrato adulto e 16 no regenerante) e Lagoa (13 indivíduos no estrato adulto e 4 no estrato regenerante) e Schinopsis brasiliensis em Itaporanga (13 indivíduos no estrato adulto) que não são consideradas de baixa densidade pelo parâmetro estabelecido neste estudo, são consideradas ameaçadas de extinção, de acordo com a lista da flora brasileira apresentada em BRASIL (2008) e Martinelli; Moraes (2013). Esta observação nos permite considerar a relevância de estudos florísticos e fitossociológicos, para orientação de ações voltadas para o estabelecimento de ações que permitam identificar áreas de refúgio de espécies ameaçadas com o intuito de conservar e preservar a flora brasileira. 


\section{Padrão de distribuição espacial das espécies}

As espécies presentes nas áreas de São José do Bonfim, Itaporanga e Lagoa, na ordem de 70,00\%,71,43\% e 77,94\%, respectivamente, apresentaram distribuição espacial agregada. Na mesma ordem, 25,00\%,7,14\% e 7,35\% apresentaram tendência de agrupamento e 5,00\%,21,43\% e 14,71\% apresentaram distribuição aleatória (Anexos 1, 2 e 3).

Murphy; Lugo (1986) afirmam que padrões de distribuição espacial agregados das espécies vegetais, são comuns em florestas tropicais e que eles também são encontrados em florestas tropicais secas e semiáridas. No entanto, a distribuição espacial de uma espécie está sob a influência do ambiente em que a mesma está presente. Marangon et al. (2013) descrevem que, em áreas de vegetação de Caatinga, fatores morfológicos, como mecanismos de dispersão das espécies a curta distância, e fatores ambientais, como relevo, profundidade dos solos e disponibilidade de água, propiciam nichos muito particulares, o que favoreceu em particular, distribuição espacial agregada em grande parte das espécies vegetais.

Mendes Júnior et al. (2009), Marangon et al. (2013) e Oliveira et al. (2013), utilizando a classificação de Payandeh, descrevem que a maioria das espécies da Caatinga apresentam distribuição agregada, enquanto o restante indica distribuição com tendência ao agrupamento, com poucas espécies apresentando distribuição aleatória como em geral se percebe nos estudos relacionados à distribuição espacial em outros biomas brasileiros. Ainda, segundo estes autores, estas informações contribuem para o entendimento do comportamento das referidas espécies analisadas e colaboram para possíveis intervenções, sejam elas de caráter exploratório ou conservacionista, em áreas de Caatinga. 


\subsection{CONCLUSÕES}

Para as três áreas de estudo, no estrato adulto, as famílias Euphorbiaceae e Fabaceae são as mais ricas em número de espécies, e as dominantes em número de indivíduos.

As áreas de maior altitude, Itaporanga e Lagoa apresentaram valores elevados de diversidade (H') para áreas de Caatinga.

Este estudo apresenta o primeiro registro de ocorrência na flora arbustivo-arbórea do estrato adulto de Caatinga, no estado da Paraíba, das espécies: Mimosa acutistipula (São José do Bonfim), Annona leptopetala, Aspidosperma cuspa, Psidium appendiculatum, Eugenia flavescens, Eugenia stictopetala, Cordiera rigida, Sigmatanthus trifoliatus, Allophylus quercifolius, Stachytarpheta coccínea, Callisthene minor (Itaporanga), Erythroxylum nummularia, Byrsonima vacciniifolia, Eugenia caatingicola, Eugenia flavescens, Myrciaria floribunda, Eugenia stictopetala, Cordiera rigida, Pouteria reticulata e Callisthene minor (Lagoa).

Para as três áreas de estudo, as espécies estruturantes do estrato adulto são Poincianella pyramidalis e Croton blanchetianus, considerando os parâmetros densidade, frequência e densidade de espécies.

As áreas de Itaporanga e de Lagoa são consideradas de relevante importância para estudos florísticos/fitossociológicos por abrigarem espécies ameaçadas de extinção conforme Brasil (2008) e Martinelli; Moraes (2013), sendo as espécies: Astronium fraxinifolium e Schinopsis brasiliensis (Itaporanga); Amburana cearenses e Myracrodruon urundeuva (Itaporanga e Lagoa).

Pela participação nos estratos adulto e regenerante, as espécies mais importantes no processo de sucessão das áreas são: Croton blanchetianus, Poincianella pyramidalis, Combretum leprosum e Aspidosperma pyrifolium para São José do Bonfim; Croton blanchetianus e Amburana cearenses para Itaporanga; Croton blanchetianus, Croton blanchetianus, Croton nepetifolius, Aspidosperma riedelii, Myrciaria floribunda e Gymnanthes boticario para Lagoa.

O padrão agregado de distribuição espacial de espécies predomina nas três áreas de estudo. 


\section{REFERÊNCIAS}

AB'SÁBER, A. N. O domínio morfoclimático semiárido das Caatingas brasileiras. Geomorfologia, v.43, p.01-39, 1974.

ALCOFORADO-FILHO, F. G.; SAMPAIO, E. V. S. B.; RODAL, M. J. N. Florística e fitossociologia de um remanescente de vegetação caducifólia espinhosa arbórea em Caruaru, Pernambuco. Acta Botanica Brasilica, v.14, n.2, p.287-303, 2003.

ALVES, A. R.; RIBEIRO, I. B.; SOUSA, J. R. L.; BARROS, S. S.; SOUSA, P. S. Análise da estrutura vegetacional em uma área de Caatinga no município de Bom Jesus, Piauí. Revista Caatinga, v.26, n.4, p.99-106, 2013.

ALVES JUNIOR, F. T.; FERREIRA, R. L. C.; SILVA, J. A. A.; MARANGON, L. C.; CESPEDES, G. H. G. Regeneração natural de uma área de Caatinga no sertão pernambucano, Nordeste do Brasil. Cerne, v.19, n.2, p.229-235, 2013.

ALVES, L. de. S.; HOLANDA, A. C.; WANDERLEY, J. A. C.; SOUSA, J. S.; ALMEIDA, P. G. de. Regeneração natural de uma área de Caatinga situada no município de Pombal - PB - Brasil. Revista Verde, Mossoró, v.5, n.2, p.152-168, 2010.

ANDRADE, L. A.; OLIVEIRA, F. X.; NASCIMENTO, I. S.; FABRICANTE, J. R.; SAMPAIO, E. V. S. B.; BARBOSA, M. R. V. Análise Florística e estrutural de matas ciliares ocorrentes em brejo de altitude no município de Areia, Paraíba. Revista Brasileira de Ciências Agrárias, v.1, n.único, p.31-40, 2006.

ANDRADE, L. A.; OlIVEIRA, F. X.; NEVES, C. M. L.; FELIX, L. P. Análise da vegetação sucessional em campos abandonados no agreste paraibano. Revista Brasileira de Ciências Agrárias, v.2, n.2, p.135-142, 2007.

ANDRADE, L. A.; PEREIRA, I. M.; LEITE, U. T. BARBOSA, M. R. V. Análise da cobertura de duas fitofisionomias de Caatinga, com diferentes históricos de uso, no município de São João do Cariri, estado da Paraíba. Cerne, v.11, n.3, p.253-262, 2005.

ANDRADE-LIMA, D. The Caatingas dominium. Revista Brasileira de Botânica, v.4, p.149-163, 1981.

ARAÚJO, L. V. C. de. Composição florística, fitossociologia e influência dos solos na estrutura da vegetação em uma área de Caatinga no semiárido paraibano. Tese (Doutorado em Agronomia), Universidade Federal da Paraíba, 121p, 2007.

BFG. Growing knowledge: an overview of Seed Plant diversity in Brazil. Rodriguésia, Rio de Janeiro, v. 66, n. 4, p. 1085-1113. 2015.

BRASIL. Ministério do Meio Ambiente/MMA. Instrução Normativa. Lista Oficial das Espécies da Flora Brasileira Ameaçadas de Extinção, Brasília, 55p, 2008.

BROWER, J. E.; ZAR, J. H. Field \& Laboratory Methods for General Ecology. Iowa: Wm. C. Brown Company (2 nd ed.), 226p, 1984. 
CALIXTO JÚNIOR, J. T.; DRUMOND, M. A. Estudo comparativo da estrutura fitossociológica de dois fragmentos de Caatinga em níveis diferentes de conservação. Pesq.flor. bras., v.34, n.80, p.01-011, 2014.

CIENTEC. Software Mata Nativa 2.06: sistema para análise fitossociológica, elaboração de inventários e planos de manejo de florestas nativas. Viçosa, MG, 295p. 2006.

COSTA JUNIOR, R. F.; FERREIRA, R. L. C.; RODAL, M. J. N.; FELICIANO, A. L. P.; MARANGON, L. C.; SILVA, W. C. Estrutura fitossociológica do componente arbóreo de um fragmento de floresta ombrófila densa na mata sul de Pernambuco, Nordeste do Brasil. Ciência Florestal, v.18, n.2, p.173-183, 2008.

COSTA, T. C. C.; ACCIOLY, L. J. O.; OLIVEIRA, M. A. J.; BURGOS, N.; SILVA, F. H. B. B. Phytomass mapping of the "Seridó Caatinga" vegetation by the plant area and the normalized difference vegetation indeces. Scientia Agricola, v.59, p.707-715, 2002.

COSTA, T. C. C.; OLIVEIRA, M. A. J.; ACCIOLY, L. J. O.; SILVA, F. H. B. B. Análise da degradação da Caatinga no núcleo de desertificação do Seridó (RN/PB). Revista Brasileira de Engenharia Agrícola e Ambiental, v.13, p.961-974, 2009.

COUTINHO, K.; OLIVEIRA, M. I. U.; FUNCH, L. S.Four new species of Eugenia (Myrtaceae) from the Caatinga and Atlantic Forest of northeastern Brazil. Phytotaxa, v.234, n.3, p.215-226, 2015.

CUNHA, M. do. C. L. Comunidades de Árvores e o Ambiente na Floresta Estacional Montana do Pico do Jabre, PB. Tese (Doutorado em Ciências Florestais), Universidade de Brasília, 284p, 2010.

CURTIS, J. T.; McINTOSH, R. P.An upland forest continuum in the prarie-forest border region of Wisconsin. Ecology, v.32, p.476-496, 1951.

DANIEL, H.; BERNEZ, I.; HAURY, J. Relations hips between macrophytic vegetation and physical features of river habitats: the need for a morphological approach. Hydrobiologia, v.570, p.11-17, 2006.

DINIZ, C. E. F. Análise estrutural e corte seletivo baseado no método Bdq em vegetação de Caatinga. Dissertação (Mestrado em Ciências Florestais), Universidade Federal de Campina Grande, UFCG, 114p, 2011.

FABRICANTE, J. R; ANDRADE, L. A. de. Análise estrutural de um remanescente de Caatinga no Seridó paraibano. Oecologia Brasiliensis, v.11, n.3, p.341-349, 2007.

FERRAZ, E. M. N.; RODAL, M. J. N.; SAMPAIO, E. V. S. B.; PEREIRA, R. C. A. Composição florística em trechos de vegetação de Caatinga e brejo de altitude na região do Vale do Pajeú, Pernambuco. Revista Brasileira de Botânica, v.21, n.1, p.7-15, 1998.

FINOL, U. H. Nuevos parametros a considerarse en el analisis estrutural de lãs selvas virgenes tropicales. R. For, Venez., v.14, n.21, p.29-42, 1971. 
GIULIETTI, A. M.; BOCAGE NETA, A. L. DU.; CASTRO, A. A. J. F.; GAMARRAROJAS, C. F. L.; SAMPAIO, E. V. S. B.; VIRGÍNIO, J. F.; QUEIROZ, L. P.; FIGUEIREDO, M. A.; RODAL, M. DE. J. N.; BARBOSA, M. R. DE. V.; HARLEY, R. M.Diagnóstico da vegetação nativa do Bioma Caatinga. In: SILVA, J. M. C. da.; TABARELLI, M.; FONSECA, M. T. da.; LINS, L. V. Biodiversidade da Caatinga: áreas e ações prioritárias para a conservação. Ministério do Meio Ambiente, Brasília, p.48-90, 2004.

GOMES, A. P. de. S.; RODAL, M. J. N.; MELO, A. L. de. Florística e fitogeografia de vegetação arbustiva subcaducifólia da Chapada de São José, Buíque, PE, Brasil. Acta Botanica Brasilica, v.20, n.1, p.37-48, 2006.

GUEDES, R. S.; ZANELlA, F. C. V.; COSTA JÚNIOR, J. E. V.; SANTANA, G. M.; SILVA, J. A. Caracterização florístico-fitossociológica do componente lenhoso de um trecho de Caatinga no semiárido paraibano. Revista Caatinga, v.25, n.2, p.99-108, 2012.

HAMMER, Ø.; HARPER, D. A. T.; RYAN, P. D. Past: Paleontological Statistics Software Package for Education and Data Analysis. Palaeontologia Electronica, v.4, n.1, p.01-9, 2001.

HOLANDA, A. C.; LIMA, F. T. D.; SILVA, B. M.; DOURADO, R. G.; ALVES, A. R. Estrutura da vegetação em remanescentes de Caatinga com diferentes históricos de perturbação em Cajazeirinhas (PB). Revista Caatinga, v.28, n.4, p.142-150, 2015.

HOLANDA, A. C. Estrutura da comunidade arbustivo-arbórea e suas interações com o solo em uma área de Caatinga, Pombal-PB. Tese (Doutorado em Ciências Florestais), Universidade Federal Rural de Pernambuco, UFRPE, 164p, 2012.

JACOMINE, P. K. T. A nova classificação brasileira de solos. Anais da Academia Pernambucana de Ciência Agronômica, v.5 e 6, p.161-179, 2008-2009.

KUNZ, S. H.; IVANUSKAS, N. M.; MARTINS, S. V.; SILVA, E.; STEFANELLO, D. Análise da similaridade florística entre florestas do Alto Rio Xingu, da Bacia Amazônica e do Planalto Central Revista Brasileira de Botânica., v.32, n.4, p.725-736, 2009.

LAMPRECHT, H. Ensayo sobre la estructura florística de la parte sur-oriental del bosque universitario «El Caimital», Estado Barinas. Revista Forestal Venezolana, v.7, n.10/11, p. 77-119, 1964.

LAMPRECHT, H. Ensayo sobre unos metodos para el analisis estructural de los bosques tropicales. Acta Cientifica Venezolana, v.13, n.2, p.57-65, 1962.

LEMOS, J. R.; MEGURO, M. Estudo itossociológico de uma área de Caatinga na Estação Ecológica (ESEC) de Aiuaba, Ceará, Brasil. Biotemas, v.28, n.2, p.39-50, 2015.

LEMOS, J. R.; MEGURO, M. Florística e fitogeografia da vegetação decidual da Estação Ecológica de Aiuaba, Ceará, Nordeste do Brasil. Revista Brasileira de Biociências, v.8, n.1, p.34-43, 2010. 
LYONS, K. G.; BRIGHAM, C. A.; TRAUT, B. H.; SCHWARTZ, M. W. Rare species and ecosystem functioning. Conservation Biology, v.19, p.1019-1024, 2005.

LUCENA, M. F. A. Diversidade de Euphorbiaceae (s.l.) no Nordeste do Brasil. Tese (Doutorado em Biologia Vegetal), Universidade Federal de Pernambuco, Recife, 197p, 2009.

LUCENA, M. S.; SILVA, J. A.; ALVES, A. R. Regeneração natural do estrato arbustivoarbóreo em área de Caatinga na Estação Ecológica do Seridó - RN, Brasil. Revista Biotemas, v.29, n.2, p.17-31, 2016.

MAGALHÃES, T. Caatinga, um bioma desconhecido e a "Convivência com o Semiárido". Revista do Instituto Humanitas Unisinos ON-LINE, n.389, p.06-08, 2012.

MAGURRAN, A. E. Diversidad Ecologica y su Medición. Espanha: Ediciones Vedra, $199 \mathrm{p}, 1989$.

MARACAJÁ, P. B.; BATISTA, C. H. F.; SOUSA, A. H. de.; VASCONCELOS, W. E. de. Levantamento florístico e fitossociológico do extrato arbustivo-arbóreo de dois ambientes na Vila Santa Catarina, Serra do Mel, RN. Revista de Biologia e Ciências da Terra. v.3, n.2, p.01-13, 2003.

MARANGON, G. P.; FERREIRA, R. L. C.; SILVA, J. A. A.; LIRA, D. F. S.; SILVA, E. A.; LOUREIRO, G. H. Estrutura e padrão espacial da vegetação em uma área de Caatinga. Floresta, v.43, n.1, p.83-92, 2013.

MARTINELLI, G.; MORAES, M. A. (Orgs.). Livro vermelho da flora do Brasil. Rio de Janeiro, Instituto de Pesquisas Jardim Botânico do Rio de Janeiro, 1100p, 2013.

MARTINS, F. R. Estrutura de uma floresta mesófila. Campinas: Ed. da UNICAMP, $246 p, 1993$.

MEDEIROS, A. V. S. Taxocenoses de meliponina, seus recursos florais e sítios de nidificação em áreas da Caatinga, no Seridó Nordestino. Dissertação (Mestrado em Ciências Florestais), Universidade Federal de Campina Grande, 78p, 2011.

MEIRA-NETO, J. A. A.; MARTINS, F. R. Composição florística de uma floresta estacional semidecidual montana no município de Viçosa-MG. Revista Árvore, v.26, n.4, p.437-446, 2002.

MELO, A. S. O que ganhamos 'confundindo' riqueza de espécies e equabilidade em um índice de diversidade? Biota Neotropica, v.8, n.3, p.020-027, 2008.

MELO, J. I. M. de.; RODAL, M. J. N. Levantamento florístico de um trecho de floresta serrana no planalto de Garanhuns, estado de Pernambuco. Acta Scientiarum: Biological Sciences, v.25, n.1, p.173-178, 2003. 
MENDES JÚNIOR, I. J. H; FERREIRA, R. L. C.; SILVA, J. A. A.; ALVES JÚNIOR, F. T.; SILVA, A. E.; CÉSPEDES, G. H. G. Distribuição espacial, diversidade florística e regeneração de uma área de Caatinga após 20 anos de corte. In: IX JORNADA DE ENSINO, PESQUISA E EXTENSAO, 2009, Recife. Anais... Recife: EDUFRPE, v. 9, 2009.

MEWS, H. A. Generalizando índices de diversidade: perfis de diversidade. Guia prático para realização da análise estatística - Tutorial, Laboratório de Dendrologia e Ecologia Florestal, Universidade de Brasília - UnB, p.01-07, 2013.

MOONEY, H. A.; BULLOCK, S. H.; MEDINA, E. Introduction. In: MOONEY, H. A.; BULLOCK, S. H.; MEDINA, E. (Eds.). Dry tropical forests, Cambridge University Press, Cambridge. p.1-8, 1995.

MUELLER-DAMBOIS, D; ELLENBERG, H. Aims and methods of vegetation ecology. New York, Jonh Willey y Sons, 547p, 1974.

MURPHY, P. G.; LUGO, A. E. Dry forests of Central America and the Caribbean islands. In: BULLOCK, S. H.; MOONEY, H. A.; MEDINA, E. (Eds.). Seasonally dry tropical forests. Cambridge, NY: Cambridge University Press. New York, p.9-34, 1995.

MURPHY, P. G.; LUGO, A. E. Ecology of Tropical Dry Forest. Annual Review of Ecology and Systematics, v.17, p.67-88, 1986.

NAPPO, M. E.; GRIFFITH, J, J.; MARTINS, S. V.; DE MARCO JÚNIOR, P.; SOUZA, A. L.; OLIVEIRA-FILHO A. T. Dinâmica da estrutura fitossociológica da regeneração natural de espécies arbóreas e arbustivas no sub-bosque de povoamento puro de Mimosa scabrella Bentham, em área minerada, em Poços de Caldas-MG. Revista Árvore, v. 28, n. 6, p. 811-829, 2004.

NASCIMENTO, L. M. do; RODAL, M. J. N. Fisionomia e estrutura de uma floresta Estacional Montana do maciço da Borborema, Pernambuco - Brasil. Revista Brasileira de Biologia, v.31, n.1, p.27-39, 2008.

ODUM, E. P. Ecologia. Guanabara Koogan, Rio de Janeiro, Brasil, 434p, 1983.

OLIVEIRA, A. N. de.; AMARAL, I. L. do. Aspectos florísticos, fitossociológicos e ecológicos de um sub-bosque de terra firme na Amazônia Central, Amazonas, Brasil. Acta Amazonica, v.35, n.1, p.1-16, 2005.

OLIVEIRA, C. P.; LIMA, R. B.; SILVA, R. C. S.; ALVES JÚNIOR, F. T.; CESPEDES, G. H. G.; SILVA, J. A. A.; FERREIRA, R. L. C. Distribuição espacial de espécies em vegetação de Caatinga, Floresta-PE. In: XIII JORNADA DE ENSINO, PESQUISA E EXTENSÃO, 2013, Recife. Anais... Recife: JEPEX, UFRPE, p.01-03, 2013.

OLIVEIRA, P. T. B.; TROVÃO, D. M. B. M.; CARVALHO, E. C. D.; SOUZA, B. C.; FERREIRA, L. M. R. Florística e fitossociologia de quatro remanescentes vegetacionais em áreas de serra no cariri paraibano. Revista Caatinga, v.22, n.4, p.169-178, 2009. 
PAYANDEH, B. Comparacion of method for assessing spatial distribution of trees. For. Sci., v.16, n.3, p.312-317, 1970.

PEREIRA, I. M.; ANDRADE, L. A.; COSTA, J. R. M.; DIAS, J. M. Regeneração natural em um remanescente de Caatinga sob diferentes níveis de perturbação, no Agreste paraibano. Acta Botânica Brasílica, v.15, n.3, p.413-426, 2001.

PEREIRA JÚNIOR, L. R.; ANDRADE, A. P.; ARAÚJO, K. D. Composição florística e fitossociológica de um fragmento de Caatinga em Monteiro, PB. Holos, v.6, p.73-87, 2012.

PESSOA, M. F.; GUERRA, A. M. N. M.; MARACAJÁ, P. B.; LIRA, J. F. B.; DINIZ FILHO, E. T. Estudo da cobertura vegetal em ambientes da Caatinga com diferentes formas de manejo no assentamento Moacir Lucena, Apodi - RN. Revista Caatinga, v.21, n.3, p.40-48, 2008.

PRANCE, G. T. Flora da Reserva Ducke, Amazonas, Brasil: Erythroxylaceae. Rodriguesia, v.57, n.2, p.189-191, 2006.

RABINOWITZ, D.; CAIRNS, S.; DILLON, T. Seven Forms of Rarity and Their Frequency in the Flora of the British Isles. In: Soulé, M. E. (ed.). Conservation Biology: the Science of Scarcity and Diversity. Sunderland: Sinauer Assoc. 1986.

REVEAL, J. L.; CHASE, M. W. APG III: Bibliographical information and Synonymy of Magnoliidae. Phytotaxa, Nova Zelândia, v. 19, p. 71-134. 2011.

REZENDE, M. L. Regeneração natural de espécies florestais em sub-bosque de um povoamento de Eucalyptus grandis e de mata secundária, no município de Viçosa, Zona da Mata-MG. Dissertação (Mestrado em Ciência Florestal) - Universidade Federal de Viçosa, Viçosa, 116p, 1995.

REDE DE MANEJO FLORESTAL DA CAATINGA. Protocolo de Medições de Parcelas Permanentes. Recife: Associação de Plantas do Nordeste. Brasília: MMA,PNF,PNE. 28p, 2005.

RODAL, M. J. N.; MARTINS, F. R.; SAMPAIO, E. V. de. S. B. Levantamento quantitativo das plantas lenhosas em trechos de vegetação de Caatinga em Pernambuco. Revista Caatinga, v.21, n.3, p.192-205, 2008.

RODAL, M. J. N.; NASCIMENTO, L. M. The arboreal component of dry Forest in northeastern Brazil. Brazilian Journal of Biology, v.66, n.(2A), p.479-491, 2006.

RODAL, M. J. N.; SALES, M. F.; SILVA, M. J. da.; SILVA, A. G. da. Flora de um brejo de altitude na escarpa oriental do planalto da Borborema, PE, Brasil. Acta Botanica Brasilica, v.19, n.4, p.843-858, 2005.

RODAL, M. J. N.; SAMPAIO, E. V. S. B. A vegetação do Bioma Caatinga. In: SAMPAIO, E. V. S. B.; GIULIETTI, A. M.; VIRGÍNIO, J.; GAMARRA-ROJAS, C. F. L. (Eds.). Vegetação e Flora da Caatinga. Associação Plantas do Nordeste, CNIP, Recife. p.11-24, 2002. 
RODAL, M. J. N.; SAMPAIO, E. V. de. S. B.; FIGUEIREDO, M. A. Manual Sobre métodos de estudo florístico e fitossociológico - Ecossistema Caatinga. Brasília, Sociedade Botânica do Brasil, 24p, 2013. Disponível em <http://www.botanica.org.br/ebook/mas_sob_met_est_flo_fit.pdf $>$. Acesso em: 02/04/2016.

RUBEL, F.; KOTTEK, M. 2010. World Maps of Koppen-Geiger Classification. Disponível em: < http://koeppen-geiger.vu-wien.ac.at/>. Acesso em: 02/09/2015.

SAEG - Sistema para Análise Estatística e Genética. Manual de uso. Viçosa, MG: UFVFunarbe, 150p, 1997.

SALES, M. F.; MAYO, S. J.; RODAL, M. J. Plantas vasculares das florestas serranas de Pernambuco: um check-list da flora ameaçada dos brejos de altitude de Pernambuco, Brasil. Recife: Universidade Federal Rural de Pernambuco, 130 p, 1998.

SAMPAIO, E. V. S. B. Fitossociologia. In: SAMPAIO, E. V. S. B.; MAYO, S. J.; BARBOSA, M. R. V. (Eds.). Pesquisa botânica nordestina: progressos e perspectivas. Recife: Sociedade Botânica do Brasil/Seção Regional de Pernambuco. p.203-230, 1996.

SANO, P. T.; TROVÓ, M.; E C H TE RNACHT, L.; COSTA, F. N.; WATANABE, M.; GIUL I ET T I, A. M. A importância da conservação de espécies raras no Brasil. In. MARTINELLI, G.; ME S S I NA, T.; SANTOS FILHO, L. Livro vermelho da flora do Brasil. Plantas Raras do Cerrado. Rio de Janeiro, Instituto de Pesquisas Jardim Botânico do Rio de Janeiro: CNCFlora, p.16-20, 2014.

SANTANA, J. A. da. S.; SOUTO, J. S. Diversidade e Estrutura Fitossociológica da Caatinga na Estação Ecológica do Seridó-RN. Revista de Biologia e Ciências da Terra. v.6, n.2, p.232-242, 2006.

SANTOS, M. de. F. de. A. V.; GUERRA, T. N. F.; SOTERO, M. C.; SANTOS, J. I. N. dos. Diversidade e Densidade de Espécies Vegetais da Caatinga com Diferentes Graus de Degradação no Município de Floresta, Pernambuco, Brasil. Rodriguésia, v.60, n.2, p.389402, 2009.

SECTMA-PB. 2006. Solos do Estado da Paraíba. Disponível em: <http://www.aesa.pb.gov.br/perh/relatório_final/Capítulo\%202/pdf/2.11\%20-

\%20CaracSolo.pdf. >. Acesso em: 02/11/2015.

SILVA, A. F.; FERREIRA, R. L. C.; ALVES JUNIOR, F. T.; SILVA, J. A. A.; CÉSPEDES, G. H. G.; SANTOS, M. S. Dinâmica da regeneração natural (2011-2012) de Caatinga, município de Floresta-PE. XIII Jornada de Ensino, Pesquisa e Extensão JEPEX 2013, UFRPE, Recife, p.01-13, 2013.

SILVA, J, A, Fitossociologia e relações alométricas em Caatinga nos estados da Paraíba e Rio Grande do Norte. Tese (Doutorado em Ciência Florestal),Universidade Federal de Viçosa, Viçosa, MG, 93p, 2005. 
SILVA, S. O.; FERREIRA, R. L. C. F.; SILVA, J. A. A.; LIRA, M. A.; ALVES JUNIOR, F. T.; OLIVEIRA CANO, M. O.; TORRES, J. E. L. Regeneração natural em um remanescente de Caatinga com diferentes históricos de uso no Agreste Pernambucano. Revista Árvore, v.36, n.3, p.441-450, 2012.

SOUZA, A. L. Análise de agrupamento aplicada à área florestal. Viçosa: Universidade Federal de Viçosa - UFV, (Apostila ), 87p. 2002.

SOUZA, D. R.; SOUZA, A. L.; GAMA, J. R. V.; LEITE, H. G.. Emprego da análise multivariada para estratificação vertical de florestas inequiâneas. Revista Árvore, v.27, n.1, p.59-63, 2003.

SOUZA, G. F.; MEDEIROS, J. F. Fitossociologia e Florística em áreas de Caatinga na microbacia hidrográfica do Riacho Cajazeiras-RN. GEOTemas, v.3, n.1, p.161-176, 2013.

SOUZA, P. F. de. Estudos fitossociológicos e dendrométricos em um fragmento de Caatinga, São José De Espinharas - PB. Dissertação (Mestrado em Ciências Florestais), Universidade Federal de Campina Grande, UFCG, 99p, 2012.

TÓTHMÉRÉSZ, B. Comparison of different methods for diversity ordering. J. Veg. Sci. v.6, n.2, p.283-290, 1995.

UNIVERSIDADE FEDERAL DE CAMPINA GRANDE - UFCG. Departamento de Ciências Atmosféricas. Precipitação mensal - estado da Paraíba. Disponível em: <http://www.dca.ufcg.edu.br/clima/chuvapb.htm>. Acesso em: 08/06/2014.

VAN DEN BERG, E.; OLIVEIRA - FILHO, A. T. Composição florística e estrutura fitossociológica de uma floresta ripária em Itutinga, MG, e comparação com outras áreas. Revista Brasileira de Botânica, v.23, n.3, p.231-253, 2000.

VELlOSO.; A. L.; SAMPAIO, E. V. S. B.; GIULIETTI, A. R. V.; BARBOSA, M. R. V.; CASTRO, A. A.; J. F.; QUEIROZ, L. P. de.; FERNANDES, A.; OREN, D. C.; CESTARO, L. A.; CARVALHO, A. J. E. de.; PAREYN, F. G. C.; SILVA, F. B. R. da.; MIRANDA, E. E. de.; KEEL, S.; GONDIM, R. S. Ecorregiões, Propostas para o Bioma Caatinga. Instituto de Conservação Ambiental The Nature Conservancy do Brasil, Associação Plantas do Nordeste, 76p, 2002.

VIANA, V. M.; TABANEZ, A. J. A.; MARATINEZ, J. F. A. Restauração e manejo de fragmentos florestais. Revista do Instituto Florestal de São Paulo,v.4, p.400-406, 1992.

VIEIRA, D. L. M.; SCARIOT, A. Principles of Natural Regeneration of Tropical Dry Forest for Restoration. Restoration Ecology, v.14, n.1, p.11-20, 2006.

VILELA, E. A.; OLIVEIRA-FILHO, A. T.; GAVILANES, M. L.; CARVALHO, D. A. Espécies de matas ciliares com potencial para estudos de revegetação no alto rio Grande, Sul de Minas. Revista Árvore, v.17, p.117-128, 1993. 


\section{CAPÍTULO 2}

\section{ESTRUTURA INTERNA E PRODUÇÃO DE BIOMASSA EM TRÊS ÁREAS DE CAATINGA SETENTRIONAL NO ESTADA DA PARAÍBA - BRASIL}

RESUMO - Este estudo teve como objetivo caracterizar a estrutura interna da vegetação de Caatinga arbustivo-arboórea em São José do Bonfim, Itaporanga e Lagoa, no estado da Paraíba - Brasil, pela análise dos parâmetros: densidades de indivíduos e de fustes; vitalidade, qualidade e quantificação de biomassa de fuste. Foi empregada amostragem sistemática com 25 parcelas de $400 \mathrm{~m}^{2}(20 \times 20 \mathrm{~m})$ em malha retangular de $150 \times 150 \mathrm{~m}$ para cada área. Foram medidos todos os indivíduos arbustivos e arbóreos maior que $6 \mathrm{~cm}$ de CAP, sendo avaliado: o número e a altura de bifurcação, a vitalidade e a qualidade de fuste, sendo feita, ainda, a classificação das espécies por categoria de uso. Para a quantificação de biomassa foram cubados 56 fustes, sendo 44 selecionados para o ajuste dos modelos e 12 utilizados para validação das equações selecionadas. Na vegetação de Caatinga de São José do Bonfim e de Lagoa predomina a bifurcação de fuste e para Itaporanga predomina fuste único. Das 14 espécies comuns nas três áreas, dez apresentam o mesmo comportamento em relação à bifurcação, sendo de fuste único Handroanthus impetiginosus, Commiphora leptophloeos, Jatropha molissima, Manihot carthaginensis subsp. Glaziovii e Mimosa ophthalmocentra. Por sua vez, as espécies Combretum leprosum, Erythroxylum Caatinga, Libidibia ferrea, Poincianella pyramidalis e Mimosa tenuiflora apresentaram bifurcação. A vitalidade/sanidade de fustes é baixa em São José do Bonfim e Itaporanga e superior em Lagoa. As três áreas de estudo apresentam distribuição de fustes sem descontinuidade em J Invertido. As espécies de maior densidade de indivíduos e/ou de fustes e de maior gama de categorias de usos são: em São José do Bonfim: Poincianella pyramidalis, Croton blanchetianus, Mimosa tenuiflora, Bauhinia cheilantha, Aspidosperma pyrifolium, Combretum leprosum e Mimosa ophthalmocentra; em Itaporanga: Croton blanchetianus, Myracrodruon urundeuva, Amburana cearenses, Poincianella pyramidalis, Combretum leprosum, Mimosa ophthalmocentra, Annona leptopetala, Callisthene minor e Sigmatanthus trifoliatus; e em Lagoa: Croton blanchetianus, Peltogyne pauciflora, Aspidosperma riedelii, Gymnanthes boticario, Myrciaria floribunda, Luehea ochrophylla, Senegalia polyphylla, Eugenia stictopetala, Croton nepetifolius, Erythroxylum nummularia, Maytenus erythroxyla, Eugenia flavescens, Helicteres heptandra, Senna macranthera e Croton heliotropiifolius. A vegetação de Lagoa é a de maior produção de biomassa e de melhor relação desta com a vitalidade/qualidade de fustes.

Palavras-chave: Sanidade de fustes, qualidade de fustes, bifurcação de plantas e modelos matemáticos.

\section{INTERNAL STRUCTURE AND BIOMASS PRODUCTION IN THREE AREAS OF NORTHERN CAATINGA IN PARAIBA STATE - BRAZIL}

ABSTRACT - This study aimed to characterize the internal structure of the shrub-tree Caatinga vegetation in São José do Bonfim, Itaporanga and Lagoa, in Paraiba state Brazil, through the analysis of the following parameters: density of individuals and stems; vitality, quality and stem biomass quantification. A systematic sampling with 25 plots of $400 \mathrm{~m}^{2}(20 \times 20 \mathrm{~m})$ in rectangular mesh of $150 \times 150 \mathrm{~m}$ was employed for each area. All the arboreal and shrub individuals superior to $6 \mathrm{~cm}$ of CAP were measured. In addition, the 
number and bifurcation height, the vitality and stem quality were evaluated and the classification of species per category of use was also made. As to the biomass quantification, 56 stems were cubed, of which 44 were selected to the models adjustment and 12 were used in order to validate the selected equations. Stem bifurcation predominates in the Caatinga vegetation of São José do Bonfim and Lagoa, whereas single stem predominates in Itaporanga. Out of 14 common species in the three areas, ten present the same behavior regarding bifurcation, that is, single stem: Handroanthus impetiginosus, Commiphora leptophloeos, Jatropha molissima, Manihot carthaginensis subspecies. Glaziovii and Mimosa ophthalmocentra. In turn, the species Combretum leprosum, Erythroxylum Caatinga, Libidibia ferrea, Poincianella pyramidalis and Mimosa tenuiflora exhibit bifurcation. Stem vitality/health is low in São José do Bonfim and Itaporanga and high in Lagoa. The three study areas display stem distribution without discontinuity in inverted J. The following species exhibit higher density of individuals and/or stems and a wider range of uses categories: in São José do Bonfim: Poincianella pyramidalis, Croton blanchetianus, Mimosa tenuiflora, Bauhinia cheilantha, Aspidosperma pyrifolium, Combretum leprosum and Mimosa ophthalmocentra; in Itaporanga: Croton blanchetianus, Myracrodruon urundeuva, Amburana cearenses, Poincianella pyramidalis, Combretum leprosum, Mimosa ophthalmocentra, Annona leptopetala, Callisthene minor and Sigmatanthus trifoliatus; and in Lagoa: Croton blanchetianus, Peltogyne pauciflora, Aspidosperma riedelii, Gymnanthes boticario, Myrciaria floribunda, Luehea ochrophylla, Senegalia polyphylla, Eugenia stictopetala, Croton nepetifolius, Erythroxylum nummularia, Maytenus erythroxyla, Eugenia flavescens, Helicteres heptandra, Senna macranthera and Croton heliotropiifolius. The vegetation pertaining to Lagoa presents a greater biomass production as well as better relation between stems vitality/quality.

Key words: Stems health, stems quality, plants bifurcation and mathematical models. 


\subsection{INTRODUÇÃO}

A exploração desordenada da vegetação para produção de energia tem determinado a perda da diversidade dos recursos florestais, o aumento da erosão, e a diminuição da fertilidade do solo e da qualidade da água pela sedimentação. Tem gerado ainda modificações na paisagem e na estrutura das fitofisionomias arbustivo-arbóreas deste bioma (DRUMOND et al., 2000; FIGUEIRÔA et al., 2008).

A vegetação da Caatinga é utilizada para a produção de energia, construções doméstica e rurais, alimentação humana, forragem para rebanhos, dentre outro usos (LIMA et al., 2016; GUERRA et al., 2015; RIBEIRO et al., 2014; SILVA et al., 2014; CARVALHO et al., 2012; ROQUE et al., 2010). Ela é sendo considerada crucial para a sobrevivência das populações humanas no semiárido nordestino (ARAÚJO et al., 2010). No entanto, vem sendo observado uma redução significativa da cobertura vegetal no referido bioma, ocasionada pela demanda de utilização das espécies nativas (FIGUEIRÔA et al., 2008), tornando-se um bioma ameaçado, sendo as principais causas o consumo da biomassa florestal, e a expansão agrícola/pecuária (DRUMOND et al., 2000).

Esses problemas podem ser encontrados, por exemplo, no estado da Paraíba, causados principalmente pelo desmatamento da vegetação para a extração principalmente da lenha, bem como práticas de pecuária bovina e da agricultura, (ANDRADE et al., 2005; MONTEIRO, 1995). Dois terços da sua área territorial correspondem ao bioma Caatinga (ALVES et al., 2008), dos quais apenas 53,69\% da vegetação pode ser considerada remanescente (MMA, 2010).

Estudos de natureza fitossociológica com ênfase na florística e na estrutura da floresta representam a fase inicial no conhecimento de povoamentos nativos, podendo-se construir uma base teórica que subsidie a conservação da vegetação, a preservação de áreas nativas e a recuperação de ambientes florestais degradados, contribuindo substancialmente para a utilização sustentável da vegetação.

Diante do exposto, este estudo teve como objetivos caracterizar as densidades de indivíduos e fustes presentes no estrato superior arbustivo-arbóreo, analisar a estrutura interna dos fustes através das estimativas de vitalidade e qualidade, analisar a estrutura paramétrica bem como ajustar e selecionar modelos matemáticos para quantificar a biomassa total de fuste, em três áreas de vegetação de Caatinga em gradiente altitudinal nos municípios de São José do Bonfim, Itaporanga e Lagoa, no estado da Paraíba - Brasil. 


\subsection{MATERIAL E MÉTODOS}

\subsection{1. Áreas de estudo}

Este estudo foi feito em três áreas de vegetação de Caatinga arbustivo-arbórea na região semiárida do estado da Paraíba, localizadas nos municípios de São José do Bonfim, Itaporanga e Lagoa conforme descrito no item 1.2.1 do Capítulo 1.

\subsubsection{Coleta de Dados}

Mediante inventário florestal por amostragem sistemática foram estabelecidas 25 parcelas de $400 \mathrm{~m}^{2}(20 \times 20 \mathrm{~m})$ distribuídas sistematicamente em uma malha retangular de $150 \times 150 \mathrm{~m}$ em que foram inventariados os indivíduos de espécies arbustivas e arbóreas com circunferência a $1,30 \mathrm{~m}$ de altura (CAP) maiores que $6 \mathrm{~cm}$. Foram tomadas as medidas de CAP, de circunferência a $0,30 \mathrm{~m}$ de altura do solo (CAB), a altura total, a identificação botânica das espécies e as classificações de número e altura de bifurcações, vitalidade e qualidade de fustes. Estas avaliações permitem inferir sobre a estrutura interna das vegetações estudadas e foram adaptadas das recomendações do protocolo de medições de parcelas permanentes da Rede de Manejo Florestal da Caatinga (RMFC, 2005).

A análise da estrutura interna da floresta reflete na classificação da qualidade e da vitalidade dos fustes presentes no ambiente florestal. Estes são parâmetros que caracterizam estimativas econômicas da floresta (SOUZA et al., 1999).

\subsubsection{Estrutura interna: Bifurcação, vitalidade e qualidade de fuste}

Para determinação de potencial de usos de fustes é importante considerar os parâmetros quantitativo, como o número de bifurcações, e qualitativo, como a vitalidade e qualidade de fuste (RMFC, 2005). Assim, neste estudo foram quantificados e caracterizados os fustes abrangidos pela classe de inclusão descrita no item 2.2 deste capítulo, sendo: Número e altura de bifurcação de fuste; Vitalidade de fuste (Sadio = V 1; Danificado $=$ V 2; e Morto $=$ V 3); Qualidade de fuste considerando o comprimento de até 2,5 $\mathrm{m}($ Reto $=\mathrm{Q} 1 ;$ Levemente torto $=\mathrm{Q} 2$ e Tortuoso $=\mathrm{Q} 3)$. 


\subsubsection{Estrutura paramétrica}

Estimativas paramétricas foram caracterizadas por meio da distribuição das espécies por área de estudo, por número de fustes, por classes diamétricas, por classes de altura de bifurcação e por distribuição de biomassa.

O número de fustes encontrados nessa análise vai diferir, naturalmente, das estimativas do parâmetro densidade de indivíduos, em que todos os fustes pertencentes a um mesmo sistema radicular foram considerados como sendo de um único indivíduo. $\mathrm{Na}$ execução da distribuição dos fustes em classes diamétricas, cada circunferência tomada a CAB foi transformada e agrupada em classes de diâmetro, considerando uma amplitude de $5 \mathrm{~cm}$ entre uma e outra classe.

\subsubsection{Grupos de usos}

A condução dos estudos sobre o potencial de usos dos recursos lenhosos locais, foi efetuada pela observação direta através do contato com proprietários rurais, artesãos, carpinteiros, comerciantes de produtos florestais, profissionais da extensão rural e de recursos florestais na Paraíba, associado às informações obtidas da literatura especializada em Lima et al. (2016), Guerra et al. (2015), Ribeiro et al. (2014), Silva et al. (2014), Carvalho et al. (2012), Ferraz (2011), Roque et al. (2010), Gomes et al. (2008), Lucena et al. (2008), Trovão et al. (2004), Barreiros et al. (2003), Almeida; Albuquerque (2002), Albuquerque; Andrade (2002), Fonseca-Kruel et al. (2006), Galeano (2000). Todo esse aparato teórico nos permitiu categorizar os tipos de uso para este estudo conforme descrito na tabela 1 . 
Tabela 1. Categorias e respectivos tipos de usos utilizados para avaliação das espécies arbustivas e arbóreas de ocorrência nas áreas de São José do Bonfim, Itaporanga e Lagoa, no estado da Paraíba - Brasil.

\begin{tabular}{cl}
\hline Categorias de usos & \multicolumn{1}{c}{ Tipos de usos } \\
\hline Alimentação humana & Alimentação humana \\
\hline Construções domésticas & $\begin{array}{l}\text { Tábua/madeira serrada, vigas/traves de construção, vara para armação de casa } \\
\text { de taipa, caibros e ripas }\end{array}$ \\
\hline Construções rurais & Cerca de faxina, mourão e estaca de cerca \\
\hline Energia & Lenha e carvão \\
\hline Forragem & Alimentação de animais domésticos e alimentação animais silvestres \\
\hline Medicinais & $\begin{array}{l}\text { Desordens respiratórias, transtornos do sistema digestivo, cicatrizantes, } \\
\text { pressão alta, antiabortivo, doenças ginecológicas e anti-hemorrágico }\end{array}$ \\
\hline $\begin{array}{c}\text { Outros usos não } \\
\text { madeireiros }\end{array}$ & Extrativos, ornamentação e místico/religioso \\
\hline Venenosas & Veneno-abortivo, venenosas \\
\hline Tecnologia & $\begin{array}{l}\text { Móveis, carroça/carro-de-boi, artesanato, cabos de ferramentas e implementos } \\
\text { agrícolas }\end{array}$ \\
\hline Veterinária & Cura de doenças de animais \\
\hline
\end{tabular}

\subsubsection{Quantificação de biomassa}

Para a quantificação da biomassa aérea de fuste, foram cubados 56 fustes, sendo 44 fustes selecionados para o ajuste dos modelos e 12 fustes utilizados para validação das equações selecionadas. Foram escolhidas as espécies que apresentaram os maiores índices de valor de importância (IVI\%) para cada área de estudo. Foi estabelecida amplitude de $15,71 \mathrm{~cm}$ entre classes de $\mathrm{CAB}$ o que proporcionou a identificação de 7 classes, utilizadas neste estudo.

Foi obtido o peso verde de cada fuste com o auxílio de balança eletrônica com precisão de $0,05 \mathrm{~kg}$. Após a obtenção deste, foram retirados 3 discos de madeira, com $5 \mathrm{~cm}$ de espessura, coletados na base, no meio e no ápice dos fustes, sendo pesados em balança analítica de precisão de 0,01 g. As amostras foram levadas ao Laboratório de Energia do Setor de Tecnologia de Produtos Florestais da Universidade Federal de Campina Grande (UFCG/CSTR/UAEF), colocadas em estufa para secagem a uma temperatura de $103 \pm 2^{\circ} \mathrm{C}$ conforme Baraúna; Oliveira (2009), até à obtenção da massa constante (variação de 1\%). Após secagem, cada amostra foi pesada novamente para obtenção do respectivo peso seco.

A partir dos valores de peso úmido e peso seco de cada amostra, foi estimada a porcentagem de biomassa seca por meio de um coeficiente da relação (Equação 1), para cada fuste. Desta forma, foi possível estimar a biomassa seca a partir do produto entre o 
coeficiente da relação e a biomassa verde obtida em campo para cada fuste conforme Barbosa; Ferreira (2004).

$$
\mathrm{C}_{\mathrm{R}}=\frac{\mathrm{M}_{0} \%}{\mathrm{M}_{\mathrm{U}}}
$$

Em que: $\mathrm{CR}=$ Coeficiente da relação; $\mathrm{M}_{0} \%=$ peso seco da amostra em gramas; $\mathrm{M}_{\mathrm{U}}=$ peso verde da amostra em gramas.

Para a seleção modelos matemáticos para estimativa do estoque de biomassa seca de fuste foram testados seis modelos, lineares e não lineares, de acordo com Campos; Leite (2006; 2009), Rezende et al. (2006) e Sanqueta et al. (2001). Como variáveis independentes foram utilizadas: $\mathrm{CAB}_{(0,30 \mathrm{~m})}$ e altura total $\left(\mathrm{Ht}_{(\mathrm{m})}\right)$, com suas múltiplas combinações (Tabela 2).

Para a seleção do melhor modelo ajustado para a estimativa dos estoques em biomassa seca, foram adotados os critérios tradicionais utilizados na verificação da qualidade do ajuste, sendo: Coeficiente de determinação ajustado $\left(R^{2}{ }_{\text {aj }}\right)$, erro padrão da estimativa em percentagem (Syx \%) conforme Miranda et al. (2011); Rezende et al. (2006).

Tabela 2. Modelos matemáticos a serem ajustados para estimativa da biomassa seca da vegetação lenhosa de Caatinga arbustivo-arbórea nas áreas de São José do Bonfim, Itaporanga e Lagoa, no estado da Paraíba - Brasil.

\begin{tabular}{ccl}
\hline Equação & Autor & \multicolumn{1}{c}{ Modelo } \\
\hline 1 & Schumacher e Hall & $\mathrm{Y}=\beta_{0} \cdot \mathrm{CAB}^{\beta 1} \cdot \mathrm{Ht}^{\beta_{2} \cdot \varepsilon}$ \\
\hline 2 & Husch & $\mathrm{Y}=\beta_{0} \cdot \mathrm{CAB}^{\beta 1} \cdot \varepsilon$ \\
\hline 3 & Rezende et al. $(2006)$ & $\mathrm{Y}=\beta_{1} \cdot \mathrm{CAB}^{2}+\beta_{2} \cdot \mathrm{CAB}^{3}+\beta_{3} \cdot \mathrm{Ht}^{2}+\mathrm{B}_{4} \cdot \mathrm{CAB} \cdot \mathrm{Ht}+\varepsilon$ \\
\hline 4 & Meyer & $\mathrm{Y}=\beta_{0}+\beta_{1} \cdot \mathrm{CAB}+\beta_{2} \cdot \mathrm{CAB}^{2}+\beta_{3} \cdot \mathrm{Ht}+\beta_{4} \cdot \mathrm{CAB} \cdot \mathrm{Ht}+\varepsilon$ \\
\hline 5 & Stoate & $\mathrm{Y}=\beta_{0}+\beta_{1} \cdot \mathrm{CAB}^{2}+\beta_{2} \cdot \mathrm{Ht}^{2}+\beta_{3} \cdot \mathrm{CAB}{ }^{2} \cdot \mathrm{Ht}+\varepsilon$ \\
\hline 6 & Sanquetta et al. $(2001)$ & $\mathrm{Y}=\beta_{0}+\beta_{1} \cdot \mathrm{CAB}^{2}+\beta_{2} \cdot \mathrm{CAB}^{2} \cdot \mathrm{Ht}$ \\
\hline
\end{tabular}

Em que: $\mathrm{Y}=$ Biomassa seca $(\mathrm{kg}) ; \mathrm{Ht}=$ Altura total $(\mathrm{m}) ; \mathrm{CAB}=$ Circunferência $(\mathrm{cm})$ a $0,3 \mathrm{~m}$ do solo na altura da base; $\beta_{0}, \beta_{1}$ e $\beta_{2}=$ Coeficientes a serem ajustados; $\varepsilon=$ Erro associado ao modelo.

Após a seleção das equações para cada variável de interesse, procedeu-se o teste de validação, com o objetivo de avaliar a eficiência do valor estimado da variável biomassa de 
fuste. Para a realização deste teste foram utilizados 12 fustes amostrados e não utilizadas no ajuste das equações. O teste escolhido para a validação dos resultados foi o Teste de $\mathrm{t}$ para dados pareados conforme Rocha (2011).

A partir do modelo selecionado com os melhores ajustes, foram estimados os estoques de biomassa de cada fuste amostrado nas 75 parcelas do inventário florestal nas áreas de São José do Bonfim, Itaporanga e Lagoa em tonelada por hectare (t.ha ${ }^{-1}$ ) e para a comunidade total em tonelada (t). Foi utilizado o processo de amostragem sistemática com parcelas em estágio único, usando-se a fórmula da amostragem aleatória simples para a estimativa da variância da média, de acordo com Péllico Neto; Brena (1997).

As análises dos dados do inventário florestal foram realizadas utilizando o software Mata Nativa 2.0 (CIENTEC, 2006), e as análises dos modelos matemáticos utilizando o software STATISTICA 7.1 (STAT SOFT, 2005). 


\subsection{RESULTADOS E DISCUSSÃO}

\subsubsection{Bifurcação, vitalidade e qualidade de fuste}

Em relação ao comportamento de fuste quanto à bifurcação foram observados: em São José do Bonfim - 37,29\% de indivíduos com fuste único, 19,03\% com dois fustes, $10,32 \%$ com três fustes e 33,36\% com quatro ou mais fustes; Itaporanga - 51,56\% de indivíduos com fuste único, 20,23\% com dois fustes, 8,33\% com três fustes e 19,88\% com quatro ou mais fustes; e Lagoa - 47,77\% de indivíduos com fuste único, 18,98\% com dois fustes, $11,44 \%$ com três fustes e $21,82 \%$ com quatro ou mais fustes (Tabela 3).

Das 14 espécies comuns nas três áreas, 10 apresentam predominantemente o mesmo comportamento em relação a bifurcação sendo: Fuste único - Handroanthus impetiginosus, Commiphora leptophloeos, Jatropha molissima, Manihot carthaginensis subsp. Glaziovii e Mimosa ophthalmocentra; Bifurcadas - Combretum leprosum, Erythroxylum Caatinga, Libidibia ferrea, Poincianella pyramidalis e Mimosa tenuiflora. As demais espécies comuns Cynophalla hastata, Croton blanchetianus, Bauhinia cheilantha e Senna macranthera apresentaram padrões diferentes quanto a bifurcação de fustes nas áreas.

Para as três áreas as espécies que apresentaram apenas indivíduos com fuste único são todas de baixa densidade de indivíduos. Sobre estas espécies então não se pode afirmar com maior segurança se este é ou não seu comportamento predominante.

Tabela 3. Densidades de indivíduos e de fustes da vegetação de Caatinga arbustivoarbórea para as áreas de São José do Bonfim, Itaporanga e Lagoa, no estado da Paraíba Brasil.

\begin{tabular}{cccc}
\hline Parâmetro & São José do Bonfim & Itaporanga & Lagoa \\
\hline $\mathrm{N}^{\mathbf{o}}$ Indivíduos totais e $\mathrm{n}^{\circ}$ espécies totais & 3.400 e 20 & 3.076 e 70 & 3.134 e 68 \\
$\mathrm{~N}^{\mathbf{o}}$ Indivíduos mortos & 282 & 229 & 77 \\
\hline Característica de Fuste & \multicolumn{3}{c}{$\mathbf{N}^{\mathbf{0}}$ Fuste / $\mathbf{N}^{\mathbf{0}}$ Espécies } \\
\hline Fuste único & $2113 / 20$ & $2192 / 67$ & $2255 / 66$ \\
Dois fustes & $1078 / 11$ & $860 / 47$ & $896 / 44$ \\
Três fustes & $585 / 13$ & $354 / 25$ & $540 / 26$ \\
Quatro ou mais fustes & $1890 / 10$ & $845 / 29$ & $1030 / 29$ \\
\hline Total & $5666 / 20$ & $4251 / 70$ & $4721 / 68$ \\
\hline
\end{tabular}


O resultado das relações de Fuste/Vitalidade/Sanidade para as áreas de estudo é apresentado na figura 1.

Foram consideradas neste estudo Fustes V 1/ Q 1 como de excelente qualidade e Fustes V 1/ Q 2 como de boa qualidade. Assim, para as áreas obtivemos: São José do Bonfim - 28,15\% de fuste de excelente ou de boa qualidade (V 1 / Q 1 e V 1 / Q 2), cujas principais espécies neste grupo foram Anadenanthera colubrina, Poincianella pyramidalis, Mimosa ophthalmocentra, Mimosa tenuiflora, Croton blanchetianus, Bauhinia cheilantha e Aspidosperma pyrifolium; Itaporanga - 26,63\% de fustes de excelente ou de boa qualidade (V 1 / Q 1 e V 1 / Q 2), sendo as principais espécies neste grupo Myracrodruon urundeuva, Poincianella pyramidalis, Mimosa tenuiflora, Manihot carthaginensis, Croton blanchetianus e Combretum leprosum; e Lagoa - 32,90\% de fustes de excelente ou de boa qualidade (V 1 / Q 1 ou V 1/ Q 2), sendo as principais espécies Croton blanchetianus, Peltogyne pauciflora, Aspidosperma riedelii, Myrciaria floribunda, Luehea ochrophylla, Senegalia polyphylla, Eugenia stictopetala e Eugenia flavescens.

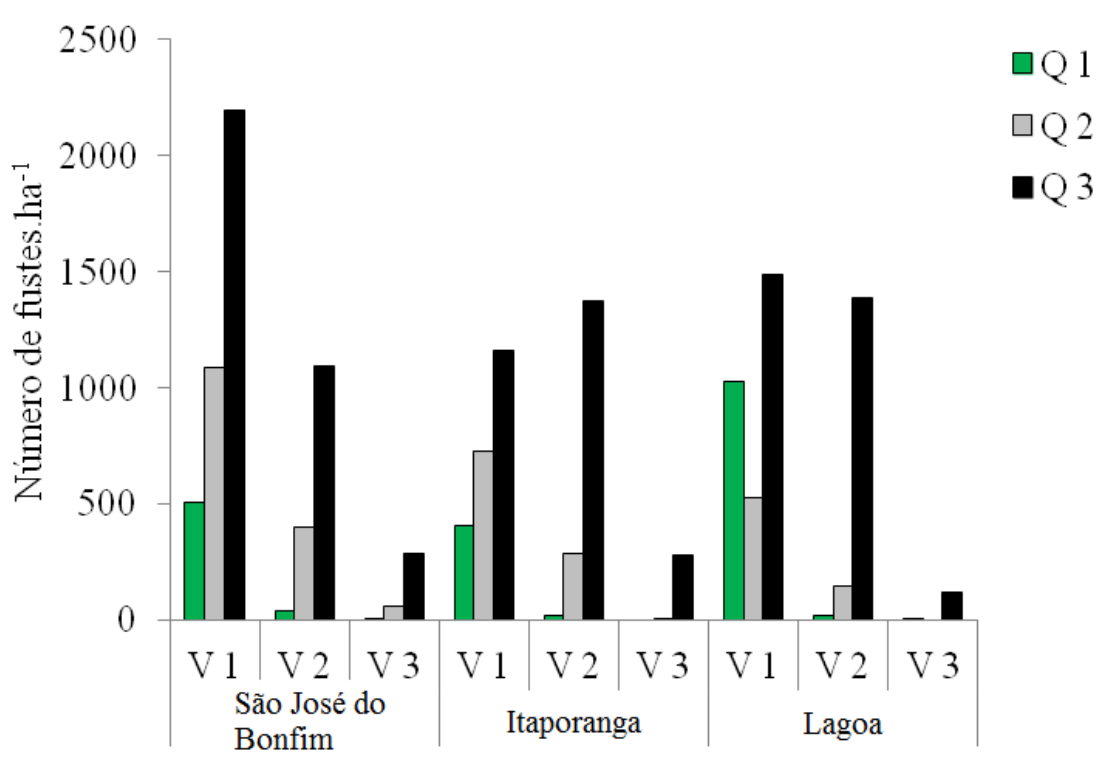

Figura 1. Distribuição do número de fustes.ha ${ }^{-1}$ para as classes de vitalidade e de qualidade de fuste em vegetação de Caatinga arbustivo-arbórea, para as áreas de São José do Bonfim, Itaporanga e Lagoa, no estado da Paraíba - Brasil. Em que: para sanidade de fuste V 1 = Sadio, V 2 = Danificado e V 3 = Morto; para qualidade de fuste Q 1 = Reto, Q 2 = Levemente torto e Q 3 = Tortuoso. 
Em estudo realizado por Souza et al. (2016) em vegetação de Caatinga arbustivoarbórea no município de São José de Espinharas-PB, foi observado baixo potencial de utilização das espécies arbustivas e arbóreas para fins mais nobres como móveis e madeira para serraria. Isto é devido tanto às características de Vitalidade (danificado e morto) como de Qualidade (tortuosidade), como observado nas áreas de São José do Bonfim e Itaporanga. Resultados contrários foram encontrados em um estudo desenvolvido em uma vegetação de transição Cerrado-Caatinga no município de Bom Jesus-PI, Oliveira et al. (2012) constataram que 79,99\% dos indivíduos amostrados apresentaram fuste retilíneo, e apenas $15,2 \%$ apresentaram tortuosidade.

Segundo Campello et al. (2000), a lenha se destaca como o principal produto, uma vez que $35 \%$ do seu parque industrial têm a lenha como sua fonte de energia primária, além de atender a $70 \%$ da demanda energética dos domicílios presentes na região. Para este uso, as diferentes classes de vitalidade e qualidade apresentam maior ou menor potencial de uso, mas todos podem ser utilizados para este fim. No entanto fustes de melhor vitalidade e qualidade, como os classificados como V 1/ Q 1 e V 1/ Q 1/Q 2 conforme utilizado no presente estudo, a princípio, podem ser direcionados para maior gama de usos e melhor aproveitamento econômico, em especial quando destinados para a construção civil conforme apresentado pela APNE (2015).

Neste contexto, a vegetação de Caatinga vem sendo explorada, em parte, de forma predatória, porque outras formas de uso e ocupação da terra representam maior potencial econômico do que o uso desta vegetação para a produção de lenha (BARBOSA et al., 2012). Assim, identificar potenciais mais atrativos pode representar maior possibilidade de uso sustentável da vegetação possibilitando a conservação da mesma (FERREIRA et al., 2011; THAINES et al., 2010).

\subsubsection{Estrutura paramétrica}

Em florestas naturais a distribuição diamétrica normalmente apresenta distribuição em J Invertido, indicando equilíbrio na dinâmica da estrutura que representa $o$ desenvolvimento do processo de sucessão natural e, por conseguinte, a perpetuação da mesma. Nesta análise considera-se que as calasses diamétricas menores resguardam a regeneração natural das subsequentes e, assim, a distribuição de forma contínua numa floresta indica a autorregeneração (MACHADO et al., 2009; RANGEL et al., 2006); ASSMANN, 1970). 
Para a Caatinga arbustiva-arbórea, a bifurcação é uma característica presente para grande parte das espécies, assim como ocorreu nas três áreas aqui estudas, segundo está descrito no item 2.3.1 deste capítulo. Desta forma, neste trabalho, foi considerada a densidade de fuste para a avaliação de distribuição diamétrica da vegetação das áreas de estudo (Figura 2).

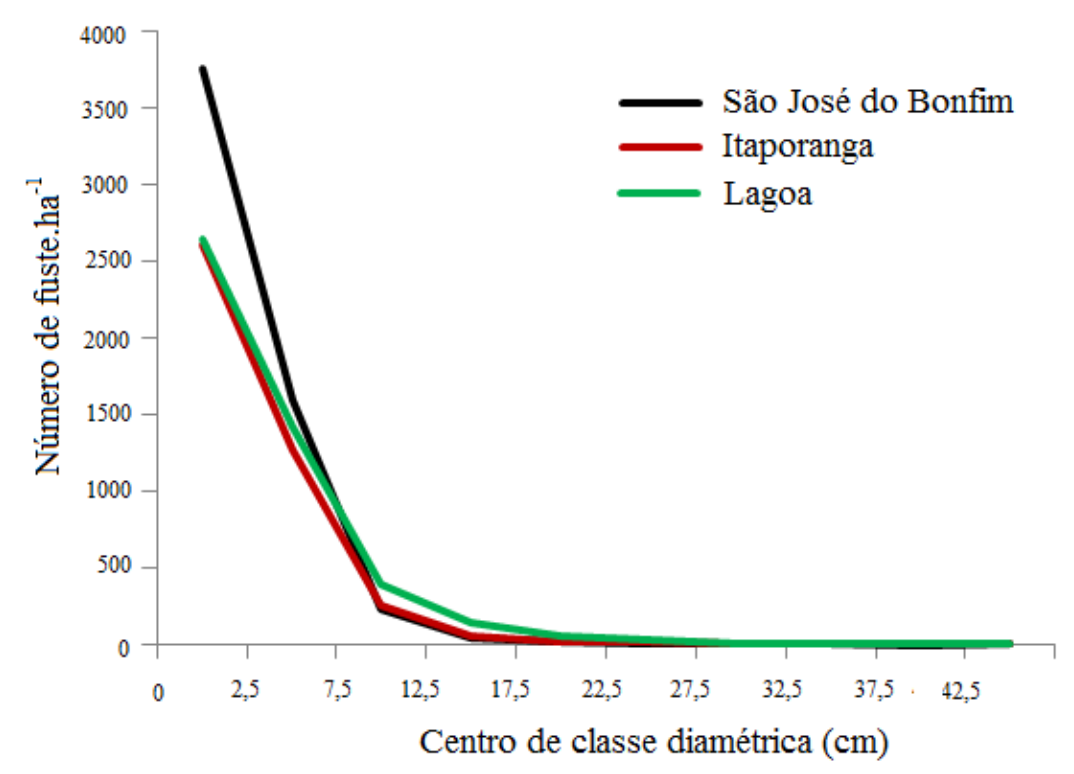

Figura 2. Distribuição diamétrica de fustes para a vegetação de Caatinga arbustivoarbórea para as áreas de São José do Bonfim, Itaporanga e Lagoa, no estado da Paraíba Brasil.

Mesmo tendo sido observados diferentes comportamentos significativos em riqueza, composição florística e parâmetros fitossociológicos, conforme abordado no capítulo 1, as três áreas apresentam distribuição de número de fustes em classes diamétricas, sem descontinuidade em J Invertido, indicando equilíbrio e a boa capacidade de autorregenerarão das mesmas. Resultados semelhantes foram observados também em outras áreas de Caatinga estudadas por Lemos; Meguro (2015), em estudo fitossociológico de uma área de Caatinga na Estação Ecológica de Aiuaba, Ceará, e por Costa et al. (2009) ao analisar 16 fragmentos de vegetação de Caatinga na região do Seridó nos estados do Rio Grande do Norte e Paraíba.

$\mathrm{Na}$ primeira classe de diâmetro de fustes $(0-5 \mathrm{~cm})$ devido à classe de inclusão adotada de $6 \mathrm{~cm}$ de CAP, conforme RMFC (2005), correspondente a 1,90 cm de DAP, 
parte do indivíduos desta não foram inventariados fazendo com que esta não seja uma classe completa. Quando considerada a dominância absoluta de fustes a partir da segunda classe de diâmetro de fuste $(5,1-10 \mathrm{~cm})$, é observada a distribuição em J Invertido para as três áreas estudadas.

As três áreas de estudo, e em destaque a de Lagoa, apresentam distribuição de dominância de fustes que reforça os aspectos anteriores referentes ao potencial de aproveitamento de fustes para todas as categorias de uso observados e discutidos no item 2.3.3 deste capítulo (Figura3).

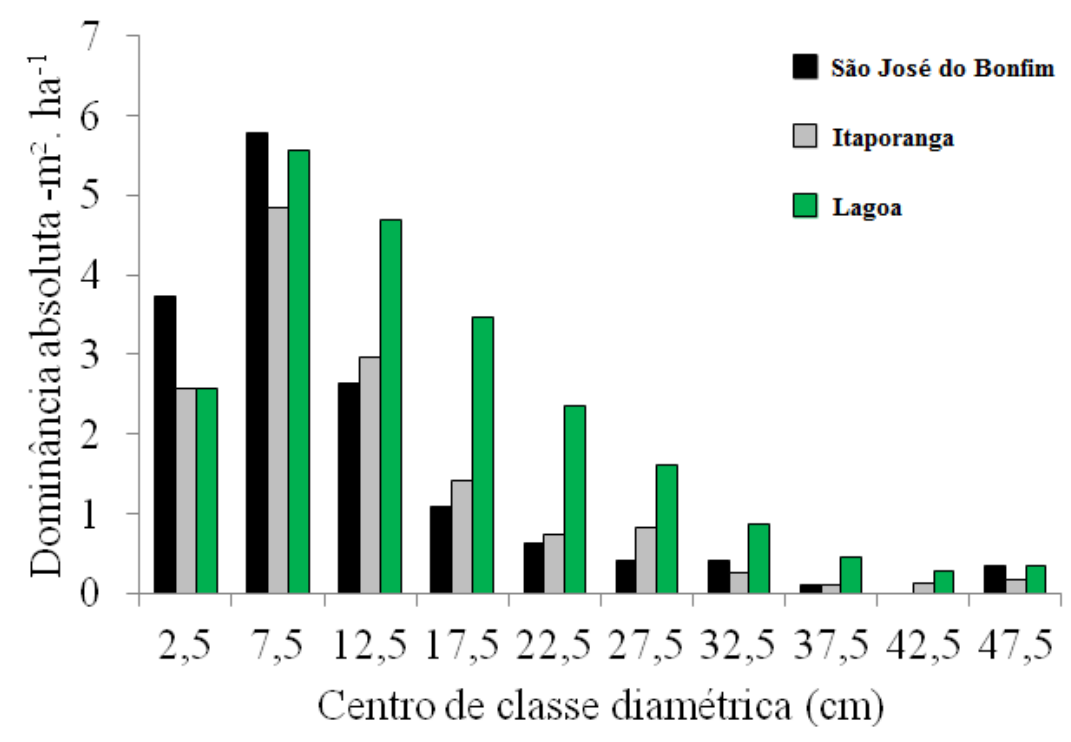

Figura 3. Distribuição da dominância absoluta $\left(\mathrm{m}^{2} \cdot h \mathrm{a}^{-1}\right)$ em classes diamétricas para a vegetação de Caatinga arbustivo-arbórea para as áreas de São José do Bonfim, Itaporanga e Lagoa, no estado da Paraíba - Brasil.

Para a Caatinga, estudos como este e os de Souza et al. (2016) na Paraíba, de Almeida Neto et al. (2009) também na Paraíba e de Santana; Souto (2006) no Rio Grande do Norte, devem ser intensificados pois permitem melhor inferência sobre riscos e oportunidades de uso para a vegetação das áreas.

O comprimento de seção e o diâmetro de fustes são parãmetros, dentre outros, importantes para a defição de uso e valoração da madeira para diversos fins, como para estacas e mourões de cerca, escoramento, táboas e ripas etc.. Assim, neste estudo, para 
cada área foi reaizada a avaliação de altura de bifurcação e diâmetro, cujos resultados são apresentados na tabela 4.

Tabela 4. Comportamento de fustes em relação a comprimento de seção e diâmetro de fustes da vegetação de Caatinga arbustivo-arbórea para as áreas de São José do Bonfim, Itaporanga e Lagoa, no estado da Paraíba - Brasil.

\begin{tabular}{c|c|c|c}
\hline $\begin{array}{c}\text { Características Tecnológicas } \\
\text { de Fustes }\end{array}$ & São José do Bonfim & Itaporanga & Lagoa \\
\hline Altura média de Bifurcação & $2,20 \mathrm{~m}$ & $2,50 \mathrm{~m}$ & $2,51 \mathrm{~m}$ \\
\hline $\begin{array}{c}\text { Sem Bifurcação ou } \\
\text { Bifurcação acima de 2,50 m }\end{array}$ & $41,10 \%$ & $51,63 \%$ & $47,45 \%$ \\
\hline Diâmetro > 10 cm & $5,54 \%$ & $8,49 \%$ & $13,87 \%$ \\
\hline
\end{tabular}

A análise da estrutura diamétrica, de acordo com Ubialli et al. (2009), permite avaliar o comportamento de uma vegetação florestal por meio de classes de diâmetro, podendo ser uma ferramenta utilizada para compreender o crescimento de uma floresta (PAULA et al., 2004). Siminski et al. (2004), afirmaram que ela permite a avaliação prévia de condições dinâmicas da floresta, possibilitando previsões quanto ao crescimento da comunidade florestal.

Para as áreas deste estudo, considerando fustes com comprimento de seção acima de $2,50 \mathrm{~m}$ e diâmetro a partir de $10 \mathrm{~cm}$, é observado potencial de aproveitamento destes para todas as categorias de uso descritos na tabela 1; observando as demais propriedades tecnológicas exigidas para cada uso. Da mesma forma, os fustes que apresentam altura de bifurcação igual ou superior a 2,50 m e que estão nas classes de diâmetricas inferiores a $10 \mathrm{~cm}$ constituem grande potencial de estoque regenerante pré-comercial a ser considerado em futuras análises de manejo para as três áreas de estudo (Figura 4).

Por apresentar muitas espécies com indivíduos bifurcados, sejam com 2, 3, e 4 ou mais fustes, é importante para o manejo, utilizar a densidade de fustes e sua distribuição diamétrica por espécie e por indivíduo como guia de exploração. Assim, o manejo pode ser feito com maior pressão sobre as espécies e indivíduos que naturalmente apresentam maior densidade de indivíduos e fustes, diminuindo a pressão sobre espécies localmente raras e, ou com baixa densidade de fustes, como alternativa para uso sustentável da vegetação de Caatinga. Tal fato pode ser observado em 14 das 20 espécies em São José do Bonfim, em 53 das 70 espécies de Itaporanga e em 53 de 68 espécies da área de Lagoa apresentam indivíduos bifurcados. 

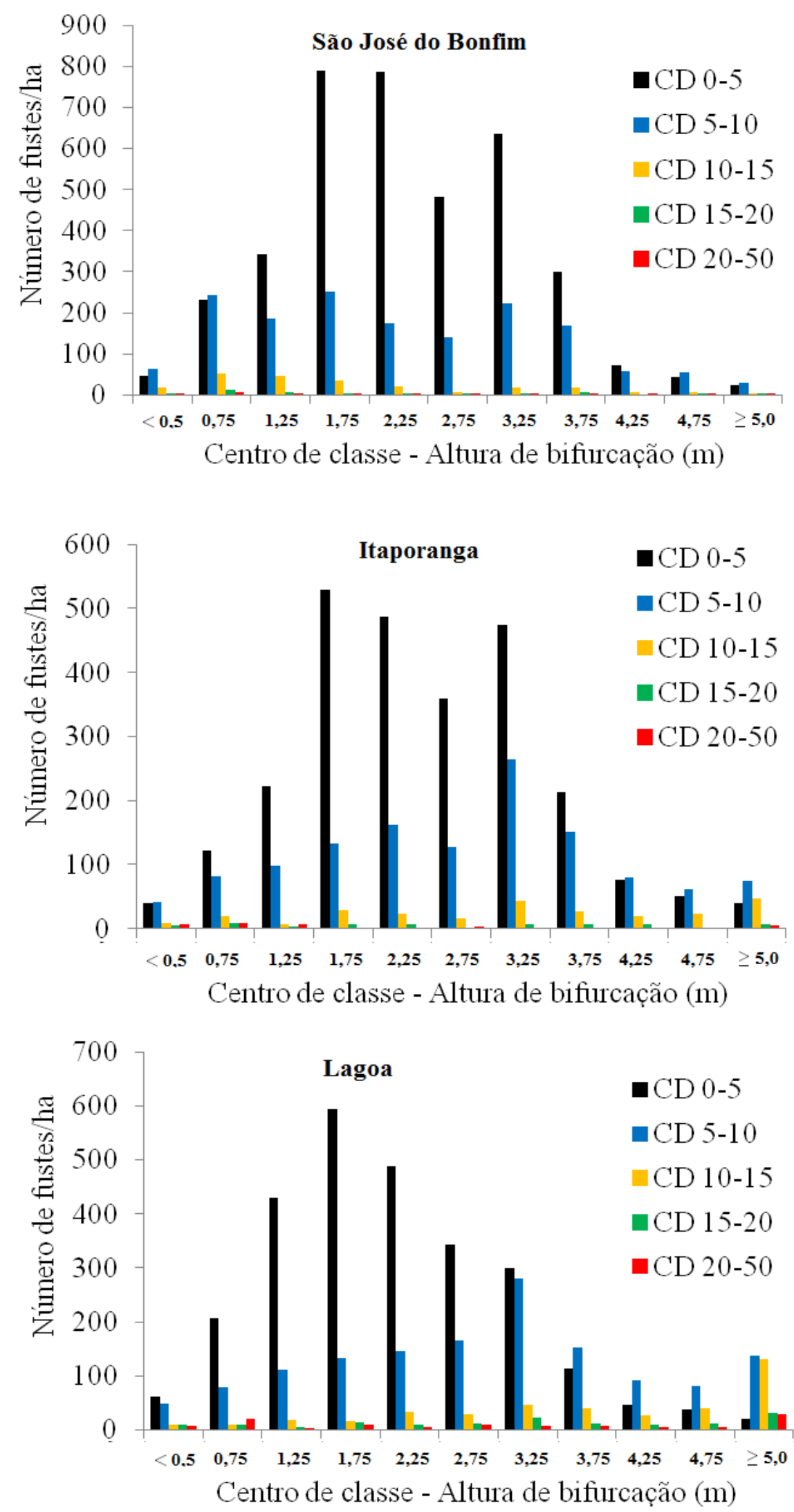

Figura 4. Distribuição do número de fustes com comprimento de seção acima de $2,50 \mathrm{~m}$ por classe diamétrica para as áreas de São José do Bonfim, Itaporanga e Lagoa, no estado da Paraíba - Brasil. Em que: $\mathrm{CD}=$ classe diamétrica $(\mathrm{cm})$. 


\subsubsection{Categorias de uso de espécies}

A identificação de categorias de uso para as espécies ocorrentes das áreas de estudo são apresentadas nas tabelas 5, 6 e 7 .

$\mathrm{Na}$ área de São José do Bonfim as espécies Poincianella pyramidalis, Croton blanchetianus, Mimosa tenuiflora, Bauhinia cheilantha, Aspidosperma pyrifolium, Combretum leprosum e Mimosa ophthalmocentra estão entre as que apresentam maior densidade de indivíduos e, ou de fustes e também apresentam as maiores gamas de categorias de usos, destacando-se em potencial: como tábua/madeira serrada, vigas/traves de construção, vara para armação de casa de taipa, caibros e ripas, cerca de faxina, mourão e estaca de cerca, lenha e carvão, alimentação de animais domésticos e alimentação animais silvestres, para desordens respiratórias, transtornos do sistema digestivo, pressão alta, doenças ginecológicas, como cicatrizantes, antiabortivos, e anti-hemorrágicos; móveis, carroça/carro-de-boi, artesanato, cabos de ferramentas e implementos agrícolas, cura de doenças de animais, extrativos, ornamentação e uso místico/religioso.

A espécie Poincianella pyramidalis é a única dentre as espécies de destaque em São José do Bonfim que apresenta grande densidade de indivíduos bifurcados sendo a espécie de maior IVI\% e a segunda de maior RNR\% conforme discutido no item 1.3.1 do capítulo 1 deste estudo. Por sua vez Croton blanchetianus se destaca por ser dentre estas a única que apresenta categoria de uso para a alimentação humana. Outras espécies, além de serem usadas para este mesmo fim, são usadas também como forrageiras. No entanto, são espécies de menor densidade de indivíduos e de fustes.

Em Itaporanga as espécies Croton blanchetianus, Myracrodruon urundeuva, Amburana cearenses, Poincianella pyramidalis, Combretum leprosum, Mimosa ophthalmocentra, Annona leptopetala, Callisthene minor e Sigmatanthus trifoliatus estão entre as que apresentam maior densidade de indivíduos e/ou de fustes que apresentam as maiores gamas de categorias de usos destacando-se: como tábua/madeira serrada, vigas/traves de construção, vara para armação de casa de taipa, caibros e ripas; cerca de faxina, mourão e estaca de cerca, lenha e carvão, alimentação de animais domésticos e alimentação de animais silvestres, desordens respiratórias, transtornos do sistema digestivo, pressão alta, doenças ginecológicas, como cicatrizantes, antiabortivos, antihemorrágicos, móveis, carroça/carro-de-boi, artesanato, cabos de ferramentas e implementos agrícolas, para cura de doenças de animais, extrativos, ornamentação e uso místico/religioso. 
Tabela 5. Densidades de indivíduos e de fustes em vegetação de Caatinga arbustivoarbórea presentes na área de São José do Bonfim, no estado da Paraíba - Brasil.

\begin{tabular}{lcccc}
\hline Espécies & DA & DAF & \% DF & Categorias de uso \\
\hline Poincianella pyramidalis & 1153 & 2699 & 134,08 & Cdo, Cru, Ene, For, Med, Oun, Tec, Ven, Vet \\
Croton blanchetianus & 867 & 1109 & 27,91 & Ali, Cdo, Cru, Ene, For, Med, Oun, Tec, Vet \\
Mimosa tenuiflora & 366 & 482 & 31,69 & Cdo, Cru, Ene, For, Med, Oun, Tec, Ven, Vet \\
Morta & 282 & 324 & 14,89 & Ene \\
Anadenanthera colubrina & 71 & 91 & 28,17 & Cdo, Cru, Ene, For, Med, Oun, Tec, Ven, Vet \\
Bauhinia cheilantha & 252 & 297 & 17,86 & Cdo, Cru, Ene, For, Med, Oun, Tec, Ven, Vet \\
Aspidosperma pyrifolium & 88 & 141 & 60,23 & Cdo, Cru, Ene, For, Med, Oun, Tec, Ven, Vet \\
Combretum leprosum & 88 & 181 & 105,68 & Cdo, Cru, Ene, Med \\
Mimosa ophthalmocentra & 118 & 195 & 65,25 & Cru, Ene, For, Oun \\
Erythroxylum caatinga & 37 & 48 & 29,73 & Ene, For \\
Libidibia ferrea & 16 & 25 & 56,25 & Cdo, Ene, For, Med, Oun, Tec \\
Senna macranthera & 9 & 9 & - & Cru, Ene \\
Handroanthus impetiginosus & 9 & 11 & 22,22 & Cdo, Cru, Ene, Med, Oun, Tec \\
Jatropha mollissima & 9 & 9 & - & Cru, Ene, For, Med, Oun, Tec, Ven, Vet \\
Cynophalla hastata & 7 & 7 & - & Ene, Cru, For, Med, Oun, Tec, Vet \\
Cnidoscolus quercifolius & 6 & 8 & 33,33 & Ali, Cdo, Ene, For, Med, Oun, Tec, Vet \\
Ziziphus joazeiro & 5 & 9 & 80,00 & Ali, Cdo, Cru, Ene, For, Med, Oun, Tec, Ven, Vet \\
Commiphora leptophloeos & 4 & 4 & - & Cdo, Cru, Ene, For, Med, Oun, Tec, Ven, Vet \\
Manihot carthaginensis & 5 & 5 & - & Ali, Cru, Ene, For, Oun, Tec, Ven \\
Dolichandra sp. & 6 & 10 & 66,67 & -
\end{tabular}

Em que: DA = Densidade absoluta de indivíduos por hectare; DAF = Densidade absoluta de fustes por hectare; $\% \mathrm{DF}=$ Diferença percentual entre DA e DF; Ali = alimentação humana; Cdo = construção doméstica; Cru = construção rural; Ene = energético; For = forragem; Med = medicinal; Oun = outros usos não madeireiros; Tec = tecnologia, Ven = veneno-abortivo; e vet $=$ veterinária .

As espécies de maior destaque quanto a sua participação na estrutura fitossociológica da área de Itaporanga são Croton blanchetianus (IVI\%, RNR\% e bifurcação), Myracrodruon urundeuva (IVI\%) e Amburana cearenses (IVI\% e RNR\%), conforme discutido no item 1.3.1 do capítulo 1 deste estudo. A única espécie de destaque que apresenta categoria de uso para a alimentação humana nesta área é Croton blanchetianus. 
Tabela 6. Densidades de indivíduos e de fustes em vegetação de Caatinga arbustivoarbórea presentes na área de Itaporanga, no estado da Paraíba - Brasil.

\begin{tabular}{|c|c|c|c|c|}
\hline Espécies & DA & DAF & $\%$ DF & Categorias de uso \\
\hline Croton blanchetianus & 963 & 1291 & 34,06 & Ali, Cdo, Cru, Ene, For, Med, Oun, Tec, Vet \\
\hline Morta & 229 & 260 & 13,54 & Ene \\
\hline Myracrodruon urundeuva & 103 & 121 & 17,48 & Cdo, Cru, Ene, For, Med, Tec, Oun, Ven, Vet \\
\hline Amburana cearensis & 104 & 114 & 9,62 & Cdo, Cru, Ene, For, Med, Oun, Tec, Vet \\
\hline Poincianella pyramidalis & 109 & 153 & 40,37 & Cdo, Cru, Ene, For, Med, Oun, Tec, Ven, Vet \\
\hline Combretum leprosum & 164 & 303 & 84,76 & Cdo, Cru, Ene, Med \\
\hline Mimosa tenuiflora & 60 & 71 & 18,33 & Cdo, Cru, Ene, For, Med, Oun, Tec, Ven, Vet \\
\hline Commiphora leptophloeos & 51 & 57 & 11,76 & Cdo, Cru, Ene, For, Med, Oun, Tec, Ven, Vet \\
\hline Sapium glandulosum & 88 & 90 & 2,27 & Cdo, For, Ven \\
\hline Mimosa ophthalmocentra & 107 & 117 & 9,35 & Cru, Ene, For, Oun \\
\hline Manihot carthaginensis & 94 & 96 & 2,13 & Ali, Cru, Ali, Ene, For, Oun, Tec, Ven \\
\hline Annona leptopetala & 68 & 127 & 86,76 & Cdo, Cru, Ene, Med, Tec \\
\hline Cordia trichotoma & 62 & 62 & - & Cdo, Cru, Ene, Oun, Tec \\
\hline Bauhinia cheilantha & 73 & 94 & 28,77 & Cdo, Cru, Ene, For, Med, Oun, Tec, Ven, Vet \\
\hline Callisthene minor & 34 & 145 & 326,47 & Cdo, Cru, Ene, Tec \\
\hline Dalbergia cearensis & 22 & 39 & 77,27 & Cdo, Cru, Ene, Tec \\
\hline Cochlospermum vitifolium & 63 & 80 & 26,98 & Tec \\
\hline Gymnanthes boticario & 49 & 69 & 40,82 & Cru, Ene, For \\
\hline Erythroxylum caatinga & 41 & 77 & 87,80 & Ene, For \\
\hline Sigmatanthus trifoliatus & 69 & 146 & 111,59 & Cdo, Cru, Ene, Tec \\
\hline Senegalia polyphylla & 47 & 54 & 14,89 & Ene \\
\hline Luetzelburgia auriculata & 27 & 35 & 29,63 & Cdo, Cru, Ene, Tec \\
\hline Ximenia americana & 40 & 56 & 40,00 & Ali, Cdo, Cru, Ene, For, Med, Oun, Tec, Vet \\
\hline Psidium appendiculatum & 19 & 38 & 100,00 & Cdo, Ene \\
\hline Aspidosperma riedelii & 21 & 29 & 38,10 & Cdo, Cru, Ene, Tec \\
\hline Aspidosperma cuspa & 31 & 32 & 3,23 & Cdo, Cru, Ene, For, Tec, Ven \\
\hline Croton rhamnifolioides & 31 & 73 & 135,48 & Cdo, Ene, For, Med \\
\hline Luehea ochrophylla & 33 & 35 & 6,06 & Cdo, Cru, Ene, Tec \\
\hline Guapira laxa & 14 & 15 & 7,14 & Cdo, Cru, Ene, Tec \\
\hline Chloroleucon foliolosum & 14 & 19 & 35,71 & Cdo, Ene, For, Oun, Tec \\
\hline Schinopsis brasiliensis & 3 & 3 & - & Cdo, Cru, Ene, For, Med, Tec, Oun, Pre, Vet \\
\hline Libidibia ferrea & 14 & 21 & 50,00 & Cdo, Ene, For, Med, Oun, Tec \\
\hline Helicteres heptandra & 24 & 40 & 66,67 & Cdo, Ene \\
\hline Aspidosperma pyrifolium & 18 & 19 & 5,56 & Cdo, Cru, Ene, For, Med, Oun, Tec, Ven, Vet \\
\hline Mimosa paraibana & 12 & 14 & 16,67 & Cru, Ene, For \\
\hline Cynophalla hastata & 10 & 15 & 50,00 & Ene, Cru, For, Med, Oun, Tec, Vet \\
\hline Fridericia dichotoma & 13 & 26 & 100 & Ene \\
\hline Senna trachypus & 16 & 18 & 12,5 & Cdo, Cru, Ene, Oun, Tec \\
\hline Eugenia flavescens & 7 & 23 & 228,57 & Cru, Ene, For \\
\hline Astronium fraxinifolium & 5 & 6 & 20,00 & Cdo, Cru, Ene, Tec \\
\hline Senegalia riparia & 12 & 16 & 33,33 & Ene, Tec \\
\hline Talisia esculenta & 12 & 14 & 16,67 & Ali, For, Tec \\
\hline Stillingia trapezoidea & 7 & 7 & - & For \\
\hline Combretum duarteanum & 8 & 9 & 12,5 & Cdo, Cru, Ene \\
\hline Vitex megapotamica & 4 & 6 & 50 & Ali, Cdo, Cru, Ene, For, Tec \\
\hline Anadenanthera colubrina & 4 & 4 & - & Cdo, Cru, Ene, For, Med, Oun, Tec, Ven, Vet \\
\hline Guettarda angelica & 16 & 19 & 18,75 & Cdo, Cru, Ene, Tec \\
\hline Pseudobombax marginatum & 4 & 4 & - & Cdo, Med, Tec, Oun, Vet \\
\hline Jatropha mollissima & 4 & 4 & - & Cru, Ene, For, Med, Oun, Tec, Ven, Vet \\
\hline Jacaranda jasminoides & 4 & 5 & 25 & Cdo, Cru, Tec \\
\hline Brosimum gaudichaudii & 4 & 7 & 75 & Cdo, Cru, Tec \\
\hline Morfo espécie 1 & 7 & 14 & 100 & - \\
\hline Hymenaea courbaril & 3 & 4 & 33,33 & Ali, Cdo, Cru, Ene, For, Med, Oun, Tec \\
\hline Eugenia stictopetala & 5 & 14 & 180 & Cru, For \\
\hline
\end{tabular}


Tabela 6. Cont.

\begin{tabular}{|c|c|c|c|c|}
\hline Espécies & DA & DAF & $\% \mathrm{DF}$ & Categorias de uso \\
\hline Dahlstedtia araripensis & 3 & 7 & 133,33 & Cdo, Cru, Ene, Tec \\
\hline Handroanthus serratifolius & 2 & 2 & - & Cdo, Cru, Ene, Oun, Tec \\
\hline Randia armata & 2 & 2 & - & Cru, Ene \\
\hline Mimosa sp. & 2 & 2 & - & Cru, Ene, For \\
\hline Senna macranthera & 2 & 2 & - & Cru, Ene \\
\hline Croton aff. Anisodontus & 4 & 5 & 25 & Cru, Ene, For \\
\hline Allamanda blanchetii & 3 & 3 & - & Oun \\
\hline Zanthoxylum syncarpum & 1 & 1 & - & Cdo, Cru, Ene, Med, Oun, Tec, Vet \\
\hline Cordiera rigida & 1 & 2 & 100 & Cdo, Cru \\
\hline Piptadenia cf. viridiflora & 2 & 2 & - & Ene \\
\hline Handroanthus impetiginosus & 1 & 1 & - & Cdo, Cru, Ene, Med, Oun, Tec \\
\hline Triplaris gardneriana & 1 & 2 & 100 & Ene, For, Med, Oun, Tec \\
\hline Tocoyena formosa & 2 & 2 & - & Ali, Cru, Ene, Med, Oun, Tec, Vet \\
\hline Allophylus quercifolius & 1 & 5 & 400 & Ali, Cru \\
\hline Varronia curassavica & 1 & 1 & - & Cru, Ene \\
\hline Coutarea hexandra & 1 & 1 & - & Cru, Ene, Med, Ven, Vet \\
\hline Stachytarpheta coccinea & 1 & 1 & - & Ene, Oun \\
\hline Total & 3076 & 4251 & 38,20 & - \\
\hline
\end{tabular}

A área de Lagoa e a que apresenta maior número de espécies com maior densidade de indivíduos e/ou de fustes são Croton blanchetianus, Peltogyne pauciflora, Aspidosperma riedelii, Gymnanthes boticário, Myrciaria floribunda, Luehea ochrophylla, Senegalia polyphylla, Eugenia stictopetala, Croton nepetifolius, Erythroxylum nummularia, Maytenus erythroxyla, Eugenia flavescens, Helicteres heptandra, Senna macranthera e Croton heliotropiifolius. No entanto, estas espécies apresentam no geral menor gama de uso ao serem comparadas às espécies de maior densidade de indivíduos e/ou fustes das demais áreas deste estudo. Sobre as categorias de usos destacam-se: tábua/madeira serrada, vigas/traves de construção, vara para armação de casa de taipa, caibros e ripas, cerca de faxina, mourão e estaca de cerca, lenha e carvão, alimentação de animais domésticos e alimentação animais silvestres, móveis, carroça/carro-de-boi, artesanato, cabos de ferramentas e implementos agrícolas, cura de doenças de animais; extrativos, ornamentação e uso místico/religioso. Apenas Croton blanchetianus apresenta uso para a alimentação humana e Croton blanchetianus Erythroxylum nummularia e Maytenus erythroxyla têm uso destacado para desordens respiratórias, transtornos do sistema digestivo, pressão alta, antiabortivo, doenças ginecológicas, como cicatrizantes e anti-hemorrágicos. 
Tabela 7. Densidades de indivíduos e de fustes em vegetação de Caatinga arbustivoarbórea presentes na área de Lagoa, no estado da Paraíba - Brasil.

\begin{tabular}{|c|c|c|c|c|}
\hline Nome Vulgar & DA & DAF & $\%$ DF & Grupos de uso \\
\hline Croton blanchetianus & 476 & 670 & 40,76 & Ali, Cdo, Cru, Ene, For, Med, Oun, Tec, Vet \\
\hline Peltogyne pauciflora & 189 & 357 & 88,89 & Cdo, Tec \\
\hline Aspidosperma riedelii & 271 & 317 & 16,97 & Cdo, Cru, Ene, Tec \\
\hline Gymnanthes boticario & 278 & 446 & 60,43 & Cru, Ene, For \\
\hline Myrciaria floribunda & 178 & 365 & 105,06 & Cru, Ene, Tec \\
\hline Luehea ochrophylla & 105 & 116 & 10,48 & Cdo, Cru, Ene, Tec \\
\hline Senegalia polyphylla & 80 & 101 & 26,25 & Ene \\
\hline Eugenia stictopetala & 130 & 191 & 46,92 & Cru, For \\
\hline Brosimum gaudichaudii & 32 & 34 & 6,25 & Cdo, Cru, Tec \\
\hline Poincianella pyramidalis & 48 & 69 & 43,75 & Cdo, Cru, Ene, For, Med, Oun, Tec, Ven, Vet \\
\hline Croton nepetifolius & 143 & 226 & 58,04 & Cdo, Ene, For \\
\hline Morta & 77 & 92 & 19,48 & Ene \\
\hline Erythroxylum nummularia & 107 & 124 & 15,89 & Cru, Ene, Med \\
\hline Guapira laxa & 49 & 54 & 10,20 & Cdo, Cru, Ene, Tec \\
\hline Maytenus erythroxyla & 48 & 109 & 127,08 & Med \\
\hline Manihot carthaginensis & 53 & 56 & 5,66 & Ali, Cru, Ene, For, Oun, Tec, Ven \\
\hline Bauhinia cheilantha & 59 & 72 & 22,03 & Cdo, Cru, Ene, For, Med, Oun, Tec, Ven, Vet \\
\hline Handroanthus impetiginosus & 49 & 51 & 4,08 & Cdo, Cru, Ene, Med, Oun, Tec \\
\hline Eugenia flavescens & 55 & 138 & 150,91 & Cru, Ene, For \\
\hline Helicteres heptandra & 66 & 118 & 78,79 & Cdo, Ene \\
\hline Hymenaea courbaril & 29 & 31 & 6,90 & Ali, Cdo, Cru, Ene, For, Med, Oun, Tec \\
\hline Cynophalla hastata & 35 & 71 & 102,86 & Ene, Cru, For, Med, Oun, Tec, Vet \\
\hline Senna macranthera & 77 & 138 & 79,22 & Cru, Ene \\
\hline Pouteria reticulata & 28 & 77 & 175,00 & Cdo, Tec \\
\hline Byrsonima vacciniifolia & 29 & 34 & 17,24 & Cdo, Cru, Ene, Tec \\
\hline Croton heliotropiifolius & 60 & 125 & 108,33 & Cru, Ene, For \\
\hline Commiphora leptophloeos & 12 & 12 & - & Cdo, Cru, Ene, For, Med, Oun, Tec, Ven, Vet \\
\hline Eugenia caatingicola & 18 & 33 & 83,33 & Ali, For \\
\hline Randia armata & 30 & 31 & 3,33 & Cru, Ene \\
\hline Myracrodruon urundeuva & 13 & 13 & - & Cdo, Cru, Ene, For, Med, Tec, Oun, Ven, Vet \\
\hline Guettarda angelica & 46 & 60 & 30,43 & Cdo, Cru, Ene, Tec \\
\hline Dalbergia cearensis & 12 & 14 & 16,67 & Cdo, Cru, Ene, Tec \\
\hline Syagrus cearensis & 8 & 16 & 100,00 & Ali, For, Med \\
\hline Senna trachypus & 30 & 56 & 86,67 & Cdo, Cru, Ene, Oun, Tec \\
\hline Amburana cearensis & 11 & 11 & - & Cdo, Cru, Ene, For, Med, Oun, Tec, Vet \\
\hline Parapiptadenia zehntneri & 4 & 4 & - & Cdo, Cru, Ene, For, Oun, Tec \\
\hline Zanthoxylum syncarpum & 11 & 11 & - & Cdo, Cru, Ene, Med, Oun, Tec, Vet \\
\hline Sapium glandulosum & 9 & 9 & - & Cdo, For, Ven \\
\hline Luetzelburgia auriculata & 11 & 14 & 27,27 & Cdo, Cru, Ene, Tec \\
\hline Senna spectabilis & 13 & 56 & 330,77 & Cdo, Cru, Ene, Med, Oun, Tec \\
\hline Cordia trichotoma & 3 & 17 & 466,67 & Cdo, Cru, Ene, Oun, Tec \\
\hline Cordiera rigida & 6 & 11 & 83,33 & Cdo, Cru \\
\hline Lantana camara & 11 & 12 & 9,09 & Cru, Ene, Med \\
\hline Cochlospermum vitifolium & 16 & 17 & 6,25 & Tec \\
\hline Combretum leprosum & 12 & 17 & 41,67 & Cdo, Cru, Ene, Med \\
\hline Mimosa paraibana & 11 & 11 & - & Cru, Ene, For \\
\hline Eugenia ligustrina & 14 & 22 & 57,14 & Cdo, Cru, Ene, For \\
\hline Talisia esculenta & 5 & 5 & - & Ali, For, Tec \\
\hline Pseudobombax marginatum & 7 & 7 & - & Cdo, Med, Tec, Oun, Vet \\
\hline Mimosa ophthalmocentra & 8 & 9 & 12,50 & Cru, Ene, For, Oun \\
\hline Erythroxylum caatinga & 5 & 7 & 40,00 & Ene, For \\
\hline Callisthene minor & 10 & 13 & 30,00 & Cdo, Cru, Ene, Tec \\
\hline Senegalia riparia & 8 & 19 & 137,50 & Ene, Tec \\
\hline
\end{tabular}


Tabela 7. Cont.

\begin{tabular}{|c|c|c|c|c|}
\hline Espécies & DA & DAF & $\%$ DF & Categorias de uso \\
\hline Morfo espécie 3 & 3 & 4 & 33,33 & - \\
\hline Mimosa tenuiflora & 1 & 3 & 200,00 & Cdo, Cru, Ene, For, Med, Oun, Tec, Ven, Vet \\
\hline Morfo espécie 2 & 3 & 4 & 33,33 & - \\
\hline Morfo espécie 1 & 4 & 6 & 50,00 & - \\
\hline Vitex megapotamica & 2 & 11 & 450,00 & Ali, Cdo, Cru, Ene, For, Tec \\
\hline Ximenia americana & 5 & 5 & - & Ali, Cdo, Cru, Ene, For, Med, Oun, Tec, Vet \\
\hline Enterolobium contortisiliquum & 2 & 2 & - & Cdo, Cru, Oun, Tec \\
\hline Jatropha mollissima & 6 & 6 & - & Cru, Ene, For, Med, Oun, Tec, Ven, Vet \\
\hline Chloroleucon foliolosum & 3 & 3 & - & Cdo, Ene, For, Oun, Tec \\
\hline Xylosma prockia & 1 & 1 & - & Cdo, Cru, Ene, Tec \\
\hline Libidibia ferrea & 2 & 3 & 50,00 & Cdo, Ene, For, Med, Oun, Tec \\
\hline Handroanthus serratifolius & 2 & 2 & - & Cdo, Cru, Ene, Oun, Tec \\
\hline Dahlstedtia araripensis & 2 & 3 & 50,00 & Cdo, Cru, Ene, Tec \\
\hline Dolichandra sp. & 1 & 1 & - & Ene \\
\hline Turnera calyptrocarpa & 1 & 1 & - & Cru, Ene \\
\hline Varronia curassavica & 1 & 2 & 100,00 & Cru, Ene \\
\hline Total & 3134 & 4721 & 50,64 & \\
\hline
\end{tabular}

Em que: DA = Densidade absoluta de indivíduos por hectare; DAF = Densidade absoluta de fustes por hectare; $\% \mathrm{DF}=$ Diferença percentual entre DA e DF; Ali = alimentação humana; Cdo = construção doméstica; $\mathrm{Cru}=$ construção rural; Ene = energético; For = forragem; Med = medicinal; Oun = outros usos não madeireiros; Tec = tecnologia, Ven = veneno-abortivo; e vet = veterinária.

As espécies de maior destaque quanto a sua participação na estrutura fitossociológica da área de Lagoa são Croton blanchetianus, Gymnanthes boticario e Myrciaria floribunda (IVI\%, RNR\% e bifurcação), Peltogyne pauciflora (IVI\% e bifurcação), Aspidosperma riedelii (IVI\% e RNR\%), Maytenus erythroxyla, Eugenia flavescens, Helicteres heptandra, Senna macranthera e Croton heliotropiifolius (bifurcação), conforme discutido nos item 1.3.1 do capítulo 1 deste estudo. A única espécie de destaque que apresenta categoria de uso para a alimentação humana nesta área é Croton blanchetianus.

Conforme pode ser observado as diferenças de riqueza florística de espécies, de densidade de indivíduos e/ou de fustes para São José do Bonfim, Itaporanga e Lagoa refletiram na relação de potencial de uso da vegetação das mesmas, o que as tornam bastantes distintas quanto às categorias de usos. Variações semelhantes foram observadas em estudos em outras áreas de Caatinga como no de Ferraz (2011) onde predominou espécies para alimentação de animais domésticos e silvestres, para cerca de faxina, lenha, mourão/estaca de cerca e energia, no de Salin et al. (2012) em que predominaram os usos para alimentação de animais domésticos e silvestres e nos de Almeida et al. (2006) onde predomina a alimentação de animais domésticos e silvestres, lenha e carvão e cerca de faxina, mourão e estaca de cerca. 
Drumond et al. (2000) entendem que o uso de produtos de origem florestal tem acontecido de forma excessiva e desordenada em ambientes de vegetação de Caatinga, tendo, como consequência, a ameaça de extinção de algumas espécies. No presente estudo, nenhuma das espécies que ocorreram em baixa densidade pelos parâmetros de inclusão estabelecidos, está na lista oficial das espécies da flora brasileira ameaçadas de extinção apresentada em Brasil (2008) e Martinelli; Moraes (2013). Esta observação reforçam as considerações de que as áreas de Itaporanga e Lagoa representam fragmentos de Caatinga bem preservados e sobre as quais se recomenda aprofundamento em estudos visando a conservação ou a preservação das mesmas.

De acordo com Guerra et al. (2015), o reconhecimento de uso de espécies é importante para uma determinada população e acrescenta subsídios para uma gestão de planos sustentáveis em um determinado ecossistema. No entanto, para Sá et al. (2009), Lucena et al. (2008), Ramos et al. (2008a), Ramos et al. (2008b), Florentino et al. (2007), Lucena et al. (2007), Monteiro et al. (2006) e outros autores, as espécies lenhosas da Caatinga sofrem riscos de extinção por ter grande versatilidade de utilização. Assim, com base nos estudos realizados, consideramos que é necessário aprofundar estudos que envolvam aspectos ecológicos, econômicos e sociais para conhecer e, assim, distinguir e priorizar a conservação e a preservação dos recursos naturais da Caatinga.

\subsubsection{Estimativa do estoque de biomassa seca}

Foram utilizados 56 fustes distribuídos nas áreas de estudo, dos quais 44 foram selecionadas para ajustar os modelos e os 12 restantes foram utilizados para validação das equações selecionadas. Na tabela 8 são apresentados os resultados dos ajustes dos modelos para biomassa seca de fuste, bem como suas respectivas medidas de precisão considerando $\mathrm{p}<0,05$.

O coeficiente de determinação $\left(\mathrm{R}^{2}\right)$ para a variável biomassa seca de fuste variou de 0,97 a 0,98 e o erro padrão da estimativa (Sxy\%) variou de $33,75 \%$ a 35,25\%. Estas estimativas de $\mathrm{R}^{2}$ apresentaram-se superiores a outros trabalhos realizados em áreas com vegetação de Caatinga envolvendo ajuste de equações de biomassa, no qual foram encontrados valores entre 0,92 e 0,95 por Sampaio; Silva (2005) e de 0,95 para espécies de maior porte, e 0,82\% para árvores de menor porte por Silva; Sampaio (2008) e de 0,76 a 0,93 com Sxy\% variando de 18,06 a 33,48 em trabalho desenvolvido por Ferraz (2011). 
Tabela 8. Estimativas dos parâmetros e medidas de precisão das equações de biomassa seca ajustadas para fuste, em vegetação de Caatinga arbustivo-arbórea nas áreas de São José do Bonfim, Itaporanga e Lagoa, no estado da Paraíba - Brasil.

\begin{tabular}{llrr}
\hline & Modelo & $\mathbf{R}^{\mathbf{2}}$ & Syx \% \\
\hline $1 \quad \mathrm{Y}=0,019963 \cdot \mathrm{CAB}^{1,911758} \cdot \mathrm{Ht}^{0,232655}$ & 0,98 & 33,75 \\
\hline $2 \mathrm{Y}=0,032136 \cdot \mathrm{CAB}^{1,905135}$ & 0,97 & 35,25 \\
\hline $3 \mathrm{Y}=0,003030335 \cdot \mathrm{CAB}^{2}+0,000117347 \cdot \mathrm{CAB}^{3}-0,143590388 \cdot \mathrm{Ht}^{2}+0,109347525 \cdot \mathrm{CAB} \cdot \mathrm{Ht}$ & 0,98 & 33,93 \\
\hline $4 \mathrm{Y}=0,233269598+0,048175848 \cdot \mathrm{CAB}+0,015555136 \cdot \mathrm{CAB}^{2}+0,131020596 \cdot \mathrm{Ht}+0,000688213 \cdot \mathrm{CAB}^{2} \cdot \mathrm{Ht}$ & 0,98 & 34,62 \\
\hline $5 \quad \mathrm{Y}=2,095589489+0,015588214 \cdot \mathrm{CAB}^{2}-0,01742048 \cdot \mathrm{Ht}^{2}+0,000771078 \cdot \mathrm{CAB}^{2} \cdot \mathrm{Ht}$ & 0,98 & 34,20 \\
\hline 6 & $\mathrm{Y}=1,6209183+0,0158457 \cdot \mathrm{CAB}^{2}+0,0007233 \cdot \mathrm{CAB}^{2} \cdot \mathrm{Ht}$ & 0,98 & 33,79
\end{tabular}

Em que: 1 = Schumacher e Hall; 2 = Husch; 3 = Rezende et al. (2006); 4 = Meyer; 5 = Stoate; 6 = Sanqueta $e t$ al. (2001); $\mathrm{Y}=$ Biomassa seca $(\mathrm{kg}) ; \mathrm{Ht}=$ Altura Total $(\mathrm{m}) ; \mathrm{CAB}=$ Circunferência a $0,3 \mathrm{~m}$ de altura do solo; $\beta 0, \beta 1$ e $\beta 2=$ Coeficientes a serem ajustados; $\varepsilon=$ Erro associado ao modelo; $\mathrm{R}^{2}$ : Coeficiente de determinação; e Syx = Erro padrão da estimativa.

O teste de validação foi aplicado nas duas equações selecionadas com as melhores estimativas, segundo Shumacher e Hall e Rezende et al. (2006), para biomassa de fuste com casca, não encontrando diferença estatística significativa entre os volumes observados e os estimados pelas equações ajustadas, ao nível de $95 \%$ de probabilidade. Isto comprova a confiabilidade das estimativas geradas pelas duas equações, sendo o modelo ajustado de Shumacher e Hall ligeiramente superior e, portanto, adotado neste estudo.

As estimativas de biomassa de fuste utilizando a equação de Shumacher e Hall para as áreas de vegetação de Caatinga arbustivo-arbórea nos municípios de São José do Bonfim, Itaporanga e Lagoa no estado da Paraíba - Brasil foram consideradas satisfatórias. $\mathrm{O}$ erro percentual de amostragem para o intervalo de confiança apresentou-se inferior a $10 \%$, sendo $6,72 \%, 8,11 \%$ e 6,57\%, respectivamente. Observa-se que a área de Lagoa com maior altitude apresentou um valor total médio de biomassa de 64,66 \pm 4,25 t.ha ${ }^{-1}$, a área de São José do Bonfim apresentou 44,53 $\pm 2,99$ t.ha $^{-1}$ e a área de Itaporanga apresentou 40,74 $\pm 3,30$ t.ha $^{-1}$ (Tabela 9).

Em diferentes áreas de vegetação de Caatinga, a biomassa aérea foi estimada apresentando variação entre 5 t.ha $^{-1}$ e 74 t.ha $^{-1}$ nos estudos de Kauffman et al. (1993), Araújo et al. (2004), Amorim et al. (2005), Accyoli et al. (2008) e Santos et al. (2016). Assim, os valores encontrados no presente estudo (de 37,44 a 68,91 t.ha ${ }^{-1}$ ) estão entre a variação encontrada nos estudos citados. Segundo estes mesmos autores, os valores mais baixos de biomassa se devem às áreas com problemas de degradação, valores estes encontrados nas microrregiões do Seridó Oriental no Rio Grande do Norte e Seridó 
Ocidental na Paraíba. Estas duas microrregiões apresentaram uma média de biomassa aérea estimada em 9 t.ha $^{-1}$, valor considerado extremamente baixo, considerando que $72 \%$ destas áreas apresentaram baixa produtividade, com estimativas variando entre 5 t.ha $^{-1}$ e 10 t.ha ${ }^{-1}$, estando correlacionadas com fortes processos erosivos provenientes da intensa exploração florestal causada pela retirada da lenha e pelos cultivos agrícolas (ACCYOLI et al., 2008).

Tabela 9. Estimadores dos parâmetros da variável biomassa seca em t.ha ${ }^{-1}$ das vegetações de Caatinga arbustivo-arbóreas, amostradas nas áreas de São José do Bonfim, Itaporanga e Lagoa, no estado da Paraíba - Brasil.

\begin{tabular}{|c|c|c|c|c|c|c|c|}
\hline Variável & Local & Área & Média (t) & Erro (\%) & Inter & de Con & ça (t) \\
\hline \multirow{6}{*}{$\begin{array}{l}\text { Biomassa } \\
\text { de Fuste }\end{array}$} & \multirow{2}{*}{$\begin{array}{l}\text { São José do } \\
\text { Bonfim }\end{array}$} & Hectare & 44,53 & \multirow{2}{*}{6,72} & 41,54 & $\leq \bar{X} \leq$ & 47,53 \\
\hline & & Total & $2.582,83$ & & $2.409,14$ & $\leq \bar{X} \leq$ & $2.756,51$ \\
\hline & \multirow{2}{*}{ Itaporanga } & Hectare & 40,74 & \multirow{2}{*}{8,11} & 37,43 & $\leq \bar{X} \leq$ & 44,04 \\
\hline & & Total & $2.362,72$ & & $2.171,10$ & $\leq \bar{X} \leq$ & $2.554,34$ \\
\hline & \multirow{2}{*}{ Lagoa } & Hectare & 64,66 & \multirow{2}{*}{6,57} & 60,41 & $\leq \bar{X} \leq$ & 68,91 \\
\hline & & Total & $3.750,30$ & & $3.503,81$ & $\leq \bar{X} \leq$ & $3.996,79$ \\
\hline
\end{tabular}

Do total do estoque de biomassa 37,71\% para São José do Bonfim, 47,26\% para Itaporanga e 64,05\% para Lagoa encontram-se estocados nas classes diamétricas a partir de $10 \mathrm{~cm}$, que representa o limite inferior associado a importantes usos como: tábua/madeira serrada, vigas/traves de construção, vara para armação de casa de taipa, caibros e ripas; cerca de faxina, mourão e estaca de cerca, lenha e carvão; e móveis, carroça/carro-de-boi, artesanato, cabos de ferramentas e implementos agrícolas (Figura 5). 


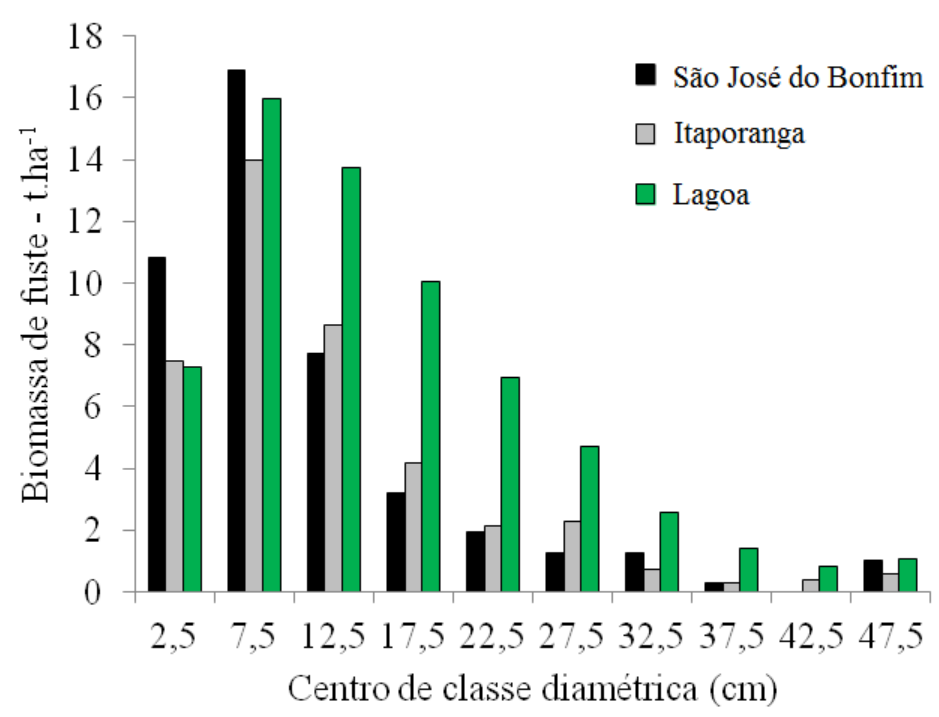

Figura 5. Estimativas do estoque de biomassa seca de fuste em (t.ha $\left.{ }^{-1}\right)$, distribuídas em classes diamétricas para as vegetações de Caatinga arbustivo-arbóreas, amostradas nas áreas de áreas de São José do Bonfim, Itaporanga e Lagoa, no estado da Paraíba - Brasil.

O resultado das relações de Biomassa/Vitalidade/Sanidade para as áreas de estudo é apresentada na figura 6.

Foram consideradas neste estudo as fração de Biomassa V 1/ Q 1 como de excelente e a fração de Biomassa V 1 / Q 2 como de boa qualidade. Assim para as áreas foi observado: a) São José do Bonfim: 27,93\% de biomassa de excelente e boa qualidade (V 1 / Q 1 e V1 / Q 2), sendo as principais espécies nesta fração Anadenanthera colubrina, Poincianella pyramidalis, Mimosa tenuiflora e Croton blanchetianus; b) em Itaporanga: 33,26\% de biomassa de excelente e boa qualidade (V 1/Q 1 e V1/Q2), sendo as principais espécies Myracrodruon urundeuva, Schinopsis brasiliensis, Sapium glandulosum, Poincianella pyramidalis, Amburana cearensis, Cordia trichotoma, Manihot carthaginensis e Croton blanchetianus; c) em Lagoa: 48,37\% - de biomassa de excelente e boa qualidade (V 1/ Q 1 e V1/Q2), sendo as principais espécies Eugenia flavescens, Parapiptadenia zehntneri, Poincianella pyramidalis, Syagrus cearensis, Peltogyne pauciflora, Senegalia polyphylla, Myrciaria floribunda, Eugenia stictopetala, Commiphora leptophloeos, Brosimum gaudichaudii, Handroanthus impetiginosus, Maytenus erythroxyla, Hymenaea courbaril, Luehea ochrophylla, Manihot carthaginensis, Croton blanchetianus, Aspidosperma riedelii, Guapira laxa e Dalbergia cearensis. 


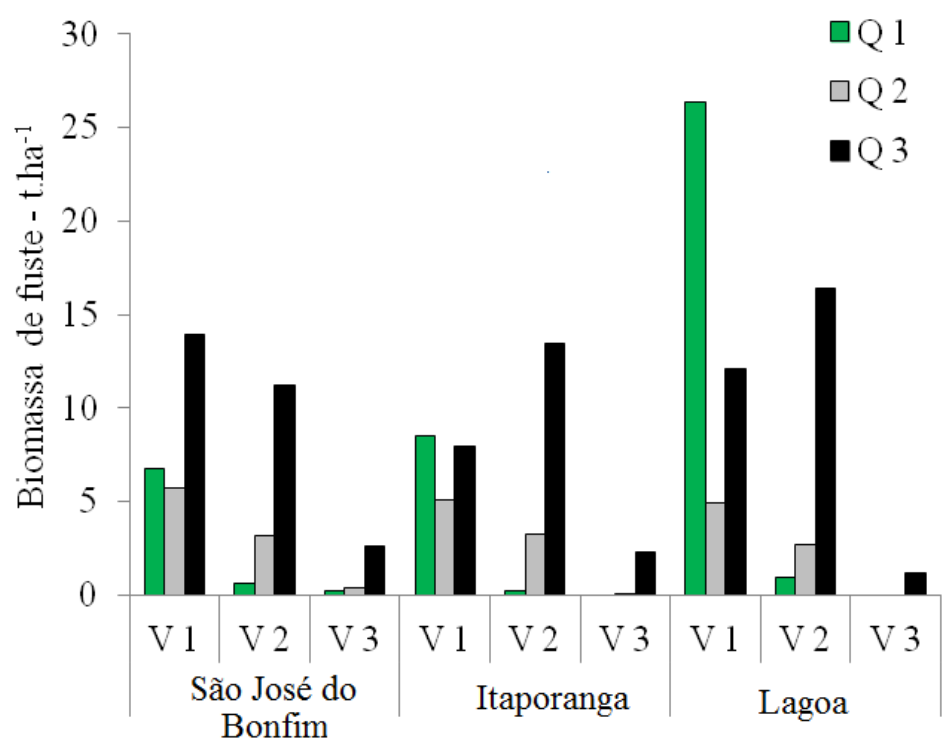

Figura 6: Estimativas do estoque de biomassa seca de fuste em $\left(\mathrm{t}_{\mathrm{h}} \mathrm{ha}^{-1}\right)$, distribuída para as classes de vitalidade e qualidade de fuste em vegetação de Caatinga arbustivo-arbórea, para as áreas de São José do Bonfim, Itaporanga e Lagoa, no estado da Paraíba - Brasil. Em que: para sanidade de fuste V $1=$ Sadio, V 2 = Danificado e V 3 = Morto; para qualidade de fuste Q 1 = Reto, Q 2 = Levemente torto e Q 3 = Tortuoso.

A área de São José do Bonfim foi identificada com menor riqueza de espécies, de maior densidade de indivíduos e de fustes, apresentando baixa vitalidade/qualidade de fustes e baixa vitalidade/qualidade de biomassa.

Itaporanga, é a área mais rica em espécies e a de menor densidade de indivíduos e de fustes, apresenta baixa vitalidade/qualidade de fustes e baixa vitalidade/qualidade de biomassa, à semelhança de São José do Bonfim.

A área de Lagoa apresenta riqueza e densidade de indivíduos semelhantes a de Itaporanga e densidade de indivíduos e de fuste intermediária em relação a São José do Bonfim e Itaporanga. Apresenta a melhor relação Fuste/Vitalidade/Qualidade bem como a melhor relação Biomassa/Vitalidade/Qualidade dentre as áreas estudadas. 


\subsection{CONCLUSÕES}

Na vegetação de Caatinga de São José do Bonfim e de Lagoa predomina o comportamento de fuste bifurcado e para Itaporanga predomina fuste único.

Nove espécies comuns às três áreas apresentam o mesmo comportamento em relação a bifurcação: as de fuste único: Handroanthus impetiginosus, Commiphora leptophloeos, Jatropha molissima, Manihot carthaginensis subsp. Glaziovii e Mimosa ophthalmocentra, e as de fuste bifurcados: Combretum leprosum, Erythroxylum Caatinga, Libidibia ferrea, Poincianella pyramidalis e Mimosa tenuiflora.

A vitalidade/sanidade de fustes é baixa em São José do Bonfim e Itaporanga e superior em Lagoa.

As três áreas de estudo apresentam distribuição de número de fustes em classes diamétricas, sem descontinuidade e em J Invertido.

As espécies de maior densidade de indivíduos e/ou de fustes e de maior gama de categorias de usos são: em São José do Bonfim - Poincianella pyramidalis, Croton blanchetianus, Mimosa tenuiflora, Bauhinia cheilantha, Aspidosperma pyrifolium, Combretum leprosum e Mimosa ophthalmocentra; em Itaporanga - Croton blanchetianus, Myracrodruon urundeuva, Amburana cearenses, Poincianella pyramidalis, Combretum leprosum, Mimosa ophthalmocentra, Annona leptopetala, Callisthene minor e Sigmatanthus trifoliatus; em Lagoa - Croton blanchetianus, Peltogyne pauciflora, Aspidosperma riedelii, Gymnanthes boticário, Myrciaria floribunda, Luehea ochrophylla, Senegalia polyphylla, Eugenia stictopetala, Croton nepetifolius, Erythroxylum numularia, Maytenus erythroxyla, Eugenia flavescens, Helicteres heptandra, Senna macranthera e Croton heliotropiifolius.

A área de Lagoa é a de maior riqueza de espécies, de maior densidade de indivíduos, de melhor relação Fuste/Vitalidade/Qualidade e de melhor relação Biomassa/Vitalidade/Qualidade dentre as áreas estudadas. 


\section{REFERÊNCIAS}

ACCIOLY, L. J. de. O.; COSTA, T. C e. C. da.; OLIVEIRA, M. A. J. de.; SILVA, E. A. da.; SILVA, J. A. da.; SILVA, A. B. da.; SOUSA, A. R. de. Biomassa nas florestas de Caatinga nas microrregiões do Seridó Oriental (RN) e Seridó Ocidental (PB). In: REUNIÃO BRASILEIRA DE MANEJO E CONSERVAÇÃO DO SOLO E DA ÁGUA, Rio de Janeiro 17, 2008.

ALBUQUERQUE, U. P.; ANDRADE, L. H. C. conhecimento botânico tradicional e conservação em uma área de Caatinga no estado de Pernambuco, Nordeste do Brasil. Acta Botanica Brasilica, v.16, n.3, p.273-285, 2002.

ALMEIDA, A. C. S.; FERREIRA, R. L. C.; SANTOS, M. V. F.; SILVA, J. A. A.; LIRA, M. A. Caracterização de produtores e propriedades rurais em três municípios do estado de Pernambuco. Revista Caatinga, v.19, n.4, p.323-332, 2006.

ALMEIDA, C. F. C. B. R.; ALBUQUERQUE, U. P. Uso e conservação de plantas e animais medicinais no estado de Pernambuco (Nordeste do Brasil): um estudo de caso. Injerciencia, v.27, n.6, p.276-285, 2002.

ALMEIDA NETO, J. X.; ANDRADE, A. P.; LACERDA, A. V.; FÉLIX, L. P.; BRUNO, R. L. A. Composição florística, estrutura e análise populacional do feijão-bravo (Capparis flexuosa L.) no semiárido Paraibano, Brasil. Revista Caatinga, v.22, n.4, p.187-194, 2009.

ALVES, J. J. A.; ARAÚJO, M. A.; NASCIMENTO, S. S. Caminhos de Geografia, v.9, n.27, p.143-155, 2008.

AMORIM, I. L. de.; SAMPAIO, E. V. S. B.; ARAÚJO, E. de. L. A. Flora e estrutura da vegetação arbustivo-arbórea de uma área de Caatinga do Seridó, RN, Brasil. Acta Botanica Brasilica, v.19, n.3, p.615-623, 2005.

ANDRADE, L. A.; PEREIRA, I. M.; LEITE, U. T.; BARBOSA, M. R. V. Análise da cobertura de duas fisionomias de Caatinga, com diferentes históricos de uso, no município de São João do Cariri, Estado da Paraíba. Cerne, v.11, n.3, p.253-262, 2005.

APNE. Associação Plantas do Nordeste. Quantidade produzida e valor (mil reais) da produção na extração vegetal por tipo de produto extrativo - 2012. IBGE - Adaptado pela APNE, p.49-52. In: Artigos, Redes e Projetos, Estatísticas Florestais, Estatística Florestal da Caatinga, Ano 2, v.2, 142f, 2015.

ARAUJO, K. D.; DANTAS, R. T.; ANDRADE, A. P.; PARENTE, H. N.; ÉDER-SILVA, É. Uso de espécies da Caatinga na alimentação de rebanhos no município de São João do Cariri - PB. R. RA'E GA, n.20, p.157-171, 2010.

ARAÚJO, L. V. C. de.; LEITE, J. A. N.; PAES, J. B. Estimativa da produção de biomassa de um povoamento de jurema-preta (Mimosa tenuiflora (WILLD.) POIRET. com cinco anos de idade. Biomassa \& Energia, v.1, n.4, p.347-352, 2004.

ASSMANN, E. The principles of forest yield: studies in the organic production, structure, increment and yield of forest stands. Braunschweig: Pergamon Press, 506p, 1970. 
BARAÚNA, E. E. P.; OLIVEIRA, V. S. Umidade de equilíbrio da madeira de angelim vermelho (Dinizia excelsa Ducke), guariúba (Clarisia racemosa Ruiz \& Pav.) e tauarí vermelho (Cariniana micrantha Ducke) em diferentes condições de temperatura e umidade relativa. Acta Amazônica, v.39, n.1, p.91-66, 2009.

BARbOSA, M. D.; MARANGON, L. C.; FELICIANO, A. L. P.; FREIRE, F. J.; DUARTE, G. M. T. Florística e Fitossociologia de Espécies Arbóreas e Arbustivas em uma Área de Caatinga em Arcoverde, PE, Brasil. Revista Árvore, Viçosa-MG, v.36, n.5, p.851-858, 2012.

BARBOSA, R. I.; FERREIRA, C. A. C. Biomassa acima do solo de um ecossistema de "campina" em Roraima, norte da Amazônia Brasileira. Acta Amazônica, v.34, n.4, p.577586, 2004.

BARREIROS, A. L. B. S.; BARREIROS, M. L.; DAVID, J. M.; DAVID, J. P.; QUEIROZ, L. P. de. Atividade antioxidante de substâncias presentes em Dioclea violacea e Erythroxylum nummularia. Rev. Bras. Farmacogn., v.13 supl.2, p.08-11, 2003.

BRASIL. Ministério do Meio Ambiente/MMA. Instrução Normativa. Lista Oficial das Espécies da Flora Brasileira Ameaçadas de Extinção, Brasília, 55p, 2008.

CAMPEllO, F. C. B.; LEAL-JUNiOR, G.; SILVA, J. A.; CAMPELlO, R. C. B. Avaliação dos recursos florestais de área de proteção Ambiental Chapada do Araripe. Projeto MMAIFAO, UTFIBRA1047, MMA - Ministério do Meio Ambiente, Secretaria da Biodiversidade e Floresta, Diretoria do Programa Nacional de Florestas, Crato-CE, 49p. 2000.

CAMPOS, J. C. C.; LEITE, H. G. Mensuração florestal: perguntas e respostas. 3.ed. Viçosa, MG: Universidade Federal de Viçosa - UFV, 548p, 2009.

CAMPOS, J. C. C.; LEITE, H. G. Mensuração Florestal: perguntas e respostas. 2 ed. Viçosa-MG: Universidade Federal de Viçosa - UFV, 407p, 2006.

CARVALHO, T. K. N.; SOUSA, R. F.; MENESES, S. S. S.; RIBEIRO, J. P. O.; FÉLIX, L. P.; LUCENA. R. F. P. Plantas usadas por uma comunidade rural na depressão sertaneja no Nordeste do Brasil. Revista de Biologia e Farmácia - Biofar, Volume especial, 92$120,2012$.

CIENTEC. Mata Nativa 3: Manual do Usuário. Viçosa, 295p, 2006.

COSTA, T. C. C.; OLIVEIRA, M. A. J.; ACCIOLY, L. J. O.; SILVA, F. H. B. B. Análise da degradação da Caatinga no núcleo de desertificação do Seridó (RN/PB). Revista Brasileira de Engenharia Agrícola e Ambiental, Campina Grande, v.13, p.961-974, 2009. 
DRUMOND, M. A.; KIILL, L. H. P.; LIMA, P. C. F.; OLIVEIRA, M. C. de.; OLIVEIRA, V. R. de.; ALBUQUERQUE, S. G. de.; NASCIMENTO, C. E. de. S.; CAVALCANTI, J.Avaliação e identificação de ações prioritárias para a conservação, utilização sustentável e repartição de benefícios da biodiversidade do bioma Caatinga. Estratégias para o uso sustentável da biodiversidade da Caatinga. Petrolina, Empresa Brasileira de Pesquisa Agropecuária (Embrapa), 23p, 2000. Disponível em: $<$ https://portais.ufg.br/uploads/160/original_uso_sustentavel.pdf>. Acesso em: 10/07/2014.

FERRAZ, J. S. F. Análise da Vegetação de Caatinga Arbustivo-Arbórea em Floresta, PE, como Subsídio ao Manejo Florestal. Tese (Doutorado em Ciências Florestais), Universidade Federal Rural de Pernambuco, Recife, PE, 131f, 2011.

FERREIRA, J. C. S.; SILVA, J. A. A. da.; MIGUEL, E. P.; ENCINAS, J. I.; TAVARES, J. A. Eficiência relativa de modelos volumétricos com e sem a variável altura da árvore. Revista Acta Tecnológica, v.6, n.1, p.89-102, 2011.

FIGUEIRÔA, J. M.; ARAÚJO, E. L.; PAREYN, F. G. C.; CUTLER, D. F.; GASSON, P.; LIMA, K. C.; SANTOS, V. F. Variações sazonais na sobrevivência e produção de biomassa de Caesalpinia pyramidalis Tul. após corte raso e implicações para o manejo da espécie. Revista Árvore, v.32, n.6, p.1041-1049, 2008.

FLORENTINO, A. T. N.; ARAÚJO, E.L.; ALBURQUEQUE, U. P. Contribuição de quintais agroflorestais na conservação de plantas da Caatinga, município de Caruaru, PE, Brazil. Acta Botanica Brasilica, v.21, n.1, p.37-47, 2007.

FONSECA-KRUEL, V. S.; PEIXOTO, A. L.; CATARINO de SÁ, C. F.; ARAUJO, D. S. D.; SILVA, W. L.; FERREIRA, A. J. Plantas úteis da restinga: $O$ saber dos pescadores artesanais de Arraial do Cabo, Rio de Janeiro. Instituto de Pesquisas Jardim Botânico do Rio de Janeiro, 42p, 2006.

GALEANO, GLÓRIA. Forest use at the Pacifi coast of Chocó, Colombia: A quantitative approach. Economic Botany, v.54, n.3, p.358-376, 2000.

GOMES, E. C. S.; BARBOSA, J.; VILAR, F. C. R.; PEREZ, J. O.; VILAR, R. C.; FREIRE, J. L. O.; LIMA. A. N.; DIAS, T. J. Plantas da Caatinga de uso terapêutico: Levantamento etnobotânico. Engenharia Ambiental, v.5, n.2, p.074-085, 2008.

GUERRA, N. M.; CARVAlHO, T. K. N.; RIBEIRO, J. E. S.; RIBEIRO, J. P. O.; BARBOSA, A. R.; LIMA, J. R. F.; ALVES, C. A. B.; OLIVEIRA, R. S.; LUCENA, R. F. P. Ecological Apparency Hypothesis and Plant Utility in the Semiarid Region of Brazil. Ethnobotany Research \& Applications, v.14, p.423-435, 2015.

KAUFFMAN, J. B.; SANFORD, R. L.; CUMMINGS, JR. D. L.; SALCEDO, I. H.; SAMPAIO, E. V.S. B. Biomass and nutrient dynamics associated with slash fires in neotropical dry forests. Ecology, v.74, n.1, p.140-151, 1993.

LEMOS, J. R.; MEGURO, M. Estudo fitossociológico de uma área de Caatinga na Estação Ecológica (ESEC) de Aiuaba, Ceará, Brasil. Biotemas, v.28, n.2, p.39-50, 2015. 
LIMA, G. D. S.; LIMA, J. R. F.; SILVA, N.; OLIVEIRA, R. S.; LUCENA, R. F. P. Inventory in situ of plant resources used as fuel in the Semiarid Region of Northeast Brazil. Brazilian Journal of Biological Sciences, v.3, n.5, p.45-62, 2016.

LUCENA, R. F. P.; ARAÚJO, E. L.; ALBUQUERQUE, U. P. Does the local availability of woody Caatinga plants (Northeastern Brazil) explain their use value? Economic Botany, v.61, n.4, p.347-361, 2007.

LUCENA, R. F. P.; NASCIMENTO, V. T.; ARAÚJO, E. L.; ALBUQUERQUE, U. P. Local uses of native plants in an area of Caatinga vegetation (Pernambuco, NE Brazil). Ethnobotany Research and Applications, v.6, p.3-13, 2008.

MACHADO, S. A.; AUGUSTYNCZIK, A. L. D.; NASCIMENTO, R. G. M.; TÉO, S. J.; MIGUEL, E. P.; FIGURA, M. A.; SILVA, L. C. R. Funções de distribuição diamétrica em um fragmento de Floresta Ombrófila Mista. Ciência Rural, v.39, p.2428-2434, 2009.

MARTINELLI, G.; MORAES, M. A. (Orgs.). Livro vermelho da flora do Brasil. Rio de Janeiro, Instituto de Pesquisas Jardim Botânico do Rio de Janeiro, 1100p, 2013.

MIRANDA, D. L. C.; MELO, A. C. G.; SANQUETTA, C. R. Equações alométricas para estimativa de biomassa e carbono em árvores de reflorestamentos de restauração. Revista Árvore, v.35, n.3, Edição Especial, p.679-689, 2011.

MINISTÉRIO DO MEIO AMBIENTE - MMA. Monitoramento do desmatamento nos biomas brasileiros por satélite acordo de cooperação técnica MMA/IBAMA. Monitoramento do Bioma Caatinga 2002 a 2008. MMA/CSR/IBAMA, Brasília, 58p, 2010.

MONTEIRO, J. M.; ALMEIDA, C. F. C. B. R.; ALBUQUERQUE, U. P.; LUCENA, R. F. P.; FLORENTINO A. T. N.; OLIVEIRA. R. L. C. Use and traditional management of Anadenanthera colubrina (Vell.) Brenan in the semiarid region of northeastern Brazil. Journal of Ethnobiology and Ethnomedicine, v.2, p.1-7, 2006.

MONTEIRO, M. Desertificação ameaça o nordeste brasileiro. Revista Ecologia e Desenvolvimento, n.51, p.15-19, 1995.

OLIVEIRA, T. M.; ALVES, A. R.; AMARAL, G. C.; ALMEIDA, K. N. S.; SOUZA, K. B.; AGUIAR, A. S.; ARAÚJO, E. F.; FARIAS, S. G. G. Análise da estrutura vegetacional em uma área de transição Cerrado-Caatinga no município de Bom Jesus-PI. Scientia Plena, v.8, n.4, p.01-05, 2012.

PAUlA, A.; SILVA, A. F.; MARCO JÚNIOR, P.; SANTOS, F. A. M.; SOUZA, A. L. Sucessão ecológica da vegetação arbórea em uma floresta estacional semidecidual, Viçosa, MG, Brasil. Acta Botânica Brasílica, n.18, v.3, p.407-423, 2004.

PÉLLICO NETO, S.; BRENA, D. A. Inventário florestal. Curitiba: Editorado pelos autores, 316p. 1997.

RAMOS, M. A.; MEDEIROS, P. M.; ALMEIDA, A. L. S.; FELICIANO A. L. P.; ALBUQUERQUE, U. P. Use and knowledge of fuelwood in an área of Caatinga vegetation in NE, Brazil. Biomass \& Bioenergy, v.32, p.510-517, 2008 a. 
RAMOS, M. A.; MEDEIROS, P. M.; ALMEIDA, A. L. S.; FELICIANO, A. L. P.; ALBUQUERQUE, U. P. Can wood quality justify local preferences for firewood in an area of Caatinga (dryland) vegetation. Biomass \& Bioenergy, v.32, p.503-509, 2008b.

RANGEL, M. S.; CALEGÁRIO, N.; MELlO, A. A. DE.; LEMOS, P. C. Melhoria na Precisão da Prescrição de Manejo para Floresta Natural. Cerne, Lavras, v.12, n.2, p.145156, 2006.

REZENDE, A. V.; VALE, A. T.; SANQUETTA, C. R.; FIGUEIREDO FILHO, A.; FELFILI, J. M. Comparação de modelos matemáticos para estimativa do volume, biomassa e estoque de carbono da vegetação lenhosa de um cerrado sensu stricto em Brasília, DF. Scientia Forestalis, n.71, p.65-76, 2006.

RIBEIRO, J. E. S.; CARVALHO, T. K. N.; RIBEIRO, J. P. de. O.; GUERRA, N. M.; SILVA, N.; PEDROSA, K. M.; ALVES, C. A. B.; SOUSA JUNIOR, S. P.; SOUTO, J. S.; NUNES, A. T.; FARIAS LIMA, J. R. de.; OLIVEIRA, R. S. de.; LUCENA, R. F. P. Ecological Apparency Hypothesis and Availability of Useful Plants: Testing different use values. Ethnobotany Research \& Applications, v.12, p.415-432, 2014.

RMFC. REDE DE MANEJO FLORESTAL DA CAATINGA. Protocolo de Medições de Parcelas Permanentes. Recife: Associação de Plantas do Nordeste.; Brasília: MMA,PNF,PNE. 28p, 2005.

ROCHA, C. C. C. Estimativa de volume, biomassa e carbono da vegetação lenhosa de floresta estacional no estado de Goiás. Dissertação (Mestrado em Ciências Florestais). Universidade de Brasília, Brasília, DF. 80p, 2011.

ROQUE, A. A.; ROCHA, R. M.; LOIOLA, M. I. B. Uso e diversidade de plantas medicinais da Caatinga na comunidade rural de Laginhas, município de Caicó, Rio Grande do Norte (nordeste do Brasil). Rev. Bras. Pl. Med., v.12, n.1, p.31-42, 2010.

SÁ, I. M. M.; MARANGON, L. C.; HANAZAKI, N.; ALBUQUERQUE, U. P. Use and knowledge of fuelwood in three rural Caatinga (dryland) communities in NE Brazil. Environment Development and Sustainability, v.11, p.833-852, 2009.

SALIN, T. C.; FERREIRA, R. L. C.; ALBUQUERQUE, S. F.; SILVA, J. A. A.; ALVES JUNIOR, F. T. Caracterização de sistemas agrícolas produtivos no semiárido brasileiro como bases para um planejamento agroflorestal. Revista Caatinga, v.25, n.2, p.109-118, 2012.

SAMPAIO, E. V. S. B.; SILVA, G. C. Biomass equations for Brazilian semiarid Caatinga plants. Acta Botanica Brasilica, v.19, n.4, p.935-943, 2005.

SANQUETTA, C. R.; WATZLAWICK, L. F.; SCHUMACHER, M. V.; MELLO, A. A. Relações individuais de biomassa e conteúdo de carbono em plantações de Araucaria angustifolia e Pinus taeda no sul do Estado do Paraná, Brasil. In: $2^{\mathbf{0}}$ Simpósio LatinoAmericano sobre Manejo Florestal, 2001, Santa Maria: p.415-427, 2001. 
SANTANA, J. A. S.; SOUTO, J. S. Diversidade e Estrutura Fitossociológica da Caatinga na Estação Ecológica do Seridó - RN. Revista de Biologia e Ciências da Terra, v.6, n.2, p.232-242, 2006.

SANTOS, R. C.; CASTRO, R. V. O.; CARNEIRO, A. C. O.; CASTRO, A. F. N. M.; PIMENTA, A. S.; PINTO, E. M.; MARINHO, I. V. Estoques de volume, biomassa e carbono na madeira de espécies da Caatinga em Caicó, RN. Pesq. flor. bras., v.36, n.85, p.1-7, 2016.

SILVA, A. A. S.; FERREIRA JÚNIOR, J. M.; SILVA, M. G. V.; MORAIS, S. M. Estudo fitoquímico e atividades biológicas do limãozinho (Zanthoxylum syncarpum Tull.). Revista Brasileira de Higiene e Sanidade Animal, v.8, n.1, p.37-53, 2014.

SILVA, G. C.; SAMPAIO, E. V. S. B. Biomassas de partes aéreas em plantas da Caatinga. Revista Árvore, v.32, n.3, p.567-575, 2008.

SIMINSKI, A.; MANTOVANI, M.; REIS, M. S.; FANTINI, A. C. Sucessão florestal secundária no município de São Pedro de Alcântara, litoral de Santa Catarina: Estrutura e diversidade. Ciência Florestal, v.14, n.1, p.21-33, 2004.

SOUZA, A. L.; COTA, A. P.; SOUZA, D. R. Um plano de manejo para a mata da silvicultura. Viçosa - MG, Manejo Florestal, Universidade Federal de Viçosa, 120p, 1999.

SOUZA, P. F.; SILVA, J. A.; LUCENA, D. S.; SANTOS, W. S.; HENRIQUES, Í. G. N.; LUCENA, M. F. A. SOUZA, A. D. Estudos fitossociológicos e dendrométricos em um fragmento de Caatinga, São José de Espinharas-PB. Ciência Florestal, v.26, n.4, p.13171330, 2016.

STAT SOFT, Inc. (2005). STATISTICA. (data analysis software system). Version 7.1. <www.statsoft.com>.

THAINES, F.; BRAZ, E. M.; MATTOS, P. P. de.; THAINES, A. A. R. Equações para estimativa de volume de madeira para a região da bacia do Rio Ituxi, Lábrea, AM. Bol. Pesq. Fl., v.30, n.64, p.283-289, 2010.

TROVÃO, D. M. B. M.; SILVA, S. C.; SILVA, A. B.; VIEIRA JÚNIOR, R. L. Estudo comparativo entre três fisionomias de Caatinga no estado da Paraíba e análise do uso das espécies vegetais pelo homem nas áreas de estudo. REVISTA DE BIOLOGIA E CIÊNCIAS DA TERRA, v.4, n.2, p.01-05, 2004.

UBIALLI, J. A.; FIGUEIREDO FILHO, A.; MACHADO, S. A.; ARCE, J. E. Comparação de métodos e processos de amostragem para estudos fitossociológicos em uma floresta ecotonal na região norte matogrossense. Revista Floresta, v.39, n.3, p.511-523, 2009. 


\title{
CAPÍTULO 3
}

\section{ANÁLISE DE GRADIENTES AMBIENTAIS EM TRÊS ÁREAS DE CAATINGA SETENTRIONAL NO ESTADO DA PARAÍBA - BRASIL}

\begin{abstract}
RESUMO - Este trabalho teve como objetivo avaliar possíveis autocorrelações de vegetação com variáveis espaciais e ambientais em três áreas de Caatinga arbustivoarbórea, nos municípios de São José do Bonfim (SJB), Itaporanga (ITA) e Lagoa (LAG), no estado da Paraíba - Brasil. Para o levantamento da vegetação, em cada área de estudo foram estabelecidas 25 parcelas de $400 \mathrm{~m}^{2}(20 \times 20 \mathrm{~m})$, sistematicamente distribuídas em malha de $150 \times 150 \mathrm{~m}$. Nas parcelas foram amostrados todos os indivíduos lenhosos cuja circunferência a $1,30 \mathrm{~m}$ (CAP) era maior que $6 \mathrm{~cm}$ sendo realizada a identificação florística e quantificação de parâmetros fitossociológicos. Em todas as parcelas os valores de altitude e de coordenadas geográficas foram registradas e o solo foi amostrado a profundidade de 0 - $60 \mathrm{~cm}$ para realização das análises químicas de rotina, CTC - Total, $\mathrm{pH}$ e matéria orgânica. Os dados obtidos foram submetidos à Análise de Redundância Redundancy Analysis (RDA), a qual relacionou variáveis de vegetação, variáveis ambientais e variáveis espaciais, utilizando o software " $R$ " versão 3.2.5. Nesta análise foi estimado preditores ambientais e espaciais que pudessem explicar a distribuição florística e participação estrutural das espécies nas três áreas estudadas. Das frações interpretadas na relação vegetação x ambiente, $4 \%$ são explicados por meio das variáveis ambientais, $11 \%$ por meio das variáveis espaciais e $27 \%$ são explicados por meio da interação espaço e ambiente. Foi observado $58 \%$ de resíduo. A variável ambiental altitude foi a que apresentou maior influência na distribuição florística estrutural das vegetações estudadas. A espécie Poincianella pyramidalis demonstra sua capacidade cosmopolita para colonização das três áreas bem como demonstrou ser indiferente às variáveis ambientais e espaciais observadas nas três áreas neste estudo.
\end{abstract}

Palavras-chave: Caatinga; Relação Vegetação Ambiente, Filtro Ambiental e Espacial

\section{ANALYSIS OF ENVIRONMENTAL GRADIENTS IN THREE AREAS OF NORTHERN CAATINGA IN PARAIBA STATE - BRAZIL}

\begin{abstract}
The present study aimed to evaluate possible vegetation autocorrelations with spatial and environmental variables in three areas of shrub-tree Caatinga, in the municipalities of São José do Bonfim (SJB), Itaporanga (ITA), and Lagoa (LAG), in Paraiba state - Brazil. With regards to the vegetation survey, 25 plots measuring $400 \mathrm{~m}^{2}(20$ x 20m) were established and systematically distributed in mesh of $150 x 150 \mathrm{~m}$ in each study area. As to the plots, all the woody individuals were sampled whose circumference at $1,30 \mathrm{~m}$ (CAP) was bigger than $6 \mathrm{~cm}$, in which the floristic identification and the quantification of phytosociological parameters were performed. The altitude and geographical coordinates values were recorded in all the plots, and the soil was sampled at a depth of $0-60 \mathrm{~cm}$ in order to perform routine chemical analyzes, CTC- Total, $\mathrm{pH}$ and organic matter. The collected data was submitted to Redundancy Analysis (RDA) which related vegetation variables, environmental variables and spatial variables, using software " $R$ " version 3.2.5. In this analysis, environmental and spatial predictors were estimated in order to explain the floristic distribution and the structural participation of species in the three areas studied. Among the fractions interpreted in light of vegetation $\mathrm{x}$ environment relation, $4 \%$ are explained through environmental variables, $11 \%$ through spatial variables
\end{abstract}


and $27 \%$ are explained through space-environment interaction. Furthermore, $58 \%$ of residue was observed. The environmental variable altitude presented major influence as to the structural floristic distribution of the vegetation studied. The specie Poincianella pyramidalis demonstrates its cosmopolitan capacity of colonization of the three areas as well as showed indifference to the environmental and spatial variables observed in the three areas of this study.

Key words: Caatinga; vegetation-environment relation; spatial and environmental filter 


\subsection{INTRODUÇÃO}

A origem da vegetação da Caatinga tem sido debatida ao longo de muitos anos, mas resultados de estudos sugerem que a mesma é parte de uma floresta tropical seca sazonal que ocupou grandes áreas da América do Sul em períodos mais secos e frios durante o Pleistoceno (PENNINGTON et al., 2000; PENNINGTON et al., 2004).

No domínio da vegetação de Caatinga, suas características edafoclimáticas são semelhantes às de outros semiáridos quentes do mundo, com secas e cheias periódicas dos rios intermitentes, solos rasos, em geral salinos, que não favorecem o desenvolvimento da vegetação. A vegetação de Caatinga apresenta diferentes formações tipológicas e todas adaptadas à estação de secas prolongadas (REBOUÇAS, 1997). No entanto, dentro deste bioma, existem áreas de altitudes consideradas diferenciadas por clima, solos e vegetação quando comparadas à vegetação do entorno, inserida dentro de uma condição climática semiárida, sendo estas áreas intensivamente utilizadas em práticas de agricultura e pecuária (ANDRADE-LIMA, 1960).

A Caatinga arbórea está presente nos solos distribuídos desde o norte de Minas Gerais até o Rio Grande do Norte. Apresenta desde florestas secas adaptadas com precipitações inferiores a $500 \mathrm{~mm}$ a florestas mais úmidas, chamadas de brejos de altitude, que se estendem sobre as encostas e topos das chapadas e serras com mais de $500 \mathrm{~m}$ de altitude, recebendo mais de $1.200 \mathrm{~mm}$ de chuvas orográficas (PRADO, 2003).

A região semiárida brasileira se caracteriza por apresentar formações do cristalino praticamente impermeáveis e terrenos sedimentares que apresentam boa reserva de água subterrânea. Os solos, com raras exceções, são pouco desenvolvidos, mineralmente ricos, pedregosos e pouco espessos, dotados de/apresentando fraca capacidade de retenção da água, fator limitante à produção primária nessa região (ALVES et al., 2008). O solo presente na paisagem é um reflexo dos fatores e dos processos de formação, desde a sua origem até o tempo atual (GHIDIN et al., 2006). Estes processos estão relacionados à litologia, ao intemperismo dos minerais, ao teor e tipo de minerais e aos elementos químicos e físicos no solo (CAMARGO et al., 2008).

Aproximadamente $50 \%$ dos solos com vegetação de Caatinga são de origem sedimentar. A altitude da região varia de 0 a $600 \mathrm{~m}$, com alguns setores que ultrapassam estas cotas, chegando a $1000 \mathrm{~m}$ de altitude, a temperatura média anual varia em torno de 20 a $28^{\circ} \mathrm{C}$ e a precipitação varia de 250 a $1000 \mathrm{~mm}$ anuais, sendo elevado o déficit hídrico (BENEVIDES; CARVALHO, 2009). As diferentes formações edáficas presentes no bioma 
Caatinga estão relacionadas com o clima semiárido e a alta variabilidade de preciptação e a ocorrência de períodos de secas frequentes (BARBOSA; LAKSHMI KUMAR, 2016). Em escalas regionais e locais estes fatores contribuem para a formação de um diversificado mosaico vegetacional xerófilo de fitofisionomias de Caatinga distribuídos na paisagem (RODAL et al., 2008).

Um fator importante a ser considerado em estudos de vegetação é a presença de autocorrelação espacial, a qual estão relacionados fenômenos ecológicos, bem como variáveis edáficas e altitudinais que caracterizam o ambiente estão sujeitas a este fator (LEGENDRE; FORTIN, 1989; LEGENDRE, 1993; LENNON, 2000; LACERDA; KAGEYAMA, 2003). Esse fator busca entender se tais fenômenos e variáveis podem influenciar na distribuição de espécies vegetais de um ambiente.

Segundo Costa et al. (2010) as espécies possuem caráter comportamental em relação às características do meio físico em que está inserida, determinando as peculiaridades das plantas. De acordo com Holanda et al. (2015), os processos biológicos envolvidos por variáveis ambientais no espaço produzem e selecionam peculiaridades adaptativas, tornando a flora endêmica da Caatinga compatível com as condições severas a que estão sujeitos os táxons.

Considerando a necessidade de conhecer mais profundamente a flora da Caatinga e seu comportamento em relação a variáveis presentes no ambiente,

Este trabalho teve como objetivo avaliar possíveis autocorrelações de vegetação com variáveis espaciais e ambientais (edáficas e altitudinais) em três áreas de Caatinga arbustivo-arbórea nos municípios de São José do Bonfim (SJB), Itaporanga (ITA) e Lagoa (LAG), no estado da Paraíba - Brasil. 


\subsection{MATERIAL E MÉTODOS}

\subsection{1. Áreas de estudo}

Este estudo foi feito em três áreas de vegetação de Caatinga arbustivo-arbórea na região semiárida do estado da Paraíba, localizadas nos municípios de São José do Bonfim, Itaporanga e Lagoa conforme descrito no item 1.2.1 do Capítulo 1.

\subsubsection{Coleta de dados}

Em cada área de estudo foi estabelecida uma malha de amostragem sistemática com 25 parcelas de $400 \mathrm{~m}^{2}(20 \times 20 \mathrm{~m})$ distantes $150 \mathrm{~m}$ uma da outra. Nestas parcelas foi inventariada a vegetação arbustivo-arbórea sendo medidos e identificados todos os indivíduos cuja circunferência a $1,30 \mathrm{~m}$ do solo na altura do peito (CAP) foi superior a $6 \mathrm{~cm}$. Foi tomada a medida de CAP, conforme procedimentos estabelecidos no protocolo de medições de parcelas permanentes da Rede de Manejo Florestal da Caatinga (2005).

Nestas parcelas foi amostrado o solo na profundidade de 0 a $60 \mathrm{~cm}$ mediante obtenção de um amostra composta por 5 amostras simples para cada parcela, para determinação de pH em água, capacidade de troca de cátions a pH 7,0 (CTC - Total) e matéria orgânica (MO) conforme descrito pela Embrapa (2011). Foram também obtidos as coordenadas geográficas e a altitude utilizando GPS de navegação com altímetro barométrico com precisão de $5 \mathrm{~m}$.

\subsubsection{Análise das variáveis}

As características químicas dos solos, juntamente com matéria orgânica e altitude de cada parcela representam a matriz de variáveis preditoras ambientais. A matriz de vegetação foi composta pela variável densidade de indivíduos por hectare e as variáveis latitude e longitude (UTM) de cada parcela foram consideradas variáveis preditoras espaciais. Estes dados foram correlacionados mediante a utilização de técnicas de estatística multivariada, com os dados de vegetação mediante Análise de Redundância Redundancy Analysis (RDA), utilizando o software "R" versão 3.2 .5 (2016) e os pacotes AEM, vegan, packfor e spacemakeR, sendo as análises aplicadas de acordo com Bocard et al. (2011), Legendre; Legendre (2012). 
Para a análise dos dados, foram construídas três matrizes: A primeira é a Matriz Florístico/Estrutural, composta pelo registro de ocorrência dos valores de densidade, número de indivíduos por parcela para as três áreas estudadas de São José do Bonfim, Itaporanga e Lagoa (Anexo 7). Para a variável florística, foram consideradas apenas as espécies que apresentaram mais de um indivíduo por hectare na amostragem em cada área de estudo. A segunda é a Matriz Variáveis Ambientais, compreendendo as variáveis pH em água, capacidade de troca de cátions a pH 7,0 (CTC - Total), matéria orgânica (MO) e altitude para cada parcela (Tabela 1). Por fim, a terceira é a Matriz Espacial, composta pelas coordenadas geográficas latitude e longitude em UTM.

Os dados de vegetação foram transformados usando "Hellinger" enquanto que as variáveis ambientais foram transformadas por "stand" conforme proposto por Puga (2007).

A partir das coordenadas geográficas de cada parcela derivamos filtros espaciais (Principal Coordinates of Neighbor Matrices - PCNM) por meio da análise de coordenadas principais da matriz de distância Euclidiana com base no "Minimum Spanning Tree" descrito por Griffith; Peres-Neto (2006). Os filtros espaciais com autovalores positivos foram selecionados iterativamente usando seleção progressiva (Forward Selection) (BLANCHET et al., 2008). Do mesmo modo, para reduzir o número de preditores e eliminar colinearidades nos modelos de RDA selecionamos interativamente as variáveis ambientais por seleção progressiva. Avaliamos, ainda, a colinearidade nos preditores mediante ao fator de inflação da variância (VIF), usando a função vif.cca no pacote vegan. Para fins de visualização, plotamos os diagramas das RDA mantendo apenas os preditores selecionados.

Nesse processo, foi realizada a partição da variância segundo Legendre; Legendre (2012), para verificar a significância dos preditores na distribuição das espécies no ambiente e no espaço, a qual a partição da variância é derivada das seguintes frações: ambiental (a), da interação ambiental e espacial (b), espacial (c) e residual (d), esta partição analisa variáveis ambientais, espaciais e as interações entre ambiente e espaço. Utilizando o diagrama de Venn foi aplicado a ANOVA com 999 permutações e alpha a 0,05, segundo as prescrições dos autores supracitados.

Através da análise de redundância, fez-se a construção do diagrama de ordenação dos dados. Essa análise multivariada é preferencialmente indicada quando o objetivo é estudar as relações entre as variáveis ambientais e espaciais na influência da vegetação (LEGENDRE; LEGENDRE, 2012). 


\subsection{RESULTADOS E DISCUSSÃO}

Na tabela 1 são apresentadas as variáveis ambientais obtidas para as áreas de estudo e utilizadas na Análise de Redundância - Redundancy Analysis (RDA).

Tabela 1: Variáveis ambientais obtidas para as áreas de São José do Bonfim, Itaporanga e Lagoa, no estado da Paraíba - Brasil.

\begin{tabular}{|c|c|c|c|c|c|c|c|c|c|c|c|c|}
\hline \multirow[b]{2}{*}{ Parcela } & \multicolumn{4}{|c|}{ São José do Bonfim } & \multicolumn{4}{|c|}{ Itaporanga } & \multicolumn{4}{|c|}{ Lagoa } \\
\hline & $\begin{array}{c}\mathrm{CTC}(\mathrm{T}) \\
\left(\mathrm{cmol}_{d} / \mathrm{dm}^{3}\right)\end{array}$ & $\mathrm{pH}$ & $\begin{array}{c}\mathrm{MO} \\
\text { (dag/kg) }\end{array}$ & $\begin{array}{l}\text { Alt } \\
(\mathrm{m})\end{array}$ & $\begin{array}{c}\mathrm{CTC}(\mathrm{T}) \\
\left(\mathrm{cmol}_{d} / \mathrm{dm}^{3}\right)\end{array}$ & $\mathrm{pH}$ & $\begin{array}{c}\mathrm{MO} \\
(\mathrm{dag} / \mathrm{kg})\end{array}$ & $\begin{array}{l}\text { Alt } \\
\text { (m) }\end{array}$ & $\begin{array}{c}\mathrm{CTC}(\mathrm{T}) \\
\left(\mathrm{cmol}_{d} / \mathrm{dm}^{3}\right)\end{array}$ & $\mathrm{pH}$ & $\begin{array}{c}\mathrm{MO} \\
(\mathrm{dag} / \mathrm{kg})\end{array}$ & $\begin{array}{l}\text { Alt } \\
\text { (m) }\end{array}$ \\
\hline 1 & 14,88 & 4,7 & 2,32 & 297 & 2,61 & 5 & 1,52 & 561 & 2,89 & 4,6 & 1,70 & 597 \\
\hline 2 & 24,74 & 5,9 & 2,69 & 296 & 3,42 & 5,4 & 1,41 & 557 & 4,17 & 4,6 & 1,63 & 604 \\
\hline 3 & 8,71 & 4,6 & 2,30 & 296 & 4,05 & 5,9 & 1,66 & 542 & 5,62 & 5,3 & 1,81 & 609 \\
\hline 4 & 12,72 & 5,0 & 3,27 & 302 & 4,62 & 5,3 & 1,51 & 540 & 4,26 & 5,7 & 1,56 & 583 \\
\hline 5 & 9,60 & 5,7 & 2,12 & 295 & 5,51 & 5,0 & 1,83 & 544 & 5,80 & 5,8 & 2,15 & 639 \\
\hline 6 & 8,74 & 5,2 & 1,66 & 286 & 4,09 & 5,3 & 1,48 & 495 & 7,81 & 5,6 & 2,98 & 651 \\
\hline 7 & 8,15 & 5,1 & 1,89 & 296 & 3,59 & 5,1 & 1,26 & 496 & 6,54 & 5,2 & 2,31 & 630 \\
\hline 8 & 7,52 & 5,4 & 2,16 & 266 & 5,47 & 5,3 & 1,67 & 450 & 4,96 & 4,8 & 1,77 & 637 \\
\hline 9 & 11,67 & 5,5 & 3,01 & 289 & 5,41 & 5,4 & 1,26 & 491 & 7,97 & 4,4 & 2,54 & 680 \\
\hline 10 & 17,59 & 5,8 & 1,36 & 299 & 4,32 & 5,2 & 1,49 & 514 & 4,70 & 5,0 & 1,60 & 715 \\
\hline 11 & 26,60 & 5,5 & 2,26 & 303 & 3,60 & 5,1 & 1,63 & 520 & 4,72 & 4,9 & 1,73 & 723 \\
\hline 12 & 12,57 & 5,5 & 2,40 & 303 & 4,84 & 5,4 & 1,57 & 537 & 6,38 & 5,9 & 2,17 & 664 \\
\hline 13 & 12,72 & 5,5 & 2,23 & 300 & 3,66 & 5,0 & 1,13 & 538 & 6,64 & 5,7 & 2,21 & 675 \\
\hline 14 & 15,57 & 6,1 & 2,18 & 299 & 2,81 & 5,0 & 1,37 & 552 & 7,06 & 5,3 & 2,42 & 742 \\
\hline 15 & 15,98 & 5,8 & 2,76 & 314 & 3,70 & 4,9 & 1,34 & 566 & 5,70 & 4,6 & 1,87 & 746 \\
\hline 16 & 12,68 & 6,4 & 1,57 & 297 & 3,68 & 4,5 & 1,57 & 582 & 5,22 & 5,3 & 1,82 & 728 \\
\hline 17 & 14,06 & 5,6 & 1,85 & 312 & 3,97 & 5,2 & 1,69 & 582 & 5,50 & 5,2 & 2,07 & 690 \\
\hline 18 & 15,97 & 5,9 & 2,10 & 312 & 3,20 & 4,9 & 1,36 & 561 & 5,29 & 4,9 & 1,83 & 735 \\
\hline 19 & 19,42 & 5,8 & 1,56 & 302 & 3,80 & 5,2 & 1,37 & 546 & 8,34 & 5,8 & 2,68 & 714 \\
\hline 20 & 13,25 & 6,0 & 2,01 & 292 & 4,41 & 5,2 & 1,66 & 513 & 6,13 & 5,5 & 2,11 & 720 \\
\hline 21 & 10,43 & 5,9 & 1,63 & 297 & 2,73 & 4,8 & 1,37 & 517 & 3,30 & 5,4 & 1,49 & 712 \\
\hline 22 & 16,06 & 6,0 & 2,04 & 304 & 3,50 & 5,0 & 1,38 & 503 & 6,05 & 5,7 & 2,49 & 707 \\
\hline 23 & 19,55 & 6,3 & 3,15 & 298 & 4,20 & 5,2 & 1,49 & 515 & 4,53 & 5,3 & 1,66 & 721 \\
\hline 24 & 16,87 & 6,1 & 2,31 & 301 & 4,91 & 5,8 & 1,43 & 514 & 7,47 & 5,9 & 2,36 & 682 \\
\hline 25 & 12,70 & 6,0 & 2,29 & 304 & 5,01 & 5,6 & 1,69 & 469 & 6,42 & 5,4 & 2,27 & 685 \\
\hline
\end{tabular}

Em que: $\mathrm{CTC}(\mathrm{T})$ = Capacidade de troca de cátions a pH 7,0; MO = matéria orgânica; Alt = Altitude em $\mathrm{m}$. 
Foram encontradas 3 variáveis ambientais e 6 filtros espaciais significativos, sendo estes os responsáveis pela composição de espécies ao longo entre as áreas de São José do Bonfim, Itaporanga e Lagoa. A RDA construída a partir dos dados ambientais, espaciais e florísticos estruturais da vegetação arbustivo-arbórea, evidenciou três grupos distintos, sendo que os eixos 1 e 2 da RDA juntos explicam 54,60\% da variação na composição florística destes grupos formados (Figura 1).

Os preditores ambientais e espaciais com os descritores florísticos estruturais da vegetação se mostraram parcialmente estruturados para as três áreas estudadas (Figura 1). As áreas de vegetação de Caatinga arbustivo-arbórea de Itaporanga e Lagoa se diferenciaram da área de São José do Bonfim (eixo 1), em função da distância devido a atuação do espaço geográfico e das características ambientais, das diferenças edáficas de pH e por apresentarem maiores altitudes. Estas características criam condições distintas que influenciam diretamente nos ambientes locais e que consequentemente apresentam diferenças na riqueza florística e na estrutura da vegetação das áreas estudadas.

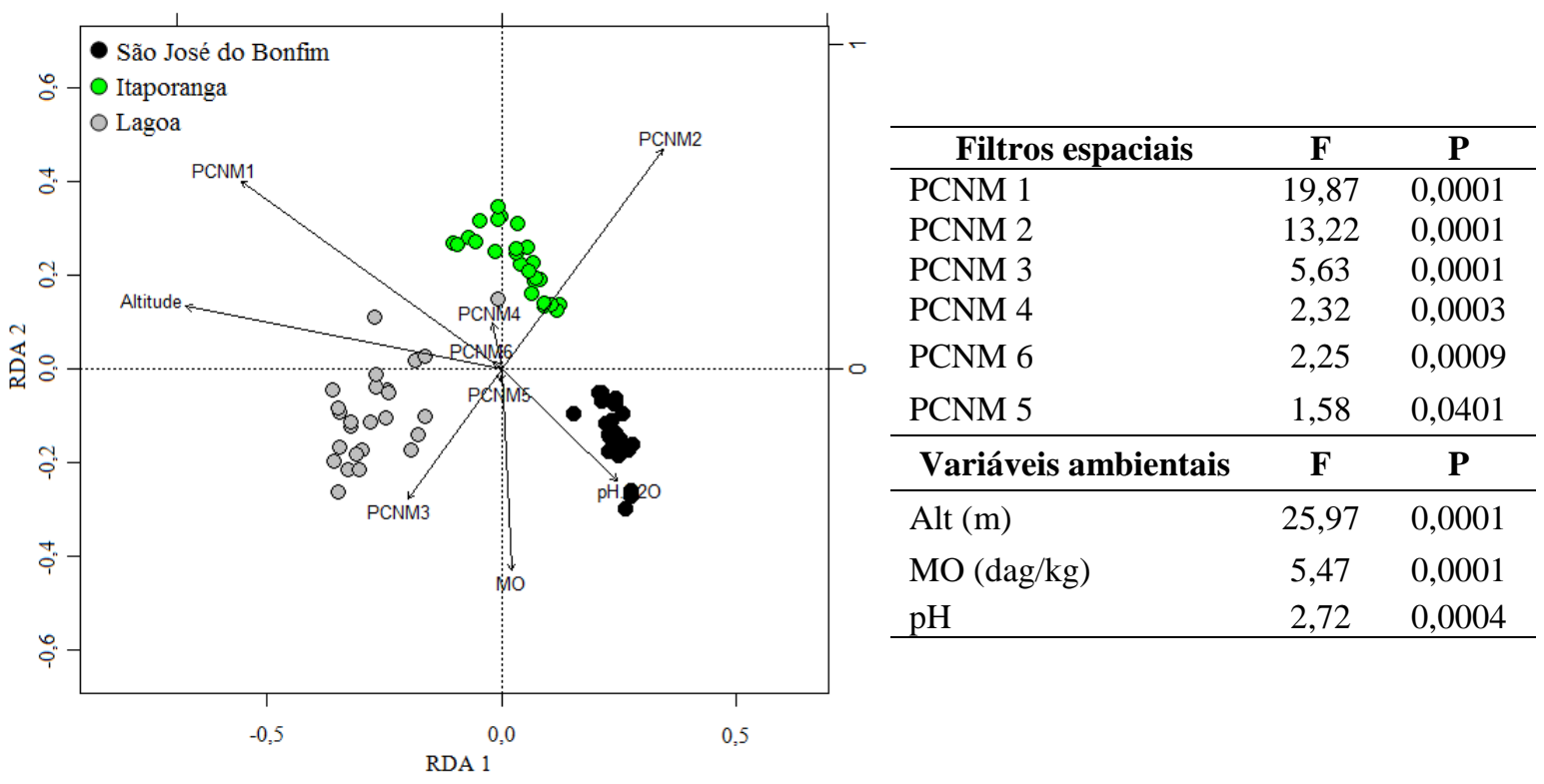

Figura 1. Diagrama de ordenação (RDA) das variáveis preditoras ambientais e espaciais para a densidade de indivíduos das espécies arbustivas e arbóreas da vegetação de Caatinga nas áreas de São José do Bonfim, Itaporanga e Lagoa, no estado da Paraíba Brasil. 
A área de Lagoa se diferenciou da área de Itaporanga tanto em função da distância devido a atuação do espaço geográfico quanto pelo fato do solo destas áreas apresentarem diferenças nos teores de matéria orgânica, a qual uma importante condicionador do solo (Figura 1).

As variáveis ambientais e espaciais interpretadas para a composição florística estrutural de vegetação de Caatinga arbustivo-arbórea para as áreas de estudo indicam que $4 \%$ são explicados por meio das variáveis ambientais, $11 \%$ por meio das variáveis espaciais e $27 \%$ são explicados por meio da interação espaço e ambiente, sendo $58 \%$ de resíduo (Figura 2).

As variáveis espaciais apresentaram maior correlação do que as ambientais para explicar a variação na composição florística estrutural de vegetação de Caatinga arbustivoarbórea nas áreas de São José do Bonfim, Itaporanga e Lagoa. A interação espaçoambiente apresentou maior importância que as frações apenas ambientais ou apenas espaciais (Figura 2). Isso demonstra que a interação das variáveis ambientais e espaciais selecionadas na RDA são e foram importantes na distribuição da vegetação de Caatinga arbustivo-arbórea nas áreas estudadas.

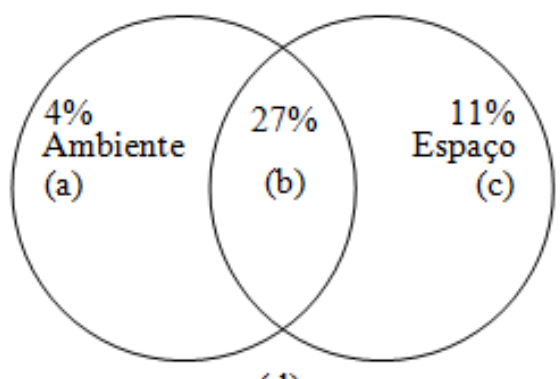

(d) Resíduo: $58 \%$

Figura 2: Partição da variância das frações que explicam a variação da densidade de indivíduos para as espécies arbustivas e arbóreas de vegetação de Caatinga nas áreas de São José do Bonfim, Itaporanga e Lagoa, no estado da Paraíba - Brasil.

As áreas de Itaporanga e Lagoa apresentam distinção em relação à área de São José do Bonfim devido a ocorrência do espaço geográfico distinto e por apresentar as maiores altitudes. A altitude foi a variável ambiental mais significativa na diferenciação florística estrutural nas áreas de estudo. Lemos, Meguro (2015) verificaram que fatores do ambiente tais como altitude e qualidade química de solos determinam riquezas florísticas entre áreas de vegetação de Caatinga. Em consonância, Bispo et al. (2010), concordaram que 
diferentes estratos de vegetação mostraram-se condicionadas sobretudo pela altitude. De acordo com Balvanera; Aguirre (2006), a vegetação ocupa diferentes gradientes ambientais no espaço, no qual proporcionam maior ou menor disponibilidade de fatores que podem ser limitantes para determinados grupos de espécies assim como verificado no presente estudo dado o maior número de espécies arbustivas-arbóreas presente nas áreas de Itaporanga e Lagoa, de maiores altitudes, em relação a São José do Bonfim, de menor altitude.

Neste estudo, para a maioria das espécies, a ocorrência e ou participação mais efetiva das variáveis espaciais e ambientais não foi identificada como determinantes na estrutura fitossociológica das áreas de São José do Bonfim, Itaporanga e Lagoa (Figura 3).

Para as 14 espécies que estiveram presentes nas três áreas de estudo foi verificado que para Handroanthus impetiginosus, Commiphora leptophloeos, Cynophalla hastata, Erythroxylum Caatinga, Jatropha mollissima, Poincianella pyramidalis, Senna macranthera e Libidibia ferrea não houve ocorrência de nenhuma correlação com variáveis ambientais e espaciais estudas. Todas estas espécies, à exceção de Poincianella pyramidalis, apresentam baixos valores de Densidade de indivíduos e de Índice de Valor de Importância (IVI\%) nas áreas de estudo (Anexos 1, 2 e 3). Desta forma Poincianella pyramidalis demonstra sua capacidade cosmopolita para colonização das três áreas bem como sua indiferença às variáveis ambientais e espaciais observadas nas três áreas deste estudo.

A espécie Croton blanchetianus apesar de ter apresentado alta correlação com variáveis espaciais, nas três áreas de estudo está entre as duas espécies de maior densidade e IVI\%. Para esta espécie as variações ambientais não apresentaram amplitude de variação suficiente para interferir significativamente em sua ocorrência e participação nas área de estudo e, ou não foram consideradas outras variáveis, como tipo de dispersão, isolamento geográfico, pragas, doenças entre outras que possam melhor explicar o comportamento desta espécie como relatado por Oliveira-Filho et al. (1994), Aubert; Oliveira-Filho (1994), Ter Braak (1987) e Ter Braak; Prentice (1988).

As espécies Gymnanthes boticario, Luehea ochrophylla, Senegalia polyphylla, Helicteres heptandra, Guapira laxa, Eugenia flavescens, Aspidosperma riedelii, Peltogyne pauciflora, Myrciaria floribunda, Erythroxylum nummularia, Croton nepetifolius apresentaram correlação com altitude e espaço (Figura 3). As espécies Myracrodruon urundeuva, Amburana cearensis, Annona leptopetala, Sapium glandulosum, Manihot carthaginensis, Cochlospermum vitifolium, Commiphora leptophloeos, Ximenia americana, Sigmatanthus trifoliatus, Luetzelburgia auriculata, Mimosa ophthalmocentra, 
Combretum leprosum e Croton blanchetianus apresentaram correlação com o espaço e alta correlação negativa com teor de matéria orgânica (Figura 3).

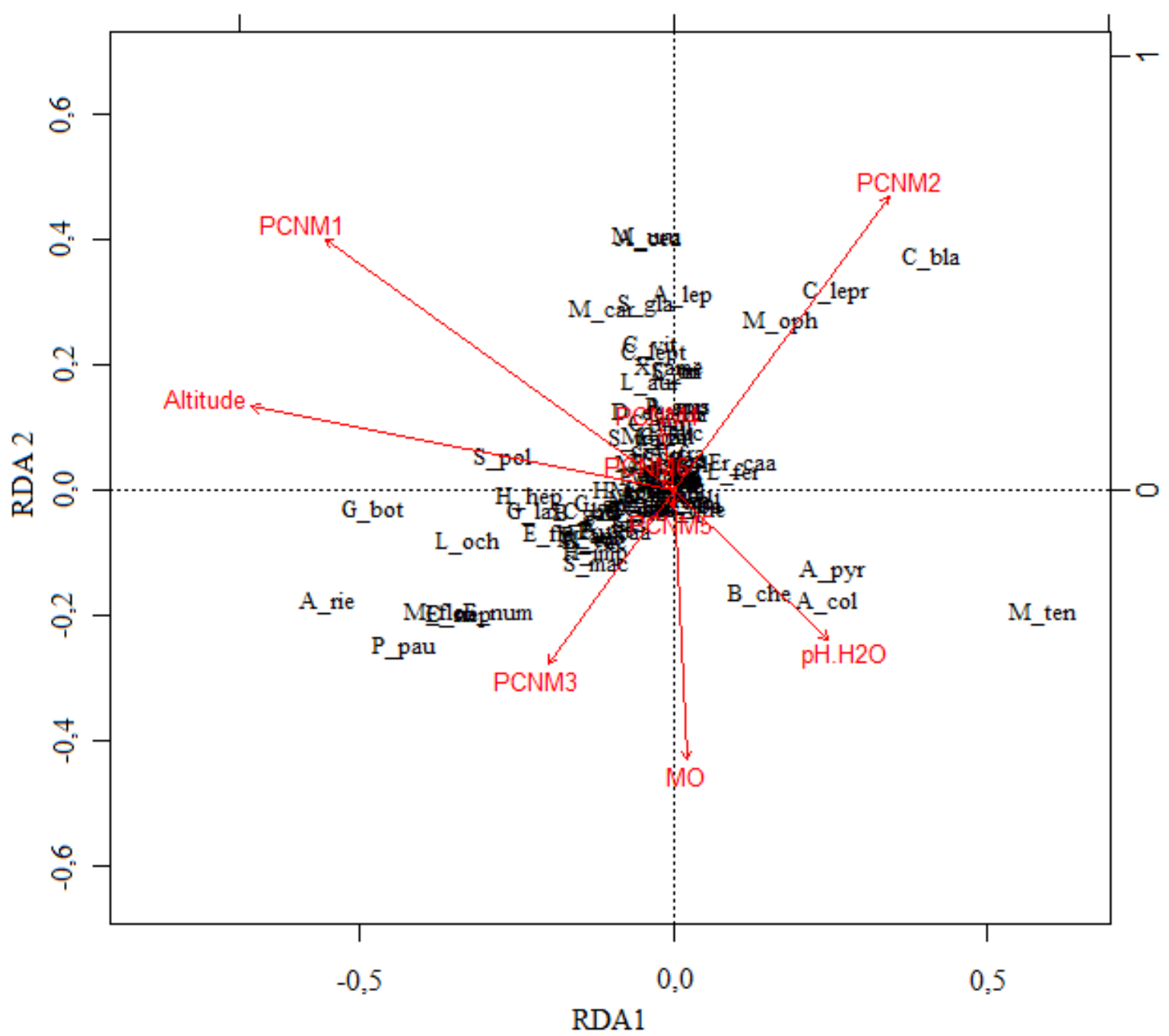

Figura 3: Composição florística selecionada pelas variáveis espaciais e ambientais significativas e selecionadas pela RDA para a vegetação arbustivo-arbórea de Caatinga nas áreas de São José do Bonfim, Itaporanga e Lagoa, no estado da Paraíba - Brasil. PCNM = filtros espaciais.

A maioria dessas espécies citadas relacionadas com variáveis ambientais e espaciais são comumente encontradas em levantamentos realizados em áreas de Caatinga no estado da Paraíba, como os de Sabino et al. (2016), Holanda et al. (2015), Pereira Júnior et al. (2014), Guedes et al. (2012) e Pereira Júnior et al. (2012); à exceção de Eugenia flavescens, Annona leptopetala, Erythroxylum nummularia, Myrciaria floribunda, Annona leptopetala, Sigmatanthus trifoliatus registradas pela primeira vez ocorrendo em vegetação de Caatinga arbustivo-arbórea em áreas de altitude no semiárido no estado da Paraíba, conforme comparação feita pela Lista de Espécies da Flora do Brasil (BFG, 2015). 
As demais espécies que ocorrem nas três áreas de estudo Combretum leprosum, Manihot carthaginensis, Mimosa ophthalmocentra, Bauhinia cheilantha e Mimosa tenuiflora apresentam correlação com preditores do ambiente e/ou do espaço com baixa correlação com sua participação na estrutura fitossociológica das áreas.

Em parte, as diferenças na composição florística estrutural se deram devido ao efeito tanto do espaço e/ou quanto do ambiente na qual estão inseridas assim como também observado no estudos de Farias et al. (2016), em que variáveis espaciais e ambientais explicam apenas em parte as variações no comportamento das características florísticas estruturais da vegetação de Caatinga em diferentes ambientes.

Teorias de sucessão ecológica apresentadas por autores como Clements (1916 e 1936), Gleason (1926), Whittaker (1953), Connell; Slatyer (1977), Connell et al. (1987), Walter (1971), Walker; Chapin (1987), Horn (1976), Tilman (1985), e Begon et al. (1996) em resumo nos levam a considerar que o processo de colonização de uma área por espécies está em sintonia com as condições abióticas e bióticas, sendo que estas interagem entre si e por vezes são causa e consequência umas das outras, em maior ou menor escala. Assim estudos como o realizado nestas áreas propiciaram o entender de que nossas avaliações ainda são frágeis e, portanto muito maior esforço deve ser dispensado em estudos florísticos e estruturais correlacionados ao ambiente e ao espaço para podermos preservar, conservar e recuperar os diversos ambientes existentes. 


\subsection{CONCLUSÕES}

Os preditores espaço e ambiente em conjunto expressam de maneira mais significativa a distribuição da vegetação de Caatinga arbustivo-arbórea nas áreas de São José do Bonfim, Itaporanga e Lagoa, do que em separado.

A variável ambiental altitude foi a que apresentou maior influência na distribuição florística estrutural de vegetação de Caatinga arbustivo-arbórea nas áreas de São José do Bonfim, Itaporanga e Lagoa.

A espécie Poincianella pyramidalis demonstra sua capacidade cosmopolita para colonização das três áreas bem como sua indiferença às variáveis ambientais e espaciais observadas nas três áreas neste estudo. 


\section{REFERÊNCIAS}

AUBERT, E.; OLIVEIRA-FILHO, A. T. Análise multivariada da estrutura fitossociológica do sub-bosque de plantios experimentais de Eucalyptus spp. e Pinus spp. em Lavras (MG). Revista Árvore, v.18, n.3, p.194-214, 1994.

ALVES, J. J. A.; ARAÚJO, M. A.; NASCIMENTO, S. S. Degradação da Caatinga: Uma Investigação Ecogeográfica. Caminhos de Geografia, v.9, n.27, p.143-155, 2008.

ANDRADE-LIMA, D. Estudos fisiogeográficos de Pernambuco. Arquivos do IPA, v.5, p.305-341, 1960.

BALVANERA, P.; AGUIRRE, E. Tree diversity, environmental heterogeneity, and productivity in a Mexican tropical dry forest. Biotropica, v.38, p.479-491, 2006.

BARBOSA, H. A.; LAKSHMI KUMAR, T. V. Influence of rainfall variability on the vegetation dynamics over Northeastern Brazil. Journal of Arid Environments, n.124, p.377-387, 2016.

BENEVIDES, D. S.; CARVALHO, F. G. de. Levantamento da flora apícola presente em áreas de Caatinga do município de Caraúbas - RN. Sociedade e Território, v.21, n.1-2, p.44-54, 2009.

BEGON, M.; HARPER, J. L.; TOWNSEND, C. R. Ecology: Individuals, populations and communities. 3.ed. Oxford, Blackwell Science, 1068p, 1996.

BISPO, P. C.; VALERIANO, M. M.; KUPLICH, T. M. Relação da vegetação de Caatinga com a condição geomorfométrica local. Revista Brasileira de Engenharia Agrícola e Ambiental, v.14, n.5, p.523-530, 2010.

BFG. Growing knowledge: an overview of Seed Plant diversity in Brazil. Rodriguésia, Rio de Janeiro, v.66, n.4, p.1085-1113. 2015.

BLANCHET, F. G.; LEGENDRE, P.; BORCARD, D. Forward selection of spatial explanatory variables. Ecology, v.89, n.9, p.2623-2632, 2008.

BOCARD, D.; GILLET, F.; LEGENDRE, P. Applied spatial data analysis with R. New York, NY: Springer New York, 2011.

CAMARGO, L. A.; MARQUES JÚNIOR, J.; PEREIRA, G. T.; HORVAT, R. A. Variabilidade espacial de atributos mineralógicos de um Latossolo sob diferentes formas do relevo. I - mineralogia da fração argila. Revista Brasileira de Ciência do Solo, v.32, p.2269-2277, 2008.

CLEMENTS, F. E. Nature and structure of the climax. The Journal of Ecology, v.24, n.1, p.252-284, 1936.

CLEMENTS, F. E. Plant Succession: Analysis of the development of vegetation. Carnegie Institute, Washington: Publication: 242, 516p, 1916. 
CONNELL, J. H.; NOBLE, I. R.; SLATYER, R. O. On the Mechanisms Producing Successional Change. Oikos, v.50, n.1 p.136-137, 1987.

CONNELL, J. H.; SLATYER, R. O. Mechanisms of Succession in Natural Communities and Their Role in Community Stability and Organization. American Naturalist, v.111, p.1119-1144, 1977.

COSTA, C. C. A.; CAMACHO, R. G. V.; MACEDO, I. D.; SILVA, P. C. M. Análise comparativa da produção de serapilheira em fragmentos arbóreos e arbustivos em área de Caatinga na Flona de Açu-RN. Revista Árvore, v.34, n.2, p.259-265, 2010.

EMBRAPA - Empresa Brasileira de Pesquisa Agropecuária. Centro Nacional de Pesquisas de Solos. DONAGEMA, G. K.; CAMPOS, D. D.; CALDERANO, S. B.; TEIXEIRA, W. G.; VIANA, J. H. M. Manual de métodos de análise de solos. 2.ed. ver. Rio de Janeiro: Embrapa Solos, 230p, 2011.

FARIAS, S. G. G.; RODAL, M. J. N.; MELO, A. L.; SILVA, M. A. M.; LIMA, A. L. A. Fisionomia e estrutura de vegetação de Caatinga em diferentes ambientes em Serra Talhada - Pernambuco. Ciência Florestal, v.26, n.2, p.435-448, 2016.

GHIDIN, A. A.; MELO, V. F.; LIMA, V. C.; LIMA, J. M. J. C. Topossequências de latossolos originados de rochas basálticas no Paraná. I - Mineralogia da fração argila. Revista Brasileira de Ciência do Solo, v.30, p.293-306, 2006.

GLEASON, H. A. The individualistic concept of the plant association. Bulletin of the Torrey Botanical Club, v.53, n.1, p.7-26, 1926.

GRIFFITH, D. A.; PERES-NETO, P. R. Spatial modeling in ecology: the flexibility of eigenfunction spatial analyses. Ecology, v.87, n.10, p.2603-13, 2006.

GUEDES, R. S.; ZANELLA, F. C. V.; COSTA, J. E. V JR.; SANTANA, G. M.; SILVA, J. A. Caracterização florístico-fitossociológica do componente lenhoso de um trecho de Caatinga no semiárido paraibano. Revista Caatinga, v.25, n.2, p.99-108, 2012.

HOLANDA, A. C.; LIMA, F. T. D.; SILVA, B. M.; DOURADO, R. G.; ALVES, A. R. Estrutura da vegetação em remanescentes de Caatinga com diferentes históricos de perturbação em Cajazeirinhas (PB). Revista Caatinga, v.28, n.4, p.142-150, 2015.

HORN, H. S. Succession. In: MAY, R. M. (Ed.). Theoretical Ecology: Principles and Applications. Saunders, Philadelphia. p.187-204, 1976.

LACERDA, C. M. B.; KAGEYAMA, P. Y. Spatial genotype structure of two natural populations of Myracrodruon urundeuva M. Allemão in a semiarid region of Brazil. Revista Árvore, v.27, n.2, p.145-150, 2003.

LEGENDRE, P.; FORTIN, M. J. Spatial pattern and ecological analysis. Vegetatio, v.80, n.2, p.107-138, 1989.

LEGENDRE, P.; LEGENDRE, L. Numerical ecology. Amsterdan, Elservier Science, 853p, 2012. 
LEGENDRE, P. Spatial autocorrelation: trouble or new paradigm? Ecology, v.74, n.6, p.1659-1673, 1993.

LEMOS, J. R.; MEGURO, M. Estudo itossociológico de uma área de Caatinga na Estação Ecológica (ESEC) de Aiuaba, Ceará, Brasil. Biotemas, v.28, n.2, p.39-50, 2015.

LENNON, J. J. Red-shifts and red herrings in geographical ecology. Ecography, v.23, n.1, p.101-113, 2000.

OLIVEIRA-FILHO, A. T.; ALMEIDA, R. J.; MELLO, J. M.; GAVILANES, M. L. Estrutura fitossociológica e variáveis ambientais em um trecho da mata ciliar do córrego dos Vilas Boas, Reserva Biológica do Poço Bonito, Lavras (MG). Revista Brasileira de Botânica , São Paulo, v. 17, n.1, p. 67-85, 1994.

PENNINGTON, R. T.; PRADO, D. E.; PENDRY, C. A. Neotropical seasonally dry forests and Quaternary vegetation changes. Journal of Biogeography, v.27, p.261-273, 2000.

PENNINGTON, R. T.; LAVIN, M.; PRADO, D. E.; PENDRY, C. A.; PELL, S. K.; BUTTERWORTH, C. A. Historical climate change and speciation: Neotropical seasonally dry forest plants show patterns of both Tertiary and Quaternary diversification. Philosophical Transactions of the Royal Society of London (B), v.359, p.515-538, 2004.

PEREIRA JÚNIOR, L. R.; ANDRADE, A. P.; ARAÚJO, K. D.; BARBOSA, A. S.; BARBOSA, F. M. Espécies da Caatinga como Alternativa para o Desenvolvimento de Novos Fitofármacos. Floresta e Ambiente, v.21, n.4, p.509-520, 2014.

PEREIRA JÚNIOR, L. R.; ANDRADE, A. P.; ARAÚJO, K. D. Composição florística e fitossociológica de um fragmento de Caatinga em Monteiro, PB. Holos, v.6, p.73-87, 2012.

PRADO, D. E. Padrões de Diversidade e Distribuição de Espécies em Escala Regional, Capítulo I, As Caatingas da América do Sul, p.03- 74. In: LEAL, I. R.; TABARELLI, M.; SILVA, J. M. C. Ecologia e Conservação da Caatinga, Recife, 822p, 2003.

PUGA, A. T. Métrica de Hellinger não paramétrica. CMNE-CILAMCE, Porto, Portugal, 14p, 2007.

REBOUÇAS, A. C. Água na região Nordeste: desperdício e escassez. Estudos Avançados, v.11, n.29, p.127-154, 1997.

REDE DE MANEJO FLORESTAL DA CAATINGA. Protocolo de Medições de Parcelas Permanentes. Recife: Associação de Plantas do Nordeste.; Brasília: MMA,PNF,PNE. 28p, 2005.

RODAL, M. J. N.; MARTINS, F. R.; SAMPAIO, E. V. de. S. B. Levantamento quantitativo das plantas lenhosas em trechos de vegetação de Caatinga em Pernambuco. Revista Caatinga, v.21, n.3, p.192-205, 2008. 
SABINO, F. G. S.; CUNHA, M. C. L.; SANTANA, G. M. Estrutura da Vegetação em Dois Fragmentos de Caatinga Antropizada na Paraíba. Floresta e Ambiente, v.23, n.4, p.487-497, 2016.

TER BRAAK, C. J. F.; PRENTICE, I. C. A theory of gradient analysis. Advances in Ecological Research, v.18, n.1, p.271-317, 1988.

TER BRAAK, C. J. F. The analysis of vegetation-environment relationships by canonical correspondence analysis. Vegetatio, v.69, p.69-77, 1987.

TILMAN, D. The Resource-Ratio Hypothesis of Plant Succession. American Naturalist, v.125, n.6, p.827-852, 1985.

WALTER, H. Ecology of tropical and subtropical vegetation. Oliver and Boyd. Edinburgh. $539 \mathrm{p}, 1971$.

WALKER, L. R.; CHAPIN, F. S. III. Interactions among processes controlling successional change. Oikos, v.50, n.1, p.131-135, 1987.

WHITTAKER, R. H. A consideration of climax theory: The climax as a population and pattern. Ecological Monographs, v.23, n.1, p.41-78, 1953. 
ANEXOS

Anexo 1. Parâmetros da estrutura horizontal das espécies arbustivo-arbóreas do estrato adulto de vegetação de Caatinga, em ordem decrescente pelo IVI (\%), presentes na área de São José do Bonfim, no estado da Paraíba - Brasil.

\begin{tabular}{|c|c|c|c|c|c|c|c|c|c|}
\hline Espécies & DA & DR & FA & FR & DoA & DoR & IVI & IVI\% & $\mathbf{P i}$ \\
\hline Poincianella pyramidalis & 1153 & 36,98 & 100 & 10,9 & 5,45 & 38,68 & 86,58 & 28,86 & Agr \\
\hline Croton blanchetianus & 867 & 27,81 & 100 & 10,9 & 1,38 & 9,79 & 48,52 & 16,17 & Agr \\
\hline Mimosa tenuiflora & 366 & 11,74 & 92 & 10 & 3,61 & 25,62 & 47,40 & 15,80 & Agr \\
\hline Anadenanthera colubrina & 71 & 2,28 & 88 & 9,61 & 2 & 14,19 & 26,08 & 8,69 & Agr \\
\hline Bauhinia cheilantha & 252 & 8,08 & 60 & 6,55 & 0,35 & 2,48 & 17,12 & 5,71 & Agr \\
\hline Aspidosperma pyrifolium & 88 & 2,82 & 84 & 9,17 & 0,21 & 1,49 & 13,48 & 4,49 & Agr \\
\hline Combretum leprosum & 88 & 2,82 & 80 & 8,73 & 0,2 & 1,42 & 12,98 & 4,33 & Agr \\
\hline Mimosa ophthalmocentra & 118 & 3,78 & 44 & 4,8 & 0,38 & 2,70 & 11,28 & 3,76 & Agr \\
\hline Erythroxylum Caatinga & 37 & 1,19 & 60 & 6,55 & 0,18 & 1,28 & 9,01 & 3,01 & Agr \\
\hline Libidibia ferrea & 16 & 0,51 & 40 & 4,37 & 0,07 & 0,50 & 5,38 & 1,79 & Agr \\
\hline Senna macranthera & 9 & 0,29 & 32 & 3,49 & 0,01 & 0,07 & 3,85 & 1,28 & Nagr \\
\hline Handroanthus impetiginosus & 9 & 0,29 & 24 & 2,62 & 0,03 & 0,21 & 3,12 & 1,04 & Tagr \\
\hline Jatropha mollissima & 9 & 0,29 & 24 & 2,62 & 0,02 & 0,14 & 3,05 & 1,02 & Tagr \\
\hline Cynophalla hastata & 7 & 0,23 & 24 & 2,62 & 0,02 & 0,14 & 2,99 & 1,00 & Tagr \\
\hline Cnidoscolus quercifolius & 6 & 0,19 & 20 & 2,18 & 0,07 & 0,50 & 2,87 & 0,96 & Tagr \\
\hline Ziziphus joazeiro & 5 & 0,16 & 12 & 1,31 & 0,04 & 0,28 & 1,75 & 0,59 & Agr \\
\hline Commiphora leptophloeos & 4 & 0,13 & 12 & 1,31 & 0,03 & 0,21 & 1,65 & 0,55 & Tagr \\
\hline Manihot carthaginensis & 5 & 0,16 & 8 & 0,87 & 0,03 & 0,21 & 1,25 & 0,42 & Agr \\
\hline Dolichandra sp. & 6 & 0,19 & 8 & 0,87 & 0,01 & 0,07 & 1,14 & 0,38 & Agr \\
\hline Mimosa acutistipula & 2 & 0,06 & 4 & 0,44 & 0,00 & 0,00 & 0,50 & 0,17 & Agr \\
\hline Total & 3118 & 100 & 916 & 100 & 14,1 & 100,00 & 300,00 & 100 & - \\
\hline
\end{tabular}

Em que: $\mathrm{DA}=$ Densidade absoluta de indivíduo; $\mathrm{DR} \%=$ Densidade relativa de indivíduo; FA = Frequência absoluta; $\mathrm{FR} \%$ = Frequência relativa; DoA $=$ Dominância absoluta; DoR\% $=$ Dominância relativa; IVI = Índice de Valor de importância; IVI\% = Índice de Valor de importância em \%; Pi = Índice de Payandeh; Agr $=$ Distribuição agregado; Tagr $=$ Tendência a agregação; e Nagr $=$ Não agregado . 
Anexo 2. Parâmetros da estrutura horizontal das espécies arbustivo-arbóreas do estrato adulto de vegetação de Caatinga, em ordem decrescente pelo IVI (\%), presentes na área de Itaporanga, no estado da Paraíba - Brasil.

\begin{tabular}{|c|c|c|c|c|c|c|c|c|c|}
\hline Espécies & DA & DR & FA & FR & DoA & DoR & IVI & IVI\% & $\mathbf{P i}$ \\
\hline Croton blanchetianus & 963 & 33,83 & 100 & 4,99 & 3,19 & 23,91 & 62,73 & 20,91 & Agr \\
\hline Myracrodruon urundeuva & 103 & 3,62 & 84 & 4,19 & 1,09 & 8,17 & 15,98 & 5,33 & Agr \\
\hline Amburana cearensis & 104 & 3,65 & 84 & 4,19 & 0,94 & 7,05 & 14,89 & 4,96 & Agr \\
\hline Poincianella pyramidalis & 109 & 3,83 & 68 & 3,39 & 0,93 & 6,97 & 14,19 & 4,73 & Agr \\
\hline Combretum leprosum & 164 & 5,76 & 96 & 4,79 & 0,46 & 3,45 & 14,00 & 4,67 & Agr \\
\hline Mimosa tenuiflora & 60 & 2,11 & 68 & 3,39 & 0,66 & 4,95 & 10,45 & 3,48 & Agr \\
\hline Commiphora leptophloeos & 51 & 1,79 & 60 & 2,99 & 0,74 & 5,55 & 10,33 & 3,44 & Agr \\
\hline Sapium glandulosum & 88 & 3,09 & 64 & 3,19 & 0,47 & 3,52 & 9,81 & 3,27 & Agr \\
\hline Mimosa ophthalmocentra & 107 & 3,76 & 88 & 4,39 & 0,21 & 1,57 & 9,72 & 3,24 & Agr \\
\hline Manihot carthaginensis & 94 & 3,30 & 68 & 3,39 & 0,34 & 2,55 & 9,24 & 3,08 & Agr \\
\hline Annona leptopetala & 68 & 2,39 & 68 & 3,39 & 0,28 & 2,10 & 7,88 & 2,63 & Agr \\
\hline Cordia trichotoma & 62 & 2,18 & 32 & 1,60 & 0,36 & 2,70 & 6,47 & 2,16 & Agr \\
\hline Bauhinia cheilantha & 73 & 2,56 & 40 & 2,00 & 0,19 & 1,42 & 5,98 & 2,00 & Agr \\
\hline Callisthene minor & 34 & 1,19 & 24 & 1,20 & 0,44 & 3,30 & 5,69 & 1,90 & Agr \\
\hline Dalbergia cearensis & 22 & 0,77 & 36 & 1,80 & 0,38 & 2,85 & 5,42 & 1,81 & Agr \\
\hline Cochlospermum vitifolium & 63 & 2,21 & 40 & 2,00 & 0,16 & 1,20 & 5,41 & 1,80 & Agr \\
\hline Gymnanthes boticario & 49 & 1,72 & 64 & 3,19 & 0,05 & 0,37 & 5,29 & 1,76 & Agr \\
\hline Erythroxylum Caatinga & 41 & 1,44 & 40 & 2,00 & 0,22 & 1,65 & 5,09 & 1,70 & Agr \\
\hline Sigmatanthus trifoliatus & 69 & 2,42 & 28 & 1,40 & 0,16 & 1,20 & 5,02 & 1,67 & Agr \\
\hline Senegalia polyphylla & 47 & 1,65 & 48 & 2,40 & 0,12 & 0,90 & 4,95 & 1,65 & Agr \\
\hline Luetzelburgia auriculata & 27 & 0,95 & 52 & 2,59 & 0,14 & 1,05 & 4,59 & 1,53 & Agr \\
\hline Ximenia americana & 40 & 1,40 & 44 & 2,2 & 0,12 & 0,90 & 4,50 & 1,50 & Agr \\
\hline Psidium appendiculatum & 19 & 0,67 & 40 & 2,00 & 0,04 & 0,30 & 2,96 & 0,99 & Agr \\
\hline Aspidosperma riedelii & 21 & 0,74 & 32 & 1,60 & 0,08 & 0,60 & 2,93 & 0,98 & Agr \\
\hline Aspidosperma cuspa & 31 & 1,09 & 32 & 1,60 & 0,03 & 0,22 & 2,91 & 0,97 & Agr \\
\hline Croton rhamnifolioides & 31 & 1,09 & 24 & 1,20 & 0,08 & 0,60 & 2,89 & 0,96 & Agr \\
\hline Luehea ochrophylla & 33 & 1,16 & 20 & 1,00 & 0,09 & 0,67 & 2,83 & 0,94 & Agr \\
\hline Guapira laxa & 14 & 0,49 & 36 & 1,80 & 0,06 & 0,45 & 2,74 & 0,91 & Agr \\
\hline Chloroleucon foliolosum & 14 & 0,49 & 32 & 1,60 & 0,07 & 0,52 & 2,61 & 0,87 & Agr \\
\hline Schinopsis brasiliensis & 3 & 0,11 & 8 & 0,40 & 0,28 & 2,10 & 2,60 & 0,87 & Agr \\
\hline Libidibia ferrea & 14 & 0,49 & 32 & 1,60 & 0,05 & 0,37 & 2,46 & 0,82 & Agr \\
\hline Helicteres heptandra & 24 & 0,84 & 28 & 1,40 & 0,03 & 0,22 & 2,47 & 0,82 & Agr \\
\hline Aspidosperma pyrifolium & 18 & 0,63 & 28 & 1,40 & 0,04 & 0,30 & 2,33 & 0,78 & Agr \\
\hline Mimosa paraibana & 12 & 0,42 & 32 & 1,60 & 0,02 & 0,15 & 2,17 & 0,72 & Tagr \\
\hline Cynophalla hastata & 10 & 0,35 & 28 & 1,40 & 0,05 & 0,37 & 2,12 & 0,71 & Tagr \\
\hline Fridericia dichotoma & 13 & 0,46 & 24 & 1,20 & 0,05 & 0,37 & 2,03 & 0,68 & Agr \\
\hline Senna trachypus & 16 & 0,56 & 24 & 1,20 & 0,03 & 0,22 & 1,98 & 0,66 & Agr \\
\hline Eugenia flavescens & 7 & 0,25 & 24 & 1,20 & 0,03 & 0,22 & 1,67 & 0,56 & Tagr \\
\hline Astronium fraxinifolium & 5 & 0,18 & 20 & 1,00 & 0,06 & 0,45 & 1,62 & 0,54 & Nagr \\
\hline Senegalia riparia & 12 & 0,42 & 20 & 1,00 & 0,02 & 0,15 & 1,57 & 0,52 & Agr \\
\hline Talisia esculenta & 12 & 0,42 & 12 & 0,6 & 0,04 & 0,30 & 1,32 & 0,44 & Agr \\
\hline Stillingia trapezoidea & 7 & 0,25 & 16 & 0,80 & 0,02 & 0,15 & 1,19 & 0,40 & Agr \\
\hline Combretum duarteanum & 8 & 0,28 & 12 & 0,60 & 0,04 & 0,30 & 1,18 & 0,39 & Agr \\
\hline Vitex megapotamica & 4 & 0,14 & 8 & 0,40 & 0,08 & 0,60 & 1,14 & 0,38 & Agr \\
\hline Anadenanthera colubrina & 4 & 0,14 & 12 & 0,60 & 0,05 & 0,37 & 1,11 & 0,37 & Tagr \\
\hline Guettarda angelica & 16 & 0,56 & 4 & 0,20 & 0,05 & 0,37 & 1,14 & 0,38 & Agr \\
\hline Pseudobombax marginatum & 4 & 0,14 & 16 & 0,80 & 0,01 & 0,07 & 1,01 & 0,34 & Nagr \\
\hline Jatropha mollissima & 4 & 0,14 & 16 & 0,80 & 0,01 & 0,07 & 1,01 & 0,34 & Nagr \\
\hline Jacaranda jasminoides & 4 & 0,14 & 8 & 0,40 & 0,06 & 0,45 & 0,99 & 0,33 & Agr \\
\hline Brosimum gaudichaudii & 4 & 0,14 & 12 & 0,60 & 0,03 & 0,22 & 0,96 & 0,32 & Tagr \\
\hline Morfo espécie 1 & 7 & 0,25 & 12 & 0,60 & 0,01 & 0,07 & 0,92 & 0,31 & Agr \\
\hline Hymenaea courbaril & 3 & 0,11 & 4 & 0,20 & 0,07 & 0,52 & 0,83 & 0,28 & Agr \\
\hline Eugenia stictopetala & 5 & 0,18 & 8 & 0,40 & 0,02 & 0,15 & 0,72 & 0,24 & Agr \\
\hline Dahlstedtia araripensis & 3 & 0,11 & 4 & 0,20 & 0,04 & 0,30 & 0,60 & 0,20 & Agr \\
\hline Handroanthus serratifolius & 2 & 0,07 & 8 & 0,40 & 0,00 & 0,00 & 0,47 & 0,16 & Nagr \\
\hline
\end{tabular}


Anexo 2. Cont.

\begin{tabular}{lccccccccc}
\hline Espécie & DA & DR & FA & FR & DoA & DoR & IVI & IVI\% & Pi \\
\hline Randia armata & 2 & 0,07 & 8 & 0,40 & 0,00 & 0,00 & 0,47 & 0,16 & Nagr \\
Mimosa sp. & 2 & 0,07 & 8 & 0,40 & 0,00 & 0,00 & 0,47 & 0,16 & Nagr \\
Senna macranthera & 2 & 0,07 & 8 & 0,40 & 0,00 & 0,00 & 0,47 & 0,16 & Nagr \\
Croton aff. Anisodontus & 4 & 0,14 & 4 & 0,20 & 0,00 & 0,00 & 0,34 & 0,11 & Agr \\
Allamanda blanchetii & 3 & 0,11 & 4 & 0,20 & 0,00 & 0,00 & 0,30 & 0,10 & Agr \\
Zanthoxylum syncarpum & 1 & 0,04 & 4 & 0,20 & 0,01 & 0,07 & 0,31 & 0,10 & Nagr \\
Cordiera rigida & 1 & 0,04 & 4 & 0,20 & 0,01 & 0,07 & 0,31 & 0,10 & Nagr \\
Piptadenia cf. viridiflora & 2 & 0,07 & 4 & 0,20 & 0,00 & 0,00 & 0,27 & 0,09 & Agr \\
Handroanthus impetiginosus & 1 & 0,04 & 4 & 0,20 & 0,01 & 0,07 & 0,31 & 0,10 & Nagr \\
Triplaris gardneriana & 1 & 0,04 & 4 & 0,20 & 0,01 & 0,07 & 0,31 & 0,10 & Nagr \\
Tocoyena formosa & 2 & 0,07 & 4 & 0,20 & 0,00 & 0,00 & 0,27 & 0,09 & Agr \\
Allophylus quercifolius & 1 & 0,04 & 4 & 0,20 & 0,01 & 0,07 & 0,31 & 0,10 & Nagr \\
Varronia curassavica & 1 & 0,04 & 4 & 0,20 & 0,00 & 0,00 & 0,23 & 0,08 & Nagr \\
Coutarea hexandra & 1 & 0,04 & 4 & 0,20 & 0,00 & 0,00 & 0,23 & 0,08 & Nagr \\
Stachytarpheta coccinea & 1 & 0,04 & 4 & 0,20 & 0,00 & 0,00 & 0,23 & 0,08 & Nagr \\
\hline Total & 2847 & 100,00 & 2004 & 100 & 13,34 & 100,00 & 300,00 & 100 & - \\
\hline
\end{tabular}

Em que: DA = Densidade absoluta de indivíduo; DR\% = Densidade relativa de indivíduo; FA = Frequência absoluta; FR\% = Frequência relativa; DoA = Dominância absoluta; DoR\% = Dominância relativa; IVI = Índice de Valor de importância; IVI\% = Índice de Valor de importância em \%; Pi = Índice de Payandeh; Agr $=$ Distribuição agregado; Tagr $=$ Tendência a agregação; e Nagr = Não agregado . 
Anexo 3. Parâmetros da estrutura horizontal das espécies arbustivo-arbóreas do estrato adulto de vegetação de Caatinga, em ordem decrescente pelo IVI (\%), presentes na área de Lagoa, no estado da Paraíba - Brasil.

\begin{tabular}{|c|c|c|c|c|c|c|c|c|c|}
\hline Espécies & DA & DR & FA & FR & DoA & DoR & IVI & IVI\% & $\mathbf{P i}$ \\
\hline Croton blanchetianus & 476 & 15,57 & 100 & 4,87 & 1,69 & 7,72 & 28,17 & 9,39 & Agr \\
\hline Peltogyne pauciflora & 189 & 6,18 & 76 & 3,70 & 3,41 & 15,59 & 25,47 & 8,49 & Agr \\
\hline Aspidosperma riedelii & 271 & 8,87 & 88 & 4,29 & 1,84 & 8,41 & 21,56 & 7,19 & Agr \\
\hline Gymnanthes boticario & 278 & 9,09 & 68 & 3,31 & 0,41 & 1,87 & 14,28 & 4,76 & Agr \\
\hline Myrciaria floribunda & 178 & 5,82 & 76 & 3,70 & 0,77 & 3,52 & 13,05 & 4,35 & Agr \\
\hline Luehea ochrophylla & 105 & 3,44 & 92 & 4,48 & 0,67 & 3,06 & 10,98 & 3,66 & Agr \\
\hline Senegalia polyphylla & 80 & 2,62 & 80 & 3,90 & 0,75 & 3,43 & 9,94 & 3,31 & Agr \\
\hline Eugenia stictopetala & 130 & 4,25 & 72 & 3,51 & 0,4 & 1,83 & 9,59 & 3,20 & Agr \\
\hline Brosimum gaudichaudii & 32 & 1,05 & 48 & 2,34 & 1,33 & 6,08 & 9,46 & 3,15 & Agr \\
\hline Poincianella pyramidalis & 48 & 1,57 & 44 & 2,14 & 1,19 & 5,44 & 9,15 & 3,05 & Agr \\
\hline Croton nepetifolius & 143 & 4,68 & 72 & 3,51 & 0,21 & 0,96 & 9,15 & 3,05 & Agr \\
\hline Erythroxylum nummularia & 107 & 3,50 & 56 & 2,73 & 0,41 & 1,87 & 8,10 & 2,70 & Agr \\
\hline Guapira laxa & 49 & 1,60 & 72 & 3,51 & 0,61 & 2,79 & 7,90 & 2,63 & Agr \\
\hline Maytenus erythroxyla & 48 & 1,57 & 28 & 1,36 & 0,96 & 4,39 & 7,32 & 2,44 & Agr \\
\hline Manihot carthaginensis & 53 & 1,73 & 48 & 2,34 & 0,56 & 2,56 & 6,63 & 2,21 & Agr \\
\hline Bauhinia cheilantha & 59 & 1,93 & 52 & 2,53 & 0,39 & 1,78 & 6,25 & 2,08 & Agr \\
\hline Handroanthus impetiginosus & 49 & 1,60 & 52 & 2,53 & 0,45 & 2,06 & 6,19 & 2,06 & Agr \\
\hline Eugenia flavescens & 55 & 1,80 & 52 & 2,53 & 0,37 & 1,69 & 6,02 & 2,01 & Agr \\
\hline Helicteres heptandra & 66 & 2,16 & 64 & 3,12 & 0,14 & 0,64 & 5,92 & 1,97 & Agr \\
\hline Hymenaea courbaril & 29 & 0,95 & 20 & 0,97 & 0,75 & 3,43 & 5,35 & 1,78 & Agr \\
\hline Cynophalla hastata & 35 & 1,15 & 44 & 2,14 & 0,42 & 1,92 & 5,21 & 1,74 & Agr \\
\hline Senna macranthera & 77 & 2,52 & 40 & 1,95 & 0,14 & 0,64 & 5,11 & 1,70 & Agr \\
\hline Pouteria reticulata & 28 & 0,92 & 32 & 1,56 & 0,38 & 1,74 & 4,21 & 1,40 & Agr \\
\hline Byrsonima vacciniifolia & 29 & 0,95 & 44 & 2,14 & 0,22 & 1,01 & 4,10 & 1,37 & Agr \\
\hline Croton heliotropiifolius & 60 & 1,96 & 32 & 1,56 & 0,12 & 0,55 & 4,07 & 1,36 & Agr \\
\hline Commiphora leptophloeos & 12 & 0,39 & 24 & 1,17 & 0,37 & 1,69 & 3,25 & 1,08 & Agr \\
\hline Eugenia caatingicola & 18 & 0,59 & 32 & 1,56 & 0,24 & 1,10 & 3,25 & 1,08 & Agr \\
\hline Randia armata & 30 & 0,98 & 40 & 1,95 & 0,03 & 0,14 & 3,07 & 1,02 & Agr \\
\hline Myracrodruon urundeuva & 13 & 0,43 & 32 & 1,56 & 0,21 & 0,96 & 2,94 & 0,98 & Tagr \\
\hline Guettarda angelica & 46 & 1,51 & 16 & 0,78 & 0,11 & 0,50 & 2,79 & 0,93 & Agr \\
\hline Dalbergia cearensis & 12 & 0,39 & 20 & 0,97 & 0,3 & 1,37 & 2,74 & 0,91 & Agr \\
\hline Syagrus cearensis & 8 & 0,26 & 24 & 1,17 & 0,23 & 1,05 & 2,48 & 0,83 & Tagr \\
\hline Senna trachypus & 30 & 0,98 & 20 & 0,97 & 0,1 & 0,46 & 2,41 & 0,80 & Agr \\
\hline Amburana cearensis & 11 & 0,36 & 32 & 1,56 & 0,02 & 0,09 & 2,01 & 0,67 & Tagr \\
\hline Parapiptadenia zehntneri & 4 & 0,13 & 12 & 0,58 & 0,25 & 1,14 & 1,86 & 0,62 & Tagr \\
\hline Zanthoxylum syncarpum & 11 & 0,36 & 28 & 1,36 & 0,03 & 0,14 & 1,86 & 0,62 & Agr \\
\hline Sapium glandulosum & 9 & 0,29 & 20 & 0,97 & 0,13 & 0,59 & 1,86 & 0,62 & Agr \\
\hline Luetzelburgia auriculata & 11 & 0,36 & 20 & 0,97 & 0,06 & 0,27 & 1,61 & 0,54 & Agr \\
\hline Senna spectabilis & 13 & 0,43 & 12 & 0,58 & 0,12 & 0,55 & 1,56 & 0,52 & Agr \\
\hline Cordia trichotoma & 3 & 0,10 & 4 & 0,19 & 0,27 & 1,23 & 1,53 & 0,51 & Agr \\
\hline Cordiera rigida & 6 & 0,20 & 24 & 1,17 & 0,02 & 0,09 & 1,46 & 0,49 & Nagr \\
\hline Lantana camara & 11 & 0,36 & 20 & 0,97 & 0,02 & 0,09 & 1,43 & 0,48 & Agr \\
\hline Cochlospermum vitifolium & 16 & 0,52 & 8 & 0,39 & 0,1 & 0,46 & 1,37 & 0,46 & Agr \\
\hline Combretum leprosum & 12 & 0,39 & 16 & 0,78 & 0,03 & 0,14 & 1,31 & 0,44 & Agr \\
\hline Mimosa paraibana & 11 & 0,36 & 16 & 0,78 & 0,02 & 0,09 & 1,23 & 0,41 & Agr \\
\hline Eugenia ligustrina & 14 & 0,46 & 12 & 0,58 & 0,04 & 0,18 & 1,23 & 0,41 & Agr \\
\hline Talisia esculenta & 5 & 0,16 & 12 & 0,58 & 0,1 & 0,46 & 1,21 & 0,40 & Agr \\
\hline Pseudobombax marginatum & 7 & 0,23 & 16 & 0,78 & 0,04 & 0,18 & 1,19 & 0,40 & Agr \\
\hline Mimosa ophthalmocentra & 8 & 0,26 & 16 & 0,78 & 0,02 & 0,09 & 1,13 & 0,38 & Agr \\
\hline Erythroxylum Caatinga & 5 & 0,16 & 16 & 0,78 & 0,03 & 0,14 & 1,08 & 0,36 & Tagr \\
\hline Callisthene minor & 10 & 0,33 & 4 & 0,19 & 0,11 & 0,50 & 1,02 & 0,34 & Agr \\
\hline Senegalia sp. & 8 & 0,26 & 12 & 0,58 & 0,03 & 0,14 & 0,98 & 0,33 & Agr \\
\hline
\end{tabular}


Anexo 3. Cont.

\begin{tabular}{|c|c|c|c|c|c|c|c|c|c|}
\hline Espécie & DA & DR & FA & FR & DoA & DoR & IVI & IVI\% & $\mathbf{P i}$ \\
\hline Morfo espécie 3. & 3 & 0,10 & 12 & 0,58 & 0,01 & 0,05 & 0,73 & 0,24 & Agr \\
\hline Mimosa tenuiflora & 1 & 0,03 & 4 & 0,19 & 0,10 & 0,46 & 0,68 & 0,23 & Nagr \\
\hline Morfo espécie 2. & 3 & 0,10 & 12 & 0,58 & - & 0,00 & 0,68 & 0,23 & Nagr \\
\hline Morfo espécie 1. & 4 & 0,13 & 8 & 0,39 & 0,01 & 0,05 & 0,57 & 0,19 & Agr \\
\hline Vitex megapotamica & 2 & 0,07 & 8 & 0,39 & 0,02 & 0,09 & 0,55 & 0,18 & Nagr \\
\hline Ximenia americana & 5 & 0,16 & 4 & 0,19 & 0,02 & 0,09 & 0,45 & 0,15 & Agr \\
\hline Enterolobium contortisiliquum & 2 & 0,07 & 8 & 0,39 & - & 0,00 & 0,46 & 0,15 & Nagr \\
\hline Jatropha mollissima & 6 & 0,20 & 4 & 0,19 & 0,02 & 0,09 & 0,48 & 0,16 & Agr \\
\hline Chloroleucon foliolosum & 3 & 0,10 & 4 & 0,19 & 0,03 & 0,14 & 0,43 & 0,14 & Agr \\
\hline Xylosma prockia & 1 & 0,03 & 4 & 0,19 & 0,03 & 0,14 & 0,36 & 0,12 & Nagr \\
\hline Libidibia ferrea & 2 & 0,07 & 4 & 0,19 & 0,01 & 0,05 & 0,31 & 0,10 & Agr \\
\hline Handroanthus serratifolius & 2 & 0,07 & 4 & 0,19 & 0,01 & 0,05 & 0,31 & 0,10 & Agr \\
\hline Dahlstedtia araripensis & 2 & 0,07 & 4 & 0,19 & - & 0,00 & 0,26 & 0,09 & Agr \\
\hline Dolichandra sp. & 1 & 0,03 & 4 & 0,19 & - & 0,00 & 0,23 & 0,08 & Nagr \\
\hline Turnera calyptrocarpa & 1 & 0,03 & 4 & 0,19 & - & 0,00 & 0,23 & 0,08 & Nagr \\
\hline Varronia curassavica & 1 & 0,03 & 4 & 0,19 & - & 0,00 & 0,23 & 0,08 & Nagr \\
\hline Total & 3057 & 100 & 2052 & 100 & 21,9 & 100 & 300 & 100 & \\
\hline
\end{tabular}

Em que: DA = Densidade absoluta de indivíduo; DR\% $=$ Densidade relativa de indivíduo; FA = Frequência absoluta; FR\% = Frequência relativa; DoA $=$ Dominância absoluta; DoR\% = Dominância relativa; IVI = Índice de Valor de importância; IVI\% = Índice de Valor de importância em \%; Pi = Índice de Payandeh; Agr $=$ Distribuição agregado; Tagr $=$ Tendência a agregação; e Nagr $=$ Não agregado . 
Anexo 4. Estimativas de indivíduos.ha ${ }^{-1}$ no estrato de regeneração natural em vegetação de Caatinga presentes na área de São José do Bonfim, no estado da Paraíba - Brasil.

\begin{tabular}{lcccccccc}
\hline Espécies & FA & FR & DA & DR & CAT & CRT & RNR & Pi \\
\hline Croton blanchetianus & 88 & 24,72 & 2064 & 45,42 & 84,67 & 48,24 & 39,46 & Agr \\
Poincianella pyramidalis & 68 & 19,1 & 704 & 15,49 & 27,83 & 15,86 & 16,82 & Agr \\
Combretum leprosum & 64 & 17,98 & 592 & 13,03 & 18,74 & 10,68 & 13,90 & Agr \\
Aspidosperma pyrifolium & 60 & 16,85 & 576 & 12,68 & 20,92 & 11,92 & 13,82 & Agr \\
Bauhinia cheilantha & 28 & 7,87 & 304 & 6,69 & 12,17 & 6,93 & 7,16 & Agr \\
Erythroxylum Caatinga & 24 & 6,74 & 160 & 3,52 & 5,49 & 3,13 & 4,46 & Agr \\
Dolichandra sp. & 8 & 2,25 & 48 & 1,06 & 2,23 & 1,27 & 1,53 & Agr \\
Anadenanthera colubrina & 4 & 1,12 & 32 & 0,70 & 1,49 & 0,85 & 0,89 & Agr \\
Libidibia ferrea & 4 & 1,12 & 32 & 0,70 & 0,51 & 0,29 & 0,70 & Agr \\
Mimosa ophthalmocentra & 4 & 1,12 & 16 & 0,35 & 0,74 & 0,42 & 0,63 & Nagr \\
Cynophalla hastata & 4 & 1,12 & 16 & 0,35 & 0,74 & 0,42 & 0,63 & Nagr \\
\hline Total & 356 & 100 & 4544 & 100 & 175,53 & 100 & 100 & - \\
\hline
\end{tabular}

Em que: FA $=$ Frequência absoluta; FR $\%=$ Frequência relativa; $\mathrm{DA}=$ Densidade absoluta; $\mathrm{DR} \%=$ Densidade relativa; CAT $=$ Classe absoluta de tamanho da regeneração da i-ésima espécie; $\mathrm{CRT}=$ Classe relativa de tamanho da regeneração da i-ésima espécie; RNR\% = Regeneração natural relativa da i-ésima espécie; $\mathrm{Pi}=$ Índice de Payandeh; Agr = Distribuição espacial agregada; Tagr = Tendência a agregação; e Nagr $=$ Não agregado. 
Anexo 5. Estimativas de indivíduos.ha ${ }^{-1}$ no estrato de regeneração natural em vegetação de Caatinga presentes na área de Itaporanga, no estado da Paraíba - Brasil.

\begin{tabular}{|c|c|c|c|c|c|c|c|c|}
\hline Espécies & FA & FR & DA & DR & CAT & CRT & RNR & $\mathbf{P i}$ \\
\hline Croton blanchetianus & 84 & 11,23 & 1680 & 24,03 & 64,69 & 24,44 & 19,90 & Agr \\
\hline Amburana cearensis & 60 & 8,02 & 448 & 6,41 & 13,54 & 5,11 & 6,51 & Tagr \\
\hline Gymnanthes boticario & 48 & 6,42 & 416 & 5,95 & 17,14 & 6,47 & 6,28 & Agr \\
\hline Varronia curassavica & 28 & 3,74 & 352 & 5,03 & 14,68 & 5,55 & 4,77 & Agr \\
\hline Croton rhamnifolioides & 20 & 2,67 & 416 & 5,95 & 13,92 & 5,26 & 4,63 & Agr \\
\hline Senegalia polyphylla & 12 & 1,60 & 480 & 6,86 & 18,22 & 6,88 & 5,11 & Agr \\
\hline Erythroxylum Caatinga & 32 & 4,28 & 288 & 4,12 & 9,46 & 3,57 & 3,99 & Agr \\
\hline Fridericia dichotoma & 32 & 4,28 & 176 & 2,52 & 6,65 & 2,51 & 3,10 & Tagr \\
\hline Lantana camara & 28 & 3,74 & 208 & 2,97 & 7,65 & 2,89 & 3,2 & Agr \\
\hline Mimosa sp. & 24 & 3,21 & 240 & 3,43 & 10,03 & 3,79 & 3,48 & Agr \\
\hline Mimosa paraibana & 24 & 3,21 & 224 & 3,20 & 6,54 & 2,47 & 2,96 & Agr \\
\hline Commiphora leptophloeos & 28 & 3,74 & 112 & 1,60 & 3,73 & 1,41 & 2,25 & Nagr \\
\hline Bauhinia cheilantha & 20 & 2,67 & 176 & 2,52 & 7,11 & 2,69 & 2,63 & Agr \\
\hline Luetzelburgia auriculata & 24 & 3,21 & 112 & 1,60 & 4,65 & 1,76 & 2,19 & Tagr \\
\hline Mimosa ophthalmocentra & 16 & 2,14 & 112 & 1,60 & 4,65 & 1,76 & 1,83 & Agr \\
\hline Dalbergia cearensis & 12 & 1,6 & 144 & 2,06 & 4,73 & 1,79 & 1,82 & Agr \\
\hline Myracrodruon urundeuva & 16 & 2,14 & 96 & 1,37 & 4,38 & 1,65 & 1,72 & Agr \\
\hline Sapium glandulosum & 16 & 2,14 & 96 & 1,37 & 4,38 & 1,65 & 1,72 & Agr \\
\hline Poincianella pyramidalis & 16 & 2,14 & 80 & 1,14 & 3,19 & 1,21 & 1,50 & Tagr \\
\hline Annona leptopetala & 16 & 2,14 & 64 & 0,92 & 2,92 & 1,10 & 1,39 & Nagr \\
\hline Aspidosperma pyrifolium & 12 & 1,60 & 96 & 1,37 & 3,00 & 1,13 & 1,37 & Agr \\
\hline Manihot carthaginensis & 12 & 1,60 & 64 & 0,92 & 2,46 & 0,93 & 1,15 & Tagr \\
\hline Combretum leprosum & 12 & 1,60 & 48 & 0,69 & 1,73 & 0,65 & 0,98 & Nagr \\
\hline Eugenia flavescens & 12 & 1,60 & 48 & 0,69 & 1,73 & 0,65 & 0,98 & Nagr \\
\hline Helicteres heptandra & 12 & 1,60 & 48 & 0,69 & 2,19 & 0,83 & 1,04 & Nagr \\
\hline Ximenia americana & 8 & 1,07 & 80 & 1,14 & 2,73 & 1,03 & 1,08 & Agr \\
\hline Callisthene minor & 8 & 1,07 & 64 & 0,92 & 2,92 & 1,10 & 1,03 & Agr \\
\hline Psidium appendiculatum & 8 & 1,07 & 48 & 0,69 & 2,19 & 0,83 & 0,86 & Agr \\
\hline Senna trachypus & 8 & 1,07 & 32 & 0,46 & 1,00 & 0,38 & 0,64 & Nagr \\
\hline Senna macranthera & 8 & 1,07 & 32 & 0,46 & 1,46 & 0,55 & 0,69 & Nagr \\
\hline Pseudobombax marginatum & 8 & 1,07 & 32 & 0,46 & 1,00 & 0,38 & 0,64 & Nagr \\
\hline Cochlospermum vitifolium & 4 & 0,53 & 48 & 0,69 & 2,19 & 0,83 & 0,68 & Agr \\
\hline Jacaranda jasminoides & 4 & 0,53 & 48 & 0,69 & 2,19 & 0,83 & 0,68 & Agr \\
\hline Brosimum gaudichaudii & 4 & 0,53 & 32 & 0,46 & 1,46 & 0,55 & 0,51 & Agr \\
\hline Aspidosperma riedelii & 4 & 0,53 & 32 & 0,46 & 1,00 & 0,38 & 0,46 & Agr \\
\hline Handroanthus serratifolius & 4 & 0,53 & 32 & 0,46 & 1,46 & 0,55 & 0,51 & Agr \\
\hline Stachytarpheta coccinea & 4 & 0,53 & 32 & 0,46 & 1,46 & 0,55 & 0,51 & Agr \\
\hline Aspidosperma cuspa & 4 & 0,53 & 32 & 0,46 & 1,46 & 0,55 & 0,51 & Agr \\
\hline Zanthoxylum syncarpum & 4 & 0,53 & 16 & 0,23 & 0,73 & 0,28 & 0,35 & Nagr \\
\hline Randia armata & 4 & 0,53 & 16 & 0,23 & 0,73 & 0,28 & 0,35 & Nagr \\
\hline Talisia esculenta & 4 & 0,53 & 16 & 0,23 & 0,73 & 0,28 & 0,35 & Nagr \\
\hline Anadenanthera colubrina & 4 & 0,53 & 16 & 0,23 & 0,73 & 0,28 & 0,35 & Nagr \\
\hline Senegalia riparia & 4 & 0,53 & 16 & 0,23 & 0,73 & 0,28 & 0,35 & Nagr \\
\hline Sigmatanthus trifoliatus & 4 & 0,53 & 16 & 0,23 & 0,73 & 0,28 & 0,35 & Nagr \\
\hline Schinopsis brasiliensis & 4 & 0,53 & 16 & 0,23 & 0,27 & 0,10 & 0,29 & Nagr \\
\hline Vitex megapotamica & 4 & 0,53 & 16 & 0,23 & 0,27 & 0,10 & 0,29 & Nagr \\
\hline Morfo espécie 4 & 4 & 0,53 & 16 & 0,23 & 0,73 & 0,28 & 0,35 & Nagr \\
\hline Stillingia trapezoidea & 4 & 0,53 & 16 & 0,23 & 0,73 & 0,28 & 0,35 & Nagr \\
\hline Cordia trichotoma & 4 & 0,53 & 16 & 0,23 & 0,27 & 0,10 & 0,29 & Nagr \\
\hline Chloroleucon foliolosum & 4 & 0,53 & 16 & 0,23 & 0,73 & 0,28 & 0,35 & Nagr \\
\hline Guapira laxa & 4 & 0,53 & 16 & 0,23 & 0,73 & 0,28 & 0,35 & Nagr \\
\hline Allophylus quercifolius & 4 & 0,53 & 16 & 0,23 & 0,73 & 0,28 & 0,35 & Nagr \\
\hline Total & 748 & 100 & 6992 & 100 & 264,73 & 100 & 100 & - \\
\hline
\end{tabular}

Em que: $\mathrm{FA}=$ Frequência absoluta; FR\% $=$ Frequência relativa; $\mathrm{DA}=$ Densidade absoluta; $\mathrm{DR} \%=$ Densidade relativa; $\mathrm{CAT}=$ Classe absoluta de tamanho da regeneração da i-ésima espécie; $\mathrm{CRT}=$ Classe relativa de tamanho da regeneração da i-ésima espécie; RNR\% = Regeneração natural relativa da i-ésima espécie; Pi = Índice de Payandeh; Agr = Distribuição espacial agregada; Tagr = Tendência a agregação; e Nagr $=$ Não agregado. 
Anexo 6. Estimativas de indivíduos.ha ${ }^{-1}$ no estrato de regeneração natural em vegetação de Caatinga presentes na área de Lagoa, no estado da Paraíba - Brasil.

\begin{tabular}{|c|c|c|c|c|c|c|c|c|}
\hline Espécies & FA & FR & DA & DR & CAT & CRT & RNR & $\mathbf{P i}$ \\
\hline Croton nepetifolius & 64 & 10,26 & 1472 & 21,5 & 52,45 & 22,2 & 17,99 & Agr \\
\hline Croton heliotropiifolius & 36 & 5,77 & 1136 & 16,59 & 36,31 & 15,37 & 12,58 & Agr \\
\hline Croton blanchetianus & 52 & 8,33 & 688 & 10,05 & 25,53 & 10,81 & 9,73 & Agr \\
\hline Aspidosperma riedelii & 48 & 7,69 & 352 & 5,14 & 12,61 & 5,34 & 6,06 & Agr \\
\hline Myrciaria floribunda & 40 & 6,41 & 368 & 5,37 & 12,31 & 5,21 & 5,66 & Agr \\
\hline Randia armata & 36 & 5,77 & 288 & 4,21 & 10,93 & 4,63 & 4,87 & Agr \\
\hline Gymnanthes boticario & 36 & 5,77 & 256 & 3,74 & 9,29 & 3,93 & 4,48 & Agr \\
\hline Helicteres heptandra & 20 & 3,21 & 384 & 5,61 & 14,58 & 6,17 & 5,00 & Agr \\
\hline Guapira laxa & 36 & 5,77 & 208 & 3,04 & 6,34 & 2,68 & 3,83 & Agr \\
\hline Cordiera rigida & 24 & 3,85 & 208 & 3,04 & 6,66 & 2,82 & 3,24 & Agr \\
\hline Eugenia stictopetala & 16 & 2,56 & 112 & 1,64 & 3,66 & 1,55 & 1,92 & Agr \\
\hline Peltogyne pauciflora & 12 & 1,92 & 144 & 2,10 & 4,98 & 2,11 & 2,04 & Agr \\
\hline Senegalia polyphylla & 16 & 2,56 & 96 & 1,40 & 3,00 & 1,27 & 1,74 & Agr \\
\hline Luehea ochrophylla & 16 & 2,56 & 64 & 0,93 & 1,68 & 0,71 & 1,40 & Nagr \\
\hline Erythroxylum Caatinga & 4 & 0,64 & 176 & 2,57 & 5,02 & 2,12 & 1,78 & Agr \\
\hline Mimosa paraibana & 12 & 1,92 & 80 & 1,17 & 2,34 & 0,99 & 1,36 & Agr \\
\hline Morfo espécie 2 & 12 & 1,92 & 80 & 1,17 & 2,98 & 1,26 & 1,45 & Agr \\
\hline Maytenus erythroxyla & 20 & 3,20 & 96 & 1,40 & 3,32 & 1,40 & 2,00 & Agr \\
\hline Eugenia flavescens & 8 & 1,28 & 64 & 0,93 & 2,64 & 1,12 & 1,11 & Agr \\
\hline Hymenaea courbaril & 8 & 1,28 & 48 & 0,70 & 1,66 & 0,70 & 0,89 & Agr \\
\hline Senna macranthera & 8 & 1,28 & 48 & 0,70 & 1,98 & 0,84 & 0,94 & Agr \\
\hline Parapiptadenia zehntneri & 8 & 1,28 & 48 & 0,70 & 1,34 & 0,57 & 0,85 & Agr \\
\hline Zanthoxylum syncarpum & 8 & 1,28 & 48 & 0,70 & 1,34 & 0,57 & 0,85 & Agr \\
\hline Handroanthus serratifolius & 8 & 1,28 & 32 & 0,47 & 1,00 & 0,42 & 0,72 & Nagr \\
\hline Combretum leprosum & 8 & 1,28 & 32 & 0,47 & 1,32 & 0,56 & 0,77 & Nagr \\
\hline Senegalia riparia & 8 & 1,28 & 32 & 0,47 & 1,00 & 0,42 & 0,72 & Nagr \\
\hline Poincianella pyramidalis & 8 & 1,28 & 32 & 0,47 & 1,00 & 0,42 & 0,72 & Nagr \\
\hline Cynophalla hastata & 4 & 0,64 & 48 & 0,70 & 1,66 & 0,70 & 0,68 & Agr \\
\hline Xylosma prockia & 4 & 0,64 & 32 & 0,47 & 1,32 & 0,56 & 0,56 & Agr \\
\hline Mimosa tenuiflora & 4 & 0,64 & 16 & 0,23 & 0,66 & 0,28 & 0,38 & Nagr \\
\hline Amburana cearensis & 4 & 0,64 & 16 & 0,23 & 0,34 & 0,14 & 0,34 & Nagr \\
\hline Brosimum gaudichaudii & 4 & 0,64 & 16 & 0,23 & 0,66 & 0,28 & 0,38 & Nagr \\
\hline Bauhinia cheilantha & 4 & 0,64 & 16 & 0,23 & 0,66 & 0,28 & 0,38 & Nagr \\
\hline Pouteria reticulata & 4 & 0,64 & 16 & 0,23 & 0,34 & 0,14 & 0,34 & Nagr \\
\hline Senna spectabilis & 4 & 0,64 & 16 & 0,23 & 0,66 & 0,28 & 0,38 & Nagr \\
\hline Turnera calyptrocarpa & 4 & 0,64 & 16 & 0,23 & 0,66 & 0,28 & 0,38 & Nagr \\
\hline Lantana camara & 4 & 0,64 & 16 & 0,23 & 0,34 & 0,14 & 0,34 & Nagr \\
\hline Eugenia caatingicola & 4 & 0,64 & 16 & 0,23 & 0,66 & 0,28 & 0,38 & Nagr \\
\hline Syagrus cearensis & 4 & 0,64 & 16 & 0,23 & 0,34 & 0,14 & 0,34 & Nagr \\
\hline Erythroxylum nummularia & 4 & 0,64 & 16 & 0,23 & 0,66 & 0,28 & 0,38 & Nagr \\
\hline Total & 624 & 100 & 6848 & 100 & 236,25 & 100 & 100 & - \\
\hline
\end{tabular}

Em que: $\mathrm{FA}=$ Frequência absoluta; FR $\%=$ Frequência relativa; DA $=$ Densidade absoluta; DR $\%=$ Densidade relativa; $\mathrm{CAT}=$ Classe absoluta de tamanho da regeneração da i-ésima espécie; $\mathrm{CRT}=$ Classe relativa de tamanho da regeneração da i-ésima espécie; RNR\% = Regeneração natural relativa da i-ésima espécie; $\mathrm{Pi}$ = Índice de Payandeh; Agr = Distribuição espacial agregada; Tagr = Tendência a agregação; $\mathrm{e}$ Nagr $=$ Não agregado. 